\title{
In-vitro-Untersuchungen zur reduktiven Acetogenese im Pansen
}

\author{
Dissertation \\ zur Erlangung des Doktorgrades \\ der Fakultät für Agrarwissenschaften \\ der Georg-August-Universität Göttingen
}

vorgelegt von

\section{Claudius da Costa Gomez}

geboren in Rindern

Göttingen, im Januar 1999

Gefördert durch die DFG im Graduiertenkolleg „Landwirtschaft und Umwelt“ am Forschungs- und Studienzentrum Landwirtschaft und Umwelt des Fachbereichs Agrarwissenschaften 
D7

Referent:

Prof. Dr. sc. agr. Hj. Abel

Korreferent:

Prof. Dr. rer. nat. U. Eberhardt

Tag der mündlichen Prüfung:

28. Januar 1999 


\section{Danksagung}

An dieser Stelle möchte ich all jenen danken, die zum Gelingen der Arbeit beigetragen haben.

Herrn Professor Dr. Hj. Abel danke ich für die Überlassung des Themas, das mir entgegengebrachte Vertrauen und seine stetige Diskussionsbereitschaft, die mich sowohl fachlich als auch persönlich bereicherte.

Herrn Professor Dr. U. Eberhardt danke ich für die Übernahme des Korreferates und die in allen Phasen der Arbeit gewährte sehr konkrete fachliche Unterstützung.

Mein besonderer Dank gilt Frau Dr. Irmgard Immig, die mich während der gesamten Doktorandenzeit wissenschaftlich begleitete und in vielen Diskussionen durch konstruktive Anregungen zum Fortgang dieser Arbeit beigetragen hat.

Frau Ingrid Gründel vom Institut für Angewandte Nutztierwissenschaften der Humboldt-Universität Berlin danke ich für ihre zuverlässige und freundliche Einsatzbereitschaft bei der Durchführung der batch-culture-Inkubationen.

Für die sehr engagierte Zusammenarbeit bei der Planung sowie für die Durchführung der ${ }^{13} \mathrm{C}-\mathrm{NMR}$-Messungen danke ich

Frau Dr. Stephanie Grond und Herrn R. Machinek vom Institut für Organische Chemie der GEORG-AUGUST-UNIVERSITÄT Göttingen. Ihre uneigennützige Bereitschaft zur interdisziplinären Zusammenarbeit hat sehr zum Gelingen dieser Arbeit beigetragen.

Herrn Rolf Jeromin danke ich für die geduldige Einführung in die praktische Laborarbeit, das sehr gute Teamwork am RUSITEC und die vielen interessanten Gespräche in der Mittagspause.

Allen Mitarbeiterinnen und Mitarbeitern des Institutes für Tierphysiologie und Tierernährung danke ich für die freundliche Kooperation, die dazu beigetragen hat, daß ich mich im Institut immer wohlgefühlt habe.

Allen Mitdoktoranden und Freunden danke ich für ihren Zuspruch und die Anteilnahme an den kleinen und großen Problemen des Doktorandenalltags sowie für die fröhlichen gemeinsamen Stunden.

Frau Dr. Bettina Rother danke ich für die liebevolle und geduldige Unterstützung vor allem in der letzten Phase dieser Arbeit.

Meinen Eltern danke ich für Ihr Verständnis, ihr Vertrauen und ihre Unterstützung, ohne die es mir nicht möglich gewesen wäre, diese Arbeit anzufertigen.

Für das gewährte Stipendium danke ich der STIFTUNG FÜR ERNÄHRUNGSWISSENSCHAFTEN Göttingen. 


\section{Inhaltsverzeichnis}

1 Einleitung 1

2 Fragestellung

\section{Material und Methoden}

3.1 Versuchsplan

\section{2 in-vitro-Methoden}

3.2.1 Fütterung der Spendertiere __ 10

3.2.2 Pansensaftentnahme _ 11

3.2.3 Defaunierung des Pansensaftes ___ 11

3.2.4 Gewinnung der Bakteriensuspension __ 12

3.2.5 batch-culture-Methode _ 12

3.2.6 Pansensimulationstechnik (RUSITEC) 15

\subsection{Analytische Methoden}

3.3.1 Messung von $\mathrm{pH}$-Wert und Redoxpotential __ 18

3.3.2 Bestimmung der Protozoenzahl___ 19

3.3.3 Messung der Fermentationsgase __ 19

3.3.4 Messung der flüchtigen Fettsäuren ___ 22

3.3.5 Berechnung der Wasserstoffwiederfindung __ 25

3.3.6 ${ }^{13}$ C-Kernresonanzspektroskopie (NMR) _ 27

3.4 Statistische Auswertung ___ 27

\section{Versuchsergebnisse}

4.1 batch-culture-Untersuchungen mit nicht defauniertem Pansensaft ___ 29

4.1.1 Einfluß der Ration des Spendertieres __ 29

4.1.2 Einfluß der Nüchterungsdauer des Spendertieres __ 30

4.1.3 Einfluß des in-vitro-Substrates____ 31

4.1.4 Einfluß der Wechselwirkungen zwischen den Faktoren Ration, Nüchterungsdauer und in-vitro-Substrat __ 32

4.2 batch-culture-Untersuchungen mit defauniertem Pansensaft

4.2.1 Einfluß der Ration des Spendertieres __ 36

4.2.2 Einfluß der Nüchterungsdauer des Spendertieres ___ 36

4.2.3 Einfluß des in-vitro-Substrates___ 37

4.2.4 Einfluß der Wechselwirkungen zwischen den Faktoren Ration, Nüchterungsdauer und in-vitro-Substrat __ 38

\subsection{Zusammenfassung der Ergebnisse aus den batch-culture-Untersuchungen_ 41}

\section{4 in-vitro-Untersuchungen zum Nachweis der reduktiven Acetogenese} mit Hilfe von ${ }^{13} \mathrm{C}-\mathrm{CO}_{2}$

4.4.1 Nachweis der reduktiven Acetogenese durch Mikroben des Schweinedarms ___ 43

4.4.2 Untersuchungen zum Nachweis einer reduktiven Acetogenese im Pansensaft ___ 45

4.4.3 Untersuchungen zum Nachweis einer reduktiven Acetogenese durch pansenstämmige Mikroorganismen aus dem RUSITEC-System 


\section{Diskussion}

5.1 Versuchsplan und Versuchskritik 51

5.2 Auswahl des verwendeten Defaunierungsverfahrens 51

5.3 Auswahl der verwendeten in-vitro-Methoden 52

5.4 Nachweis der reduktiven Acetogenese mittels ${ }^{13} \mathrm{C}-\mathrm{NMR}$ 54

5.5 Einfluß der untersuchten Faktoren auf die Fermentation 55

5.5.1 Protozoen 55

5.5.2 Verfügbarkeit von Kohlenhydraten 59

5.5.3 Substanzen endogenen und mikrobiellen Ursprungs 64

6 Schlußfolgerungen 70

7 Zusammenfassung 71

8 Summary 73

9 Literaturverzeichnis 75

10 Anhang 81 


\section{Einleitung}

Die Wiederkäuer produzieren weltweit schätzungsweise 80 Mio. t Methan pro Jahr, davon verursachen die Hauswiederkäuer ca. 73 Mio.t und tragen damit zu rund $20 \%$ zum jährlich anthropogen verursachten Methan in unserer Atmosphäre bei (CRUTZEN ET AL. 1986, Moss 1993). Die hohe Wirksamkeit dieses Treibhausgases hat in den letzten Jahren die ruminale Methanogenese, bei der von Pansenbakterien aus Wasserstoff und Kohlendioxid Methan gebildet wird, wieder verstärkt in die wissenschaftliche Diskussion gebracht.

Da mit dem Methan ein Anteil von 2 bis $12 \%$ der mit dem Futter aufgenommenen Energie ungenutzt wieder abgegeben wird, ist es für die Tierernährungswissenschaften schon lange ein wichtiges Ziel, die ruminale Methanogenese zu senken (JOHNSON und JOHNSON 1995). Aus diesem Grund gibt es eine Vielzahl von Arbeiten, in denen die verschiedenen Einflußfaktoren der Methanentstehung im Pansen untersucht werden (CZERKAWSKI und BRECKENRIDGE 1972, MARTY und DemeYer 1973, Aguilera und Prieto 1991, VAN NeVel und DemeYer 1992, BlüMmel and Ørskov 1993, Garcia-Lopez et AL. 1996, JouANY 1994, VAN NeVEL und DEMEYER 1996, MACHMÜLLER ET AL. 1998). Dabei werden unterschiedliche Strategien zur Senkung der Methanogenese verfolgt. Entweder wird die Methanbildung mit direkt auf methanogene Bakterien wirkende Substanzen reduziert oder aber die Rationszusammensetzung wird dahingehend variiert, daß pro Einheit fermentierter Substanz weniger Methan entsteht. Der Einsatz der die Methanbildung hemmenden Substanzen führt, insofern überhaupt in vivo eine nachhaltige Wirkung erzielt werden kann (VAN NEVEL und DEMEYER 1996), zum Anstieg der Wasserstoffkonzentration und damit zu einer ungünstigen Verschiebung der Fermentationsprodukte (MILLER 1995). Die Änderung der Rationszusammensetzung zur Reduzierung der Methanbildung wird durch einen Anstieg leichtverdaulicher Futteranteile erreicht (Moss 1994 a). Damit steigen allerdings die Anforderungen an die Fütterung, und die Fähigkeit der Wiederkäuer, hochwertige Nahrungsmittel (Fleisch und Milch) aus pflanzlichen Gerüstsubstanzen und Nicht-Protein-Stickstoff zu produzieren, verliert an Bedeutung.

In der vorliegenden Arbeit steht die reduktive Acetogenese im Mittelpunkt des Interesses. Dieser mikrobielle Stoffwechselweg liefert aus Kohlendioxid und Wasserstoff nicht - wie im Pansen - Methan, sondern Acetat, das vom Wiederkäuer effizient genutzt werden könnte. Vor 10 Jahren wurden im Pansen erstmalig Organismen, die zur reduktiven Acetogenese befähigt sind, nachgewiesen (GREENING und LEEDLE 1989). Es ist allerdings bislang ungeklärt unter welchen Bedingungen, dieser Stoffwechselweg von den Mikroorganismen im Pansen auch tatsächlich beschreitbar wird. Die vorliegende Arbeit soll hierzu einen Beitrag leisten. 


\section{$2 \quad$ Fragestellung}

Der Abbau gering verdaulicher Nahrungsbestandteile im Intestinaltrakt von Mensch und Tier erfolgt durch die hochgradig spezialisierte Mikroorganismengemeinschaft in diesem anaeroben Ökosystem (NolleT und VerSTRAETE 1996). Endprodukte der Fermentation sind, neben den vom Wirt genutzten flüchtigen Fettsäuren (SCFA), Wasserstoff und Kohlendioxid (GIBSON ET AL. 1993 a, WOLIN und MILLER 1993, DEMEYER ET AL. 1996). Die SCFA werden zum überwiegenden Teil vom Wirt direkt aus dem Lumen resorbiert, während der Wasserstoff entweder von sulfatreduzierenden, methanogenen oder aber von reduktiv acetogenen Bakterien genutzt wird (DorÉ ET AL. 1995, Nollet und Verstraete 1996). Die Nutzung des metabolischen Wasserstoffs ist für die Aufrechterhaltung des mikrobiellen Systems wichtig, da bei einem zu hohen Wasserstoffpartialdruck die Re-Oxidation des bei der Glycolyse reduzierten Koenzyms NADH beeinträchtigt (GIBSON ET AL. 1993 a, GOTTSCHALK 1986) und das Fermentationsmuster in Richtung vermehrter Ethanolund Lactatbildung verschoben wird (MILLER 1995).

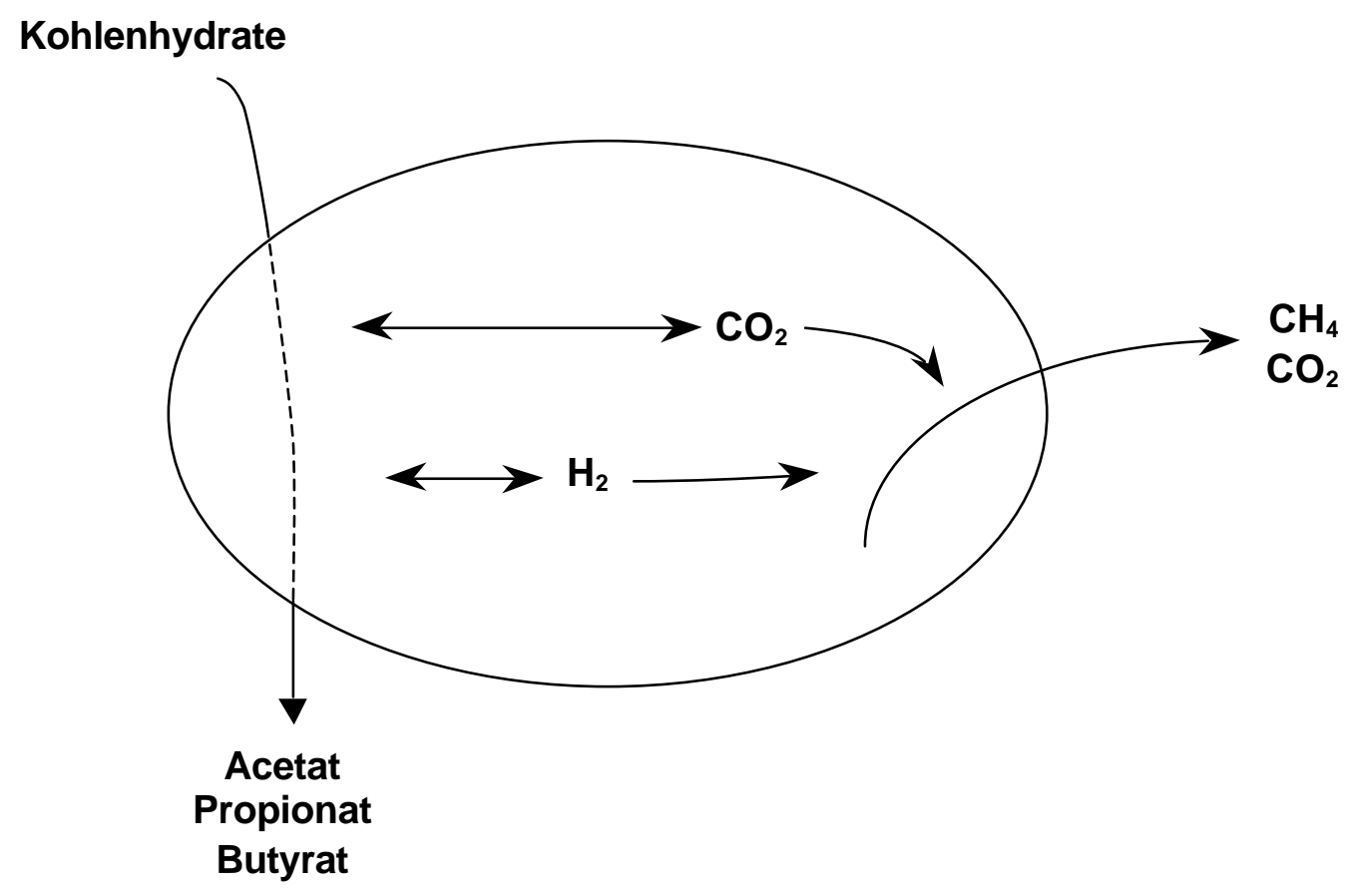

Abb. 1: Schematische Darstellung der Fermentationsvorgänge im Pansen.

Dickdarm und Pansen unterscheiden sich hinsichtlich der mikrobiellen Strategien des Wasserstoffverbrauchs. Im Pansen dominiert die Methanogenese (Abb. 1), bei der Wasserstoff nach der Reaktionsgleichung $\mathrm{H}_{2}+\mathrm{CO}_{2} \rightarrow 2 \mathrm{H}_{2} \mathrm{O}+\mathrm{CH}_{4}$ für die Reduktion von Kohlendioxid zu Methan verbraucht wird (JOHNSON und JOHNSON 1995, DEMEYER ET AL. 1996). Demgegenüber wird im Dickdarm der Wasserstoff vor allem durch sulfatreduzierende bzw. reduktiv acetogene Mikroorganismen gebunden (DE GRAEVE 
ET AL. 1994, IMMIG 1996). Das im Pansen gebildete Methan wird beim Ructus in die Atmosphäre abgegeben (GüRTLER 1989). Das hat für das Tier einen Energieverlust (JOHNSON und JOHNSON 1995) und für die Erdatmosphäre eine zusätzliche Umweltbelastung zur Folge (Moss 1993). Als Alternative zur ruminalen Methanogenese kann die Sulfatreduktion als mögliche Wasserstoffsenke ausgeschlossen werden, da im Pansen nur geringe Sulfatmengen vorliegen und die Endprodukte dieser Reduktion eine toxische Wirkung auf andere Mikroben sowie das Wirtstier haben (MORVAN ET AL. 1996). Dagegen wird, seitdem GREENING und LEEDLE (1989) mit dem Bakterium Acetitomaculum ruminis erstmals reduktiv acetogene Organismen im Pansen nachgewiesen haben, die reduktive Acetogenese als mögliche Alternative zur Methanogenese im Pansen diskutiert (STEVANI ET AL. 1991, Rieu-Lesme et AL. 1996, Demeyer et AL. 1996, IMmig 1996, IMMig 1998, LE VAN ET AL. 1998). Die bisher aus dem Pansen isolierten, reduktiv acetogenen Bakterien sind obligat anaerob, mesophil, Gram-positiv und zeigen bei $\mathrm{pH6,5}$ bis 7,2 optimales Wachstum (DURAND und BERNALIER 1993, RIEU-LEME ET AL. 1996).

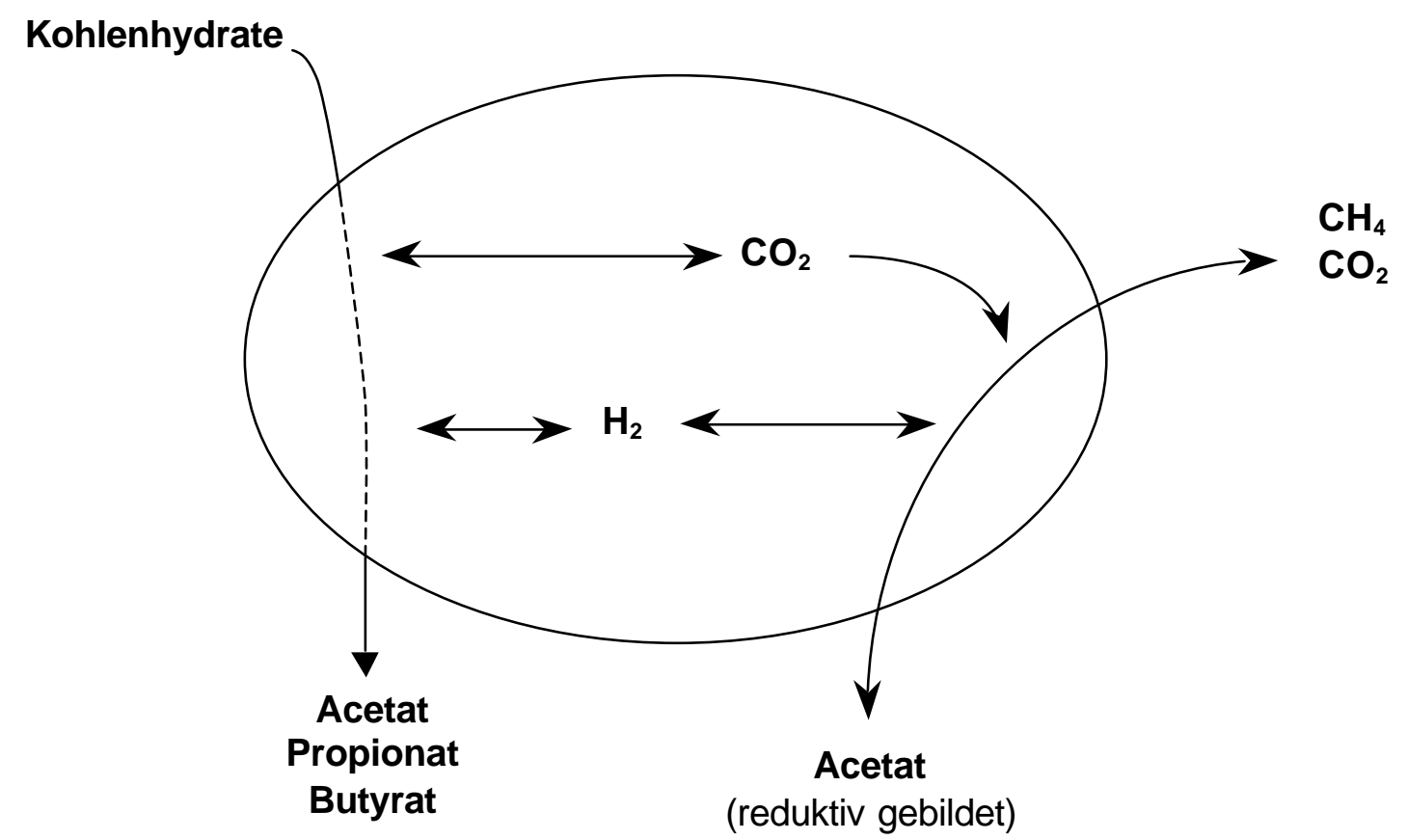

Abb. 2: Schematische Darstellung der Fermentationsprozesse im Pansen unter Einbeziehung einer autotrophen reduktiven Acetogenese.

Bei der reduktiven Acetogenese wird Kohlendioxid durch den metabolischen Wasserstoff nach der Reaktionsgleichung $2 \mathrm{CO}_{2}+4 \mathrm{H}_{2} \rightarrow \mathrm{CH}_{3} \mathrm{COOH}+2 \mathrm{H}_{2} \mathrm{O} \mathrm{zu}$ Acetat reduziert. Es können zwei Synthesewege unterschieden werden: 1) der autotrophe, bei dem die acetogenen Organismen ausschließlich Kohlendioxid und Wasserstoff zu Acetat synthetisieren und 2) der heterotrophe, bei dem aus einem Hexoseäquivalent zwei Mol Acetat oxidativ und ein Mol Acetat aus Kohlendioxid 
sowie intermediär anfallenden Reduktionsäquivalenten gebildet werden (DE GRAEVE ET AL. 1994). Im Pansen würde sich durch die autotrophe Nutzung des metabolischen Wasserstoffs als Reduktionsäquivalent eine zusätzliche Acetatquelle erschließen (Abb.2), die sowohl die energetische Effizienz der Fermentation verbessern, als auch die Methanemissionen der Wiederkäuer reduzieren könnte (DE GRAEVE ET AL. 1994, MACKIE UND BRYANT 1994).

Diese Form der Kohlendioxidreduktion mit dem Ergebnis der Acetatbildung wurde bisher im Verdauungstrakt von Termiten (BREZNACK und KANE 1990) im Dickdarm des Menschen (LAJOIE ET AL. 1988, Wolin und MilleR 1993, KamLAGE ET AL. 1997, LECLERC ET AL. 1997) im Dickdarm von Schweinen(De GraEVE ET AL. 1994) und Kaninchen (PIATTONI ET AL. 1996) und im Pansen von neugeborenen Lämmern (MORVAN ET AL. 1994, RIEU-LeSME ET AL. 1996) nachgewiesen. Im Pansen adulter Tiere sind zwar auch reduktiv acetogene Bakterien vorhanden, in vivo oxidieren sie jedoch Formiat, Glucose und Cellobiose zu Acetat (GREENING und LeEDLE 1989, GIBSON ET AL. 1990).

Da im Vergleich zu reduktiv acetogenen Organismen die methanogenen Bakterien des Pansens eine höhere Affinität zu Wasserstoff besitzen (BREZNACK und KANE 1990, LE VAN ET AL. 1998), wurde durch den Einsatz der die Methanbildung hemmenden BES (Bromethansulfonsäure) versucht, die reduktive Acetogenese im Pansen zu initiieren. In Untersuchungen von NOLLET ET AL. (1997) konnte bei gleichzeitigem Einsatz von BES und dem Zusatz von Peptostreptococcus productus, einem zur reduktiven Acetogenese befähigten Organismus, die reduktive Acetogenese in vitro stimuliert werden. Da die methanogenen Organismen sich in-vivo an BES adaptieren (IMMIG 1996), wurde in einem anderen Ansatz die Hemmung der Methanogenese mit Metaboliten des Lactobacillus plantarum 80 überprüft. Auch bei dieser, die methanogenen Bakterien hemmenden Substanz, zeigte sich nach einigen Erfolgen bei in-vitro-Untersuchungen in-vivo nur eine kurzzeitige Wirkung (NOLLET ET AL. 1998).

Ausgehend von den grundsätzlichen Unterschieden der mikrobiellen Umsetzungen in Dickdarm und Pansen sollten in der vorliegenden Arbeit die Faktoren untersucht werden, die das reduktiv acetogene Potential im Pansen stimulieren können. Dazu wurden zunächst auf Grundlage der wesentlichen Unterschiede zwischen den Habitaten drei Hypothesen formuliert.

Die reduktive Acetogenese wird im Pansen gefördert, wenn ...

1. ... Protozoen fehlen,

2. ... weniger leicht abbaubare Kohlenhydrate vorhanden sind,

3. ... Substanzen endogenen oder mikrobiellen Ursprungs anwesend sind. 
Im Pansen wird die Methanogenese über den Interspezies-Wasserstoff-Transfer durch symbiontische Assoziation der methanogenen Bakterien mit entodiniomorphen Protozoen gefördert (KRUMHOLZ ET AL. 1983). Im Gegensatz zum Pansen werden die in den Dickdarm gelangenden Kohlenhydrate durch Bakteriengemeinschaften ohne Beteiligung von Protozoen abgebaut (DEMEYER und DE GRAEVE 1991). Als wichtigste Gründe für das Fehlen der Protozoen im Dickdarm gelten die geringere Kohlenhydratverfügbarkeit (LENG 1988) und die kürzere Verweildauer der Digesta in diesem Habitat (GROVUM und WILLIAMS 1977). Der Einfluß von Protozoen wurde in der vorliegenden Arbeit mit nicht defauniertem und defauniertem Pansensaft als Inokulum untersucht.

Im Pansen sind im Vergleich zum Dickdarm mehr leicht abbaubare Kohlenhydrate verfügbar (HOOVER 1978). Diese Kohlenhydrate dienen den reduktiv acetogenen Organismen im Pansen als Substrat (GREENING und LEEDLE 1989), während die ausschließlich autotroph methanogenen Bakterien den metabolischen Wasserstoff nutzen. Eine Verringerung der leicht verfügbaren Kohlenhydrate im Pansen könnte eine mikrobielle Gemeinschaft fördern, in der der metabolische Wasserstoff von reduktiv acetogenen und methanogenen Organismen genutzt und damit die Konkurrenz um das Substrat verschärft wird (IMMIG 1996). Der Einfluß einer geringeren Verfügbarkeit leicht abbaubarer Kohlenhydrate wurde in der vorliegenden Arbeit mit unterschiedlichen Inokulumherkünften und in-vitro-Substraten in batchculture-Versuchen untersucht.

In den Dickdarm gelangen endogene Substanzen in Form von Proteinen, Muzinen, Epithelzellen oder Gallensalzen. Darüber hinaus nimmt der Dickdarm Mikroorganismen, Restfraktionen von Mikroorganismen und mikrobielle Stoffwechselprodukte aus dem praecaecalen Darmabschnitt auf. In in-vitroInkubationen stellten DEMEYER ET AL. (1996) keine Wirkung von Muzinen und freien Aminosäuren auf die reduktive Acetogenese im Pansen fest. In batch-cultureInkubationen untersuchte IMMIG (1998) die Wirkung von Gallensalzen. Es ergab sich zwar eine sehr effektive Hemmung der Methanogenese, eine reduktive Acetogenese konnte jedoch auch hier nicht nachgewiesen werden. In der vorliegenden Arbeit wurden die Einflüsse eines aus der Langzeit-Pansensimulationstechnik RUSITEC stammenden Inokulums ohne und mit Gallensalzzugabe sowie autoklavierter Dickdarminhalt als in-vitro-Substrat untersucht. 


\subsection{Versuchsplan}

Die Entscheidung über die Annahme oder Ablehnung der drei Arbeitshypothesen:

Die reduktive Acetogenese wird gefördert, wenn ...

I. ... Protozoen fehlen,

II. ... weniger leicht abbaubare Kohlenhydrate vorhanden sind oder

III. ... Substanzen endogenen oder mikrobiellen Ursprungs anwesend sind,

sollte anhand von Ergebnissen aus in-vitro-Untersuchungen mit Pansensaft in der batch-culture getroffen werden. Dazu wurden als unabhängige Faktoren die Anwesenheit von Protozoen (1), die Ration (2) sowie die Nüchterungsdauer des Spendertieres (3) und das Substrat in den Inkubationsgefäßen (4) im Hinblick auf die Hypothesen gezielt variiert. Als abhängige Parameter für die in-vitro-Fermentation galten bei allen Versuchsanstellungen die kurzkettigen flüchtigen Fettsäuren (SCFA) sowie die Fermentationsgase Methan $\left(\mathrm{CH}_{4}\right)$ und Kohlendioxid $\left(\mathrm{CO}_{2}\right)$. Bei einigen in-vitro-Untersuchungen wurde außerdem die Wasserstoffwiederfindungsrate errechnet, sowie die Protozoenzahl und die ${ }^{13} \mathrm{C}$-Anreicherung in der Essigsäure bestimmt. Die Zuordnung der Arbeitshypothesen zu den Faktoren und deren Faktorstufen kann Übersicht 1 entnommen werden.

Übersicht 1: Zuordnung der Arbeitshypothesen zu den unabhängigen Faktoren und deren Faktorstufen.

\begin{tabular}{|c|c|c|c|}
\hline & Hypothese & Faktor & Faktorstufe \\
\hline \multirow{2}{*}{ (I) } & \multirow{2}{*}{ Protozoen } & \multirow{2}{*}{ (1) Protozoen } & nicht defaunierter Pansensaft \\
\hline & & & defaunierter Pansensaft \\
\hline \multirow{6}{*}{ (II) } & \multirow{6}{*}{ Kohlenhydrate } & \multirow{2}{*}{ (2) Ration des Spendertieres } & Heu-Kraftfutter \\
\hline & & & Stroh-Harnstoff \\
\hline & & \multirow{2}{*}{$\begin{array}{l}\text { (3) Nüchterungsdauer des } \\
\text { Spendertieres }\end{array}$} & 16 Stunden \\
\hline & & & 24 Stunden \\
\hline & & \multirow{2}{*}{ (4) in-vitro-Substrat } & $\mathrm{Heu}$ \\
\hline & & & Stroh \\
\hline (IIII) & $\begin{array}{l}\text { Endogene } \\
\text { Substanzen }\end{array}$ & (4) in-vitro-Substrat & autoklavierter Blinddarminhalt \\
\hline
\end{tabular}


Aus den vier Faktoren mit ihren insgesamt 9 Faktorstufen, wurde ein balanciertes, orthogonales Versuchsdesign entworfen, welches es ermöglichte, alle Faktoren miteinander zu vergleichen (Übersicht 2).

Übersicht 2: Versuchsdesign für in-vitro-Untersuchungen mit insgesamt 9 Faktorstufen der Faktoren Protozoen, Ration sowie Nüchterungsdauer des Spendertieres und in-vitro-Substrat. Jede Zahl steht für eine der 24 Faktorkombinationen.

\begin{tabular}{|c|c|c|c|c|}
\hline \multicolumn{5}{|c|}{ Pansensaft nicht defauniert } \\
\hline \multicolumn{2}{|c|}{ in-vitro-Substrat } & Heu & Stroh & Blinddarminhalt \\
\hline \multirow{2}{*}{$\begin{array}{l}\text { Ration } \\
\text { Heu und } \\
\text { Kraftfutter }\end{array}$} & $\begin{array}{l}16 \text { Stunden } \\
\text { Nüchterung }\end{array}$ & 1 & 2 & 3 \\
\hline & $\begin{array}{l}24 \text { Stunden } \\
\text { Nüchterung }\end{array}$ & 4 & 5 & 6 \\
\hline \multirow{2}{*}{$\begin{array}{l}\text { Ration } \\
\text { Stroh und } \\
\text { Harnstoff }\end{array}$} & $\begin{array}{l}16 \text { Stunden } \\
\text { Nüchterung }\end{array}$ & 7 & 8 & 9 \\
\hline & $\begin{array}{l}24 \text { Stunden } \\
\text { Nüchterung }\end{array}$ & 10 & 11 & 12 \\
\hline \multicolumn{5}{|c|}{ Pansensaft defauniert } \\
\hline \multicolumn{2}{|c|}{ in-vitro-Substrat } & Heu & Stroh & Blinddarminhalt \\
\hline \multirow{2}{*}{$\begin{array}{l}\text { Ration } \\
\text { Heu und } \\
\text { Kraftfutter }\end{array}$} & $\begin{array}{l}16 \text { Stunden } \\
\text { Nüchterung }\end{array}$ & 13 & 14 & 15 \\
\hline & $\begin{array}{l}24 \text { Stunden } \\
\text { Nüchterung }\end{array}$ & 16 & 17 & 18 \\
\hline \multirow{2}{*}{$\begin{array}{l}\text { Ration } \\
\text { Stroh und } \\
\text { Harnstoff }\end{array}$} & $\begin{array}{l}16 \text { Stunden } \\
\text { Nüchterung }\end{array}$ & 19 & 20 & 21 \\
\hline & $\begin{array}{l}24 \text { Stunden } \\
\text { Nüchterung }\end{array}$ & 22 & 23 & 24 \\
\hline
\end{tabular}

Jede der 24 in Übersicht2 dargestellten, möglichen Faktorkombinationen wurde insgesamt 9 mal wiederholt. Dabei wurden pro batch-culture-Inkubation die Faktorkombinationen mit gleicher Ration und Nüchterungsdauer aber unterschiedlichem in-vitro-Substrat, einerseits nicht defauniert und andererseits defauniert, in dreifacher Wiederholung in einem Ansatz integriert. Eine solche Inkubation entsprach in Übersicht 2 beispielsweise den Faktorkombinationen 1, 2, 3, 13, 14 und 15, die in einem Ansatz jeweils in drei Wiederholungen vorlagen. Damit waren pro Inkubation bzw. pro Ansatz 18 Gefäße zu inkubieren. Jede dieser Inkubationen oder Ansätze wurde wiederum dreimal wiederholt und damit ergaben sich in 12 batch-culture-Ansätzen insgesamt 216 zu inkubierende Gefäße. 
Anhand der Ergebnisse aus diesem Versuch wurde entschieden, welche Versuchsansätze Anzeichen für das Vorkommen von reduktiver Acetogenese aufwiesen und somit den Einsatz von ${ }^{13} \mathrm{C}_{-} \mathrm{CO}_{2}$ als Marker sinnvoll erscheinen ließen.

Aufgrund von Hinweisen aus der Literatur (IMMIG 1998) und eigenen Untersuchungen zum Einsatz von Gallensalzen als eine die Methanbildung im Pansen hemmende Substanz wurde ein zusätzlicher Versuch mit der Langzeit-in-vitro-Methode RUSITEC (CZERKAWSKI und BRECKENRIDGE 1977) zur Entwicklung der Biozönose von Pansenbakterien unter Einfluß von Gallensalzen durchgeführt. Dieser Faktor, der der Hypothese "Endogene Substanzen" (III) zuzuordnen ist, wurde mit in den Versuchsplan für den ${ }^{13} \mathrm{C}$ - $\mathrm{CO}_{2}$-Einsatz aufgenommen.

Übersicht 3: Übersicht über die mit ${ }^{13} \mathrm{C}-\mathrm{CO}_{2}$-Marker durchgeführten Versuche sowie deren Behandlungen und Zuordnung zu den unabhängigen Faktoren.

\begin{tabular}{|c|c|c|c|c|c|}
\hline Ansatz & Inokulum & $\mathbf{n}$ & $\begin{array}{l}\text { in-vitro- } \\
\text { Substrat }\end{array}$ & Gasatmosphäre & Faktor \\
\hline \multirow{2}{*}{1} & $\begin{array}{l}\text { Bakteriensuspension } \\
\text { aus Schweinedarm }\end{array}$ & 2 & - & $\begin{array}{c}80 \% \mathrm{Ar}+ \\
20 \%{ }^{13} \mathrm{C}-\mathrm{CO}_{2}\end{array}$ & Kontrolle \\
\hline & $\begin{array}{l}\text { Bakteriensuspension } \\
\text { aus Schweinedarm }\end{array}$ & 3 & - & $\begin{array}{c}80 \% \mathrm{H}_{2}+ \\
20 \%{ }^{13} \mathrm{C}-\mathrm{CO}_{2}\end{array}$ & $\begin{array}{c}\text { Einfluß der } \\
\mathrm{H}_{2} \text {-Konzentration }\end{array}$ \\
\hline \multirow{3}{*}{2} & $\begin{array}{l}\text { nicht defaunierter } \\
\text { Pansensaft }\end{array}$ & 3 & Heu & $\begin{array}{c}80 \% \mathrm{H}_{2}+ \\
20 \%{ }^{13} \mathrm{C}-\mathrm{CO}_{2}\end{array}$ & Kontrolle \\
\hline & $\begin{array}{l}\text { nicht defaunierter } \\
\text { Pansensaft }\end{array}$ & 3 & $\begin{array}{l}\text { Blinddarm- } \\
\text { inhalt }\end{array}$ & $\begin{array}{c}80 \% \mathrm{H}_{2}+ \\
20 \%{ }^{13} \mathrm{C}-\mathrm{CO}_{2}\end{array}$ & in-vitro-Substrat \\
\hline & defaunierter Pansensaft & 3 & $\mathrm{Heu}$ & $\begin{array}{c}80 \% \mathrm{H}_{2}+ \\
20 \%{ }^{13} \mathrm{C}-\mathrm{CO}_{2}\end{array}$ & Protozoen \\
\hline \multirow{3}{*}{3} & $\begin{array}{l}\text { RUSITEC, } \\
\text { ohne Gallensalz }\end{array}$ & 3 & $\mathrm{Heu}$ & $\begin{array}{c}80 \% \mathrm{H}_{2}+ \\
20 \%{ }^{13} \mathrm{C}-\mathrm{CO}_{2}\end{array}$ & Kontrolle \\
\hline & $\begin{array}{l}\text { RUSITEC, vorbehandelt } \\
\text { mit Gallensalz } 0,4 \%\end{array}$ & 3 & $\mathrm{Heu}$ & $\begin{array}{c}80 \% \mathrm{H}_{2}+ \\
20 \%{ }^{13} \mathrm{C}-\mathrm{CO}_{2}\end{array}$ & Gallensalz \\
\hline & $\begin{array}{l}\text { RUSITEC, vorbehandelt } \\
\text { mit Gallensalz 0,6\% }\end{array}$ & 3 & Heu & $\begin{array}{c}80 \% \mathrm{H}_{2}+ \\
20 \%{ }^{13} \mathrm{C}-\mathrm{CO}_{2}\end{array}$ & Gallensalz \\
\hline
\end{tabular}

Insgesamt wurden drei batch-culture-Ansätze unter Verwendung von ${ }^{13} \mathrm{C}_{-} \mathrm{CO}_{2}$ Marker durchgeführt. Der Versuchsansatz 1 diente als Positivkontrolle der ${ }^{13} \mathrm{C}-\mathrm{NMR}$ Methode und wurde mit einem Inokulum aus dem Schweinedarm mit und ohne Wasserstoff in der Gasatmosphäre der Inkubationsgefäße durchgeführt (DE GRAEVE ET AL. 1994). Mit den zwei Begasungsstufen sollte überprüft werden, ob die mit einer 
Übersicht 4: Versuchsplan für in-vitro-Untersuchungen zum Nachweis der reduktiven Acetogenese

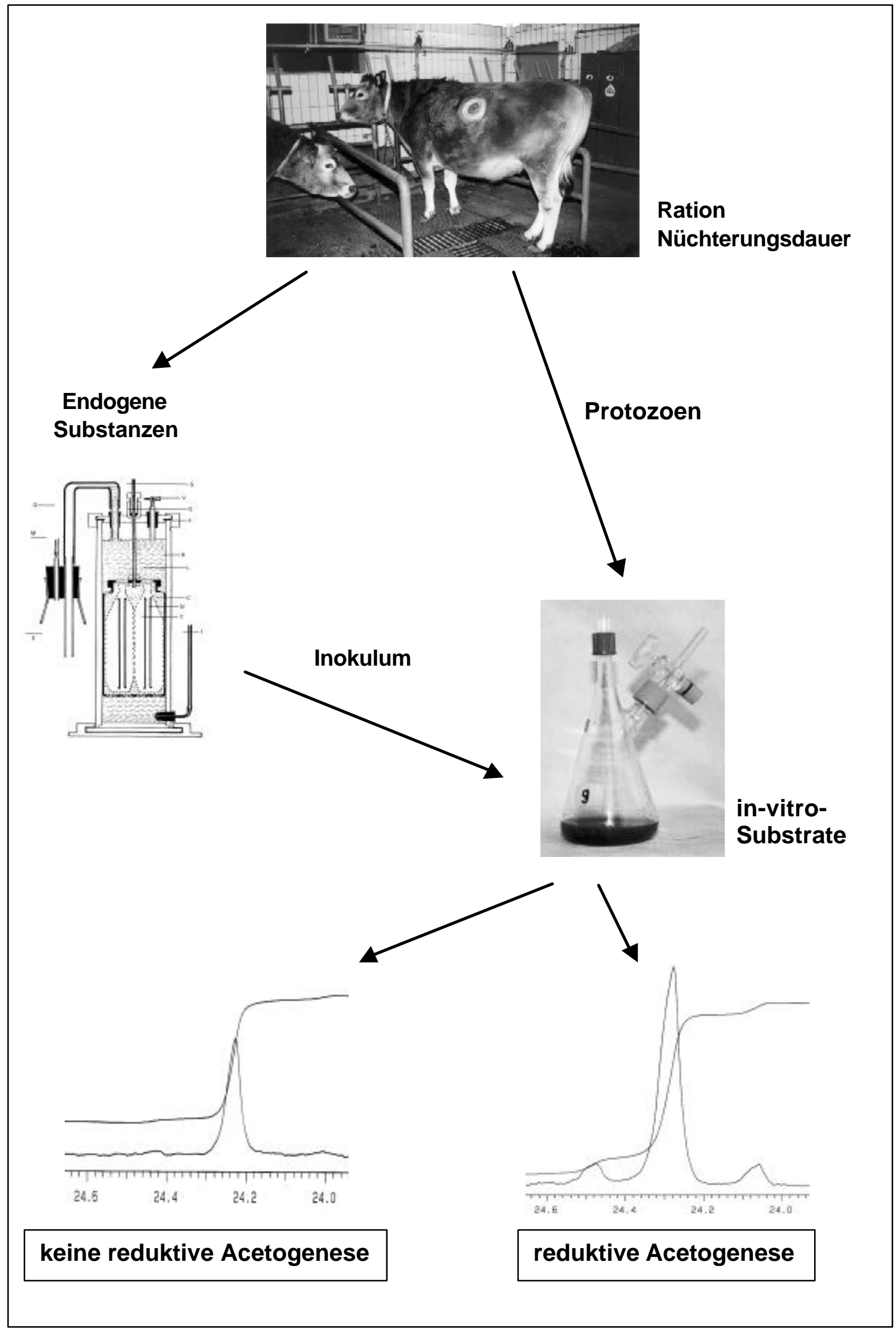


erhöhten Wasserstoffkonzentration einhergehende Anregung der reduktiven Acetogenese mit Hilfe der ${ }^{13} \mathrm{C}-\mathrm{NMR}$ quantifiziert werden kann. Der Ansatz2 beinhaltete die Faktorvariation Protozoen (nicht defaunierter und defaunierter Pansensaft) sowie in-vitro-Substrat (Heu und Blinddarminhalt). Der Ansatz 3 ergab sich aus dem Faktor Gallensalz und umfaßte die Varianten Inokulum im RUSITECSystem ohne, mit $0,4 \%$ und mit $0,6 \%$ Gallensalzkonzentration. Ein Überblick über die mit ${ }^{13} \mathrm{C}-\mathrm{CO}_{2}$-Marker durchgeführten Versuche ist in Übersicht 3 wiedergegeben. Der gesamte Versuchsablauf ist in Übersicht 4 zusammenfassend dargestellt.

\section{2}

\section{in-vitro-Methoden}

\subsubsection{Fütterung der Spendertiere}

Als Spendertiere für den Pansensaft standen eine 7 jährige Holstein-Friesian (HF) Kuh und drei 6 jährige Jersey-Ochsen zur Verfügung. Alle Tiere hatten eine permanente weitlumige Pansenfistel und ein Gewicht von ca. $600 \mathrm{~kg}$. Der Pansensaft der trockenstehenden Kuh wurde für die dreifaktoriell angelegten batch-cultureVersuche verwendet, während die Ochsen als Spendertiere für alle weiteren Untersuchungen eingesetzt wurden.

Tab. 1: $\quad$ Ration 1 und 2 für die HF-Kuh

\begin{tabular}{|l|rl|}
\hline \hline \multicolumn{3}{|c|}{ Ration (1) Heu-Kraftfutter } \\
\hline \hline Heu & 1,2 & $\mathrm{~kg} \mathrm{FS} / \mathrm{Tag}$ \\
\hline Stroh & 2,0 & $\mathrm{~kg} \mathrm{FS} / \mathrm{Tag}$ \\
\hline Kraftfutter & $4,5 \quad \mathrm{~kg} \mathrm{FS} / \mathrm{Tag}$ \\
\hline \hline \multicolumn{3}{|c|}{ Ration (2) Stroh-Harnstoff } \\
\hline \hline Stroh & $10,0 \quad \mathrm{~kg} \mathrm{FS} / \mathrm{Tag}$ \\
\hline Harnstoff & 105 & $\mathrm{~g} / \mathrm{Tag}$ \\
\hline \hline
\end{tabular}

Für den Faktor Ration des Spendertieres wurde die Kuh mit einer Heu-Kraftfutterbzw. einer Stroh-Harnstoff-Ration gefüttert (Tab.1). Die Menge des in der Ration Stroh-Harnstoff eingesetzten Harnstoffs ergab sich aus der Differenz zwischen Erhaltungsbedarf der Kuh an XP (475 g XP/Tag) abzüglich des mit dem Stroh zugeführten verdaulichen XP (175 g XP / Tag). Die zum Erhaltungsbedarf fehle nde Menge an Rohprotein ( $300 \mathrm{~g} \mathrm{XP)}$ wurde durch den im Harnstoff enthaltenen Stickstoff ersetzt $(300 * 2.2 / 6,25=105)$. Die Umstellungen des Spendertieres auf 
die jeweilige Ration erfolgte mindestens eine Woche vor Beginn des Versuchszeitraumes. Der Wechsel von der Heu-Kraftfutter- auf die Stroh-Harnstoff-Ration erfolgte über eine siebentägige Anfütterungsphase, in der, ausgehend von einer Anfangsration aus $8 \mathrm{~kg} \mathrm{Heu}, 2 \mathrm{~kg}$ Stroh und $15 \mathrm{~g}$ Harnstoff, der Stroh-HarnstoffAnteil schrittweise auf die tatsächliche Ration eingestellt wurde. Die entsprechende Harnstoffmenge wurde vor jeder Fütterung in 3 I Wasser gelöst und die Lösung mit einer Gießkanne über das Stroh gegossen.

Die für die weiteren Untersuchungen verwendeten drei Jersey-Ochsen wurden mindestens eine Woche vor der Pansensaftentnahme mit einer Ration aus $7 \mathrm{~kg} \mathrm{Heu}$ und $500 \mathrm{~g}$ Konzentratfutter (6,4 MJ NEL, $20 \%$ XP, Fa. HEMO, Scheden) pro Tag gefüttert.

\subsubsection{Pansensaftentnahme}

Die Pansensaftentnahme erfolgte immer vor der Morgenfütterung, d.h. entweder 16 Stunden oder bei längerer Nüchterungsdauer 24 Stunden nach der letzten Futteraufnahme.

Der Pansensaft wurde mit Hilfe einer $35 \mathrm{~cm}$ langen, starren Metallsonde, an deren vorderen Ende auf einer Länge von $5 \mathrm{~cm} 3 \mathrm{~mm}$ große Löcher gebohrt waren, aus dem ventralen Pansensack entnommen. Dazu wurde das zweite Ende des Rohres über einen Schlauch mit einer Saugflasche, in der über einen Druckball ein leichter Unterdruck erzeugt wurde, verbunden. Zur weitgehendsten Eliminierung von Sauerstoff aus dem System wurde das Auffanggefäß vor der Pansensaftentnahme 10 Minuten lang entweder mit $\mathrm{N}_{2}$ oder mit $\mathrm{CO}_{2}$ begast, wodurch anaerobe Bedingungen geschaffen werden konnten.

\subsubsection{Defaunierung des Pansensaftes}

Zur Defaunierung des Pansensaftes diente das Detergens Synperonic (VEIRA ET AL. 1983, KREUZER und KIRCHGEBNER 1986). Die sonst für industrielle Zwecke verwendete Substanz (Wirkstoff: Natrium-lauryl-diethoxy-Sulfat, Fa. Deutsche ICl, Frankfurt a. M., D) wurde in einer Konzentration von $0,25 \%(\mathrm{v} / \mathrm{v})$ direkt zum Inokulum gegeben. Die anschließende lichtmikroskopische Überprüfung ergab, daß schon wenige Minuten nach der Behandlung keine Protozoen mehr im Pansensaft zu erkennen waren. Die Inkubation des defaunierten Pansensaftes erfolgte kurz nach Zugabe des Detergens und immer zeitgleich mit der Inkubation des nicht defaunierten Inokulums. 


\subsubsection{Gewinnung der Bakteriensuspension}

Die Gewinnung der Bakteriensuspension wurde nach DE GRAEVE ET AL. (1994) durchgeführt. Hierzu wurde direkt nach der Schlachtung von fünf Schweinen der komplette Blinddarm (Caecum) und die erste Hälfte des Grimmdarms (Colon) entnommen, abgebunden und in verschlossenen Eimern ins Labor transportiert. Dann wurden unter $\mathrm{N}_{2}$-Begasung die jeweiligen Caecum- und Colonabschnitte entleert und getrennt nach Darmabschnitten in zwei Eimern vereint.

Während der Probenaufbereitung wurden alle Gefäße mit Stickstoff begast. Von dem Blinddarminhalt wurden $200 \mathrm{ml}$ und vom Colon $800 \mathrm{ml}$ entnommen und in einem großen Glasgefäß mit $1500 \mathrm{ml}$ harnstofffreiem Phosphatpuffer (s. batch-cultureMethode) gemischt. Die dickflüssige Masse wurde mit einem Magnetrührer und durch Einleitung von N 10 Minuten homogenisiert. Mit Hilfe einer Gaze (Nylon, ca. $1 \mathrm{~mm}$ Maschenweite) wurden anschließend die groben Bestandteile abgetrennt und dabei die Flüssigkeit in Zentrifugengefäße (Kunststoff, 200 ml) überführt.

Um gröbere Bestandteile zu entfernen, wurde die Suspension zunächst 5 Minuten bei $4^{\circ} \mathrm{C}$ und $500 \mathrm{~g}$ zentrifugiert (Minifuge RF, Fa. Heraeus Sepatech, D). Anschließend wurden die Bakterien in einer Ultrazentrifuge (Sorvall RC-5C Refigerated Superspeed Zentrifuge, Fa. Du Pont Instruments) bei $4{ }^{\circ} \mathrm{C}$ und $27000 \mathrm{~g}$ 20 Minuten lang abgetrennt. Der Überstand wurde verworfen, das Bakterienpellet mit $100 \mathrm{ml}$ Phosphatpuffer $\left(\mathrm{Na}_{2} \mathrm{HPO}_{4}\right.$ und $\mathrm{NaH}_{2} \mathrm{PO}_{4}$ je $50 \mathrm{mmol} / \mathrm{l}$ und $\mathrm{NaHCO}_{3}$ $75 \mathrm{mmol} / \mathrm{l})$ im Zentrifugenbecher aufgenommen und mit Hilfe eine Glasstabes von der Gefäßwand abgelöst. Die Suspension wurde in einem Meßzylinder $(100 \mathrm{ml}) \mathrm{mit}$ einer passenden Glaspistill homogenisiert und dann erneut bei $4^{\circ} \mathrm{C}$ und $27000 \mathrm{~g}$ 20 Minuten zentrifugiert. Insgesamt wurden die Bakterien dreimal mit Puffer aufgenommen und gereinigt. Der Überstand aus dem letzten Spülvorgang wurde verworfen, das verbliebene Pellet gewogen und mit der 3 fachen Menge (w/v) eines mit $98 \% \mathrm{NaH}^{13} \mathrm{CO}_{3}$ angereicherten Phosphatpuffers (Molarität s. o.) versetzt. Die Mischung wurde anschließend, wie bereits beschrieben, homogenisiert und $10 \mathrm{ml}$ dieser Suspension dienten als Inokulum für die Inkubationsgefäße.

\subsection{5 batch-culture-Methode}

Das Prinzip der hier verwendeten batch-culture-Methode beruht auf der Inkubation eines Substrates mit Pansensaft und einem mit $\mathrm{CO}_{2}$ gesättigten Puffer. Die sich während der Inkubation bildenden Endprodukte, Gas und SCFA, reichern sich im Inkubationsgefäß (Abb. 3) an und können am Ende der Inkubationszeit quantitativ bestimmt werden. Damit ist die batch-culture ein geschlossenes, nicht kontinuierliches in-vitro-Verfahren (statische Kultur) zur Untersuchung der fermentativen Umsetzungen pansenstämmiger Mikroorganismen. 
Bei dem in dieser Untersuchung verwendeten System wurden Pansensaft und Puffer im Verhältnis 1:5 mit dem Substrat in einem $200 \mathrm{ml}$ Erlenmeyerkolben, mit Septum und Glashahn, gemischt und bei $39{ }^{\circ} \mathrm{C}$ im Schüttelwasserbad $24 \mathrm{~h}$ inkubiert. Die Fermentation wurde mit $10 \mathrm{~N} \mathrm{H}_{2} \mathrm{SO}_{4}$ gestoppt und anschließend konnten die Parameter der Fermentation gemessen werden (VAN NEVEL und DEMEYER 1992).

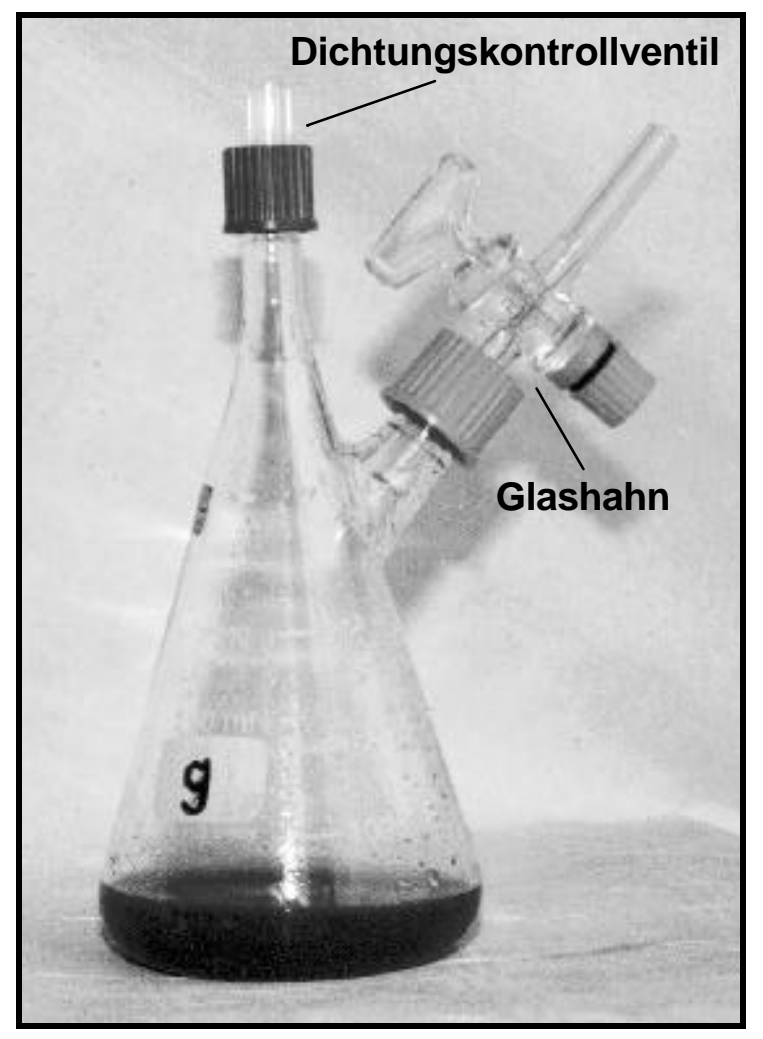

Abb. 3: Inkubationsgefäß für batch-culture.

Die in dieser Arbeit vorgestellten batch-culture-Untersuchungen umfaßten die folgenden Arbeitsschritte:

1. $10 \%$ igen Burroughs-Puffer herstellen (BURROUGHS ET AL. 1950): zu $100 \mathrm{ml}$ Lösung $110 \mathrm{ml}$ Lösung 2 geben und diese Mischung mit $\mathrm{H}_{2} \mathrm{O}$ auf $1000 \mathrm{ml}$ auffüllen. Lösung 1 und 2 haben folgende Zusammensetzung:

\section{Lösung 1:}

$\mathrm{Na}_{2} \mathrm{HPO}_{4}$ * $12 \mathrm{H}_{2} \mathrm{O} \quad 26,25 \mathrm{~g}$

$\mathrm{KCl} \quad 3,75 \mathrm{~g}$

$\mathrm{NaCl} \quad 3,75 \mathrm{~g}$

$\mathrm{MgSO}_{4}{ }^{*} 7 \mathrm{H} 2 \mathrm{O} \quad 1,13 \mathrm{~g}$

\section{Lösung 2:}

$\begin{array}{ll}\mathrm{CaCl}_{2}{ }^{*} 6 \mathrm{H}_{2} \mathrm{O} & 3,8 \mathrm{~g} \\ \mathrm{FeSO}_{4}{ }^{*} 7 \mathrm{H}_{2} \mathrm{O} & 0,8 \mathrm{~g} \\ \mathrm{MnSO}_{4}{ }^{*} \mathrm{H}_{2} \mathrm{O} & 0,3 \mathrm{~g} \\ \mathrm{ZnSO}_{4}{ }^{*} 7 \mathrm{H}_{2} \mathrm{O} & 0,4 \mathrm{~g} \\ \mathrm{CuSO}_{4}{ }^{*} 5 \mathrm{H}_{2} \mathrm{O} & 0,2 \mathrm{~g} \\ \mathrm{CoCl}_{2}{ }^{*} 6 \mathrm{H}_{2} \mathrm{O} & 0,1 \mathrm{~g}\end{array}$

ad $1000 \mathrm{ml} \mathrm{H}_{2} \mathrm{O}$

ad $1000 \mathrm{ml} \mathrm{H} \mathrm{H}_{2}$ 
Dem Puffer zur Sicherstellung der von den Mikroorganismen zur mikrobiellen Proteinsynthese benötigten Stickstoffmengen $1,4 \mathrm{~g} \mathrm{NH}_{4} \mathrm{HCO}_{3}$ / I Puffer zusetzen. Zur weitgehensten Eliminierung des Sauerstoffs aus der Pufferlösung Puffer unter Vakuum 15 Minuten kalt sieden und anschließend 90 Minuten mit $\mathrm{CO}_{2}$ begasen.

2. Substrat in Inkubationsgefäße einwiegen: je nach Versuchsansatz entweder $500 \mathrm{mg} \mathrm{Heu}, 500 \mathrm{mg}$ Stroh oder $500 \mathrm{mg}$ autoklavierten Blinddarminhalt. Alle in-vitro-Substrate zuvor lufttrocken mahlen (Siebgröße $1 \mathrm{~mm}$; Zusammensetzung der in-vitro-Substrate siehe Tab.2).

3. Inkubationsgefäße ins Wasserbad $\left(39^{\circ} \mathrm{C}\right)$ stellen und kontinuierlich über Begasungsrechen mit $\mathrm{CO}_{2}$ begasen.

4. In jedes Inkubationsgefäß $40 \mathrm{ml}$ Burroughs-Puffer pipettieren.

5. Pansensaft entnehmen und $10 \mathrm{ml}$ unter $\mathrm{CO}_{2}$-Begasung in jedes Inkubationsgefäß einpipettieren.

6. Inkubationsgefäße verschließen, 6 mal abwechselnd evakuieren und mit $\mathrm{CO}_{2}$ begasen.

7. Nach letzter Begasung eventuellen $\mathrm{CO}_{2}$-Überdruck ablassen und Inkubationsgefäße mit Glashahn schließen. Bei Ansätzen mit einer Mischung in der Gasatmosphäre die den Evakuierungsstufen entsprechende Gasmenge des 1. Gases mit Kolbenprober entnehmen und anschließend gleiche Menge des 2. Gases zugeben.

8. Wassersäule in Dichtungskontrollventilen der Septen herstellen, Deckel des Wasserbades schließen und Schüttelvorrichtung des Wasserbades in Gang setzen (ca. eine Bewegung pro Sekunde).

9. Pansensaft zur pH-Messung und Bestimmung der flüchtigen Fettsäuren (SCFA) im Inokulum entnehmen und entsprechend aufbereiten.

10. Nach 24 Stunden Fermentation durch Injektion von $1 \mathrm{ml} 10 \mathrm{~N} \mathrm{H}_{2} \mathrm{SO}_{4}$ stoppen.

Tab. 2: $\quad$ Inhaltsstoffe der verwendeten in-vitro-Substrate.

\begin{tabular}{|c|c|c|c|c|c|c|c|c|c|c|c|}
\hline \hline & $\%$ FM & \multicolumn{10}{|c|}{$\%$} \\
in-vitro-Substrat & TM & XA & XL & XP & XF & NDF & ADF & Lignin & Cellulose & Hemicell. & org. Rest \\
\hline Stroh & 95,50 & 4,62 & 0,98 & 1,72 & 47,53 & 80,58 & 53,35 & 7,56 & 45,79 & 27,23 & 12,10 \\
Heu & 95,65 & 7,15 & 1,52 & 10,03 & 30,17 & 58,66 & 34,26 & 3,16 & 31,10 & 24,40 & 22,64 \\
Blinddarminhalt & 87,86 & 18,55 & 6,95 & 17,44 & 16,37 & 46,05 & 21,52 & 5,71 & 15,81 & 24,53 & 11,01 \\
\hline \hline
\end{tabular}


Nach Ende der Inkubationen konnten die Proben mit einer verschließbaren, gasdichten $1 \mathrm{ml}$ Spritze (Nr. 050033, Fa. Alltech, Unterhaching) durch das Septum an der oberen Öffnung des Inkubationsgefäßes für die Gasanalysen entnommen werden. Nach Abschluß der Gasanalyse wurde das Gefäß geöffnet und der flüssige Inhalt zur Messung der SCFA verwendet.

Der Einsatz von ${ }^{13} \mathrm{C}-\mathrm{CO}_{2}$ als Marker erfolgte gleichzeitig sowohl über ${ }^{13} \mathrm{C}_{-}-\mathrm{CO}_{2}$ in der Gasphase als auch durch zu $98 \%$ mit ${ }^{13} \mathrm{C}$ angereichertem $\mathrm{NaH}^{13} \mathrm{CO}_{3}$ (Fa. Deutero, Kastellaun) im Puffer.

Das ${ }^{13} \mathrm{C}-\mathrm{CO}_{2}$ in der Gasphase wurde durch Austreiben von ${ }^{13} \mathrm{CO}_{2}$ aus $\mathrm{NaH}^{13} \mathrm{CO}_{3}$ erhalten. Dazu wurden $250 \mathrm{mg} \mathrm{NaH}{ }^{13} \mathrm{CO}_{3}$ in $10 \mathrm{ml} \mathrm{H}_{2} \mathrm{O}_{\text {dest. }}$ gelöst und in einen mit einem Dreiwegehahn versehenen $100 \mathrm{ml}$ Kolbenprober blasenfrei aufgezogen. Eine Öffnung des Dreiwegehahns war mit einem Septum (Nr.Z12433-8, Fa. Aldrich, Steinheim) versehen, durch das mit Hilfe einer $5 \mathrm{ml}$ Einwegspritze mit Kanüle $1 \mathrm{ml}$ $10 \mathrm{~N} \mathrm{H}_{2} \mathrm{SO}_{4}$ in den Kolbenprober injiziert wurde. Auf diese Weise wurde das ${ }^{13} \mathrm{CO}_{2}$ nahezu vollständig aus der Lösung ausgetrieben und konnte dann, wie oben beschrieben, aus dem Kolbenprober in die Inkubationsgefäße überführt werden.

Als Puffer wurde bei den batch-culture-Ansätzen mit ${ }^{13} \mathrm{C}_{-} \mathrm{CO}_{2}$-Markierung ein von DE GRAEVE ET AL. (1994) beschriebener Phosphatpuffer verwendet. Dieser Puffer enthielt $50 \mathrm{mmol} / \mathrm{I} \mathrm{Na} \mathrm{HPO}_{4}$, die gleiche Konzentration $\mathrm{NaH}_{2} \mathrm{PO}_{4}, 3,75 \mathrm{mmol} / \mathrm{I}$ Harnstoff und $75 \mathrm{mmol} / \mathrm{I} \mathrm{NaH}^{13} \mathrm{CO}_{3}$. Wie oben beschrieben, wurde der Puffer kalt gesiedet und mit $\mathrm{N}_{2}$ begast. Der $\mathrm{pH}-$ Wert des Puffer lag bei 6,9.

\subsubsection{Pansensimulationstechnik (RUSITEC)}

Das RUSITEC-System wurde von CZERKAWSKI und BRECKENRIDGE (1977) als eine semi-kontinuierliche, offene Langzeit-in-vitro-Methode zur Simulation des mikrobiellen Stoffwechsels pansenstämmiger Mikroorganismen entwickelt (CZERKAWSKI 1986, ChEng und MCALLISTER 1997). Das System ermöglicht die Untersuchung auch extremer Fütterungssituationen, ohne dabei das Wirtstier zu belasten. Das Kernstück der Apparatur sind die Fermenter, die kontinuierlich mit Puffer versorgt werden. Ein Überlauf ermöglicht die getrennte Sammlung von Gas und flüssigem Fermenterinhalt. Jeder der insgesamt 6 Fermenter wird einmal täglich geöffnet, um in Nylonbeuteln abgefülltes Substrat hineinzugeben und das bereits fermentierte Substrat entnehmen zu können.

Das für den hier vorgestellten Versuch verwendete Simulationssystem ist in Abbildung 4 schematisch dargestellt, die technischen Daten des Geräts können der Legende entnommen werden. 


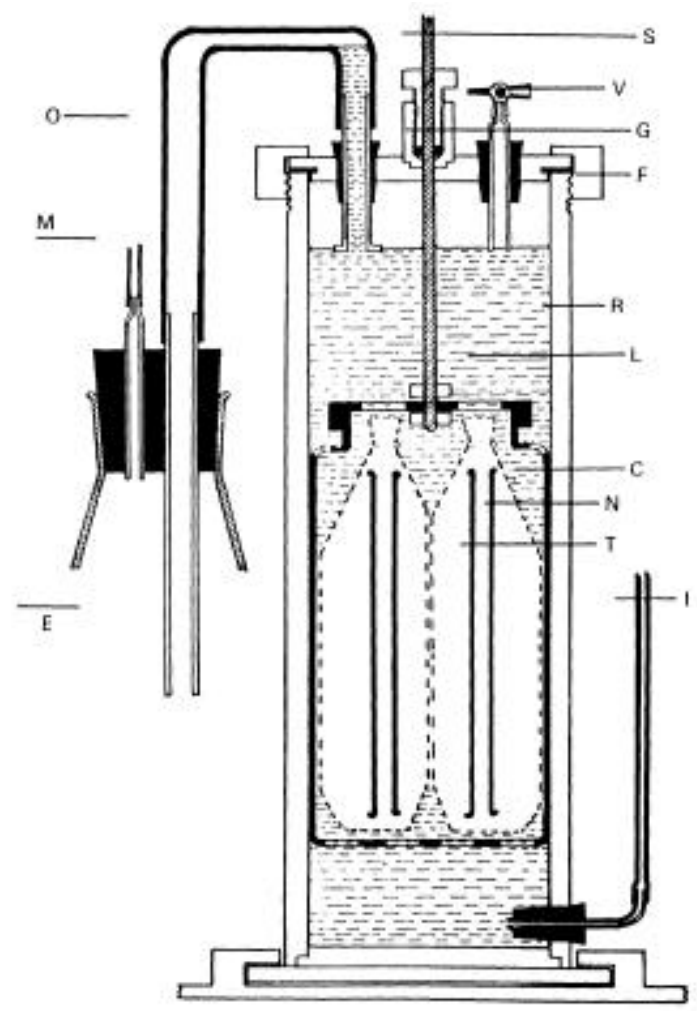

Abb. 4: $\quad$ Schematischer Aufbau eines RUSITEC-Fermenters (CZERKAWSKI und BRECKENRIDGE 1977)

C perforierter Innenbehälter

E Überlaufgefäß, Volumen $750 \mathrm{ml}$

F Schraubverschluß des Fermenters

G geschraubte Dichtung (gasdicht)

I Pufferzulaufschlauch, verbunden mit Walzenpumpe (Typ IPS-8, Fa. ISMATEC, Zürich, CH), eingestellte Förderleistung $700 \mathrm{ml} / \mathrm{Tag}$

L Gemisch aus Pansenflüssigkeit und Puffer

M Verbindungsschlauch zu Gassammelbeutel TECOBAG mit Zapfhahn, Volumen 5 I (Fa. Tesseraux, Bürstadt)

$\mathrm{N} \quad$ Kunststoffrohr zur Aufrichtung der Nylonbeutel (hier nicht verwendet)

O gasdichter Überlaufschlauch

R Fermenter, Plexiglas mit Schraubdeckel und Gummidichtung, Volumen $1080 \mathrm{ml}$

S Hubstange (8 Hübe à $7 \mathrm{~cm}$ pro Minute)

T Nylonbeutel (40 $\mu \mathrm{m}$ Maschenweite) mit Substrat

V Dreiwege-Probeentnahmehahn 
Der in dieser Arbeit vorgestellte RUSITEC-Versuch wurde nach folgendem täglichem Ablauf durchgeführt:

1. Tag:

(1) $\quad 85 \mathrm{~g}$ festen Panseninhalt in Nylonbeutel einwiegen (Maschenweite $100 \mu \mathrm{m})$.

(2) $690 \mathrm{ml}$ Pansensaft in Fermenter füllen.

(3) Beutel mit festem Panseninhalt und Beutel mit Substrat $(8 \mathrm{~g} \mathrm{Heu}, 4 \mathrm{~g}$ Gerste, $0,15 \mathrm{~g}$ Mineralfutter) in perforierten Innenbehälter des Fermenters geben (Maschenweite $40 \mu \mathrm{m}$ ).

(4) Innenbehälter in den Fermenter einführen.

(5) Fermenter mit vorbereitetem Burroughs-Puffer auffüllen und verschließen.

(6) Im Fermenter befindliches Gas durch fünfmaliges kräftiges Herabdrücken des Innenbehälters entfernen.

(7) Fermenter in das auf $39^{\circ} \mathrm{C}$ vorgeheizte Wasserbad stellen und Führungsstange des Innenbehälters an der Hubstange des RUSITECApparatur festklemmen.

(8) Pufferschlauch an Walzenpumpe und Überlaufschlauch an Überlaufflasche anschließen, in der sich $2 \mathrm{ml}$ einer $\mathrm{HgCl}_{2}$ Lösung $\left(1,15 \mathrm{~g} \mathrm{HgCL}_{2} / 100 \mathrm{ml} \mathrm{H}_{2} \mathrm{O}\right)$ zum Stoppen der Fermentation befinden.

(9) Durch Probeentnahmehahn des Fermenters System 2 Minuten mit Stickstoff spülen.

(10) Nach Beendigung der Begasung Gassammelbeutel anschließen.

(11) Vorgehen für Fermenter 2 und 3 wiederholen.

(12) Aus jedem Fermenter am Probeentnahmehahn mit Hilfe einer $25 \mathrm{ml}$ Einwegspritze Probe $(10 \mathrm{ml})$ des flüssigen Fermenterinhalts zur Bestimmung des pH-Wertes, des Redoxpotentials und der Protozoenzahl entnehmen.

2. Tag:

(1) Aus jedem der 3 Fermenter Probe $(10 \mathrm{ml})$ zur $\mathrm{pH}-$, Redoxpotential- und Protozoenzählung entnehmen.

(2) Gasbeutel verschließen und vom Überlaufgefäß abnehmen. 
(3) Ersten Fermenter aus Wasserbad nehmen und öffnen. Beutel mit festem Panseninhalt aus Innenbehälter entnehmen und durch einen zweiten mit Substrat (8 $\mathrm{g} \mathrm{Heu}, 4 \mathrm{~g}$ Gerste, $0,15 \mathrm{~g}$ Mineralfutter) gefüllten Beutel ersetzen (Maschenweite $40 \mu \mathrm{m}$ ).

(4) Entnommener Beutel mit $60 \mathrm{ml}$ vorgewärmtem Puffer im Plastikbeutel gleichmäßig spülen und anschließend auswringen, Spülflüssigkeit in den Fermenter geben, Beutelinhalt verwerfen.

(5) Fermenter wieder verschließen und das in inm befindliche Gas durch fünfmaliges kräftiges Herabdrücken des Innenbehälters entfernen.

(6) Überlaufgefäß leeren, Flüssigkeitsmenge bestimmen und Probe zur Messung der SCFA entnehmen.

(7) - (12) wie Schritt 7 bis 12 von Tag 1.

An allen weiteren Versuchstagen wurde so vorgegangen wie an Tag 2. Nach vier Tagen Vorlaufzeit, die das System benötigt, um sich auf steady-state-Bedingungen einzustellen, wurde Fermenter 1 weiter so behandelt wie zuvor. Den Fermentern 2 und 3 wurden ab dem 5. Tag über den Puffer 0,432 g (0,4 \%) bzw. 0,648 g (0,6 \%) Gallensalz (Nr. B-8756, Sigma Bile Salts) pro Tag zugeführt. Diese Menge ergibt sich aus der Überlegung, daß Galle zu ca. $10 \%$ aus Gallensalzen besteht (KoLB 1989). $\left(1080 \mathrm{ml}^{*} 0,004{ }^{*} 0,10=0,432 \mathrm{~g}\right)$. Am siebten Versuchstag wurde aus jedem der drei Fermenter Inokulum für einen sich anschließenden batch-culture-Versuch entnommen und das RUSITEC System anschließend gestoppt.

\subsection{Analytische Methoden}

\subsection{1}

Messung von $\mathrm{pH}-$ Wert und Redoxpotential

Der pH-Wert des Pansensaftes und der flüssigen Phasen aus den in-vitroUntersuchungen wurden mit einem pH-Meter (CG 811, Fa. Schott, Hofheim) mit $\mathrm{pH}$-Einstabmeßkette gemessen. Die Meßapparatur wurde täglich mit Standardpufferlösungen auf $\mathrm{pH} 4$ und $\mathrm{pH} 7$ geeicht.

Das Redoxpotential bei den RUSITEC-Untersuchungen wurde mit einer Einstabmeßkette (PT-4805, Fa. Ingold) und einem daran angeschlossenen pH-Meter (CG 837, Fa. Schott, Hofheim) ermittelt. Die Eichung der Elektrode erfolgte täglich mit einer Redox-Pufferlösung (Nr. 209881250, Fa. Mettler Toledo, Steinbach, D). 
Die Zählung der Protozoen erfolgte in Anlehnung an HARMEYER (1965). Es wurde $1 \mathrm{ml}$ Probe aus dem RUSITEC-System bzw. dem Pansen mit $1 \mathrm{ml}$ Protozoenlösung (Herstellung: $0,6 \mathrm{~g}$ Methylgrün, $8 \mathrm{~g} \mathrm{NaCl}$ und $100 \mathrm{ml}$ Formaldehyd (35\%ig) mit $\mathrm{H}_{2} \mathrm{O}_{\text {dest. }}$ auf $1000 \mathrm{ml}$ auffüllen) gemischt und bis zur Zählung in Dunkelheit gelagert. Die Zählung erfolgte mit einem Zeiss Lichtmikroskop bei einer 160 fachen Vergrößerung unter Verwendung eines Okulars mit Zählquadrat in einer modifizierten McMaster-Zählkammer (WETZEL 1951). Diese Zählkammer besitzt drei voneinander getrennte Kammern mit Seitenlängen von $20 \mathrm{~mm}$ * $18 \mathrm{~mm}$. Vor der ersten Zählung wurde mit Hilfe eines Objektmikrometers die Seitenlänge des Zählquadrates bestimmt. Zusammen mit der Tiefe der Zählkammer konnte mit diesen Maßen das Volumen eines Zählquadrates errechnet werden (Gleichung 1):

\begin{tabular}{lll} 
Seitenlänge des Zählquadrates: & 0,40 & $\mathrm{~mm}$ \\
Tiefe der Zählkammer: & 0,98 & $\mathrm{~mm}$ \\
\hline Volumen des Zählquadrates: & 0,1568 & $\mathrm{~mm}^{3}$
\end{tabular}

Um die Zahl der in einem Quadrat ausgezählten Protozoen auf einen Milliliter zu beziehen, mußte die Protozoenzahl demnach mit dem Faktor 6377,55 $(=1000 / 0,1568)$ multipliziert werden. Für die Bestimmung der Protozoenzahl einer Probe wurden die drei Kammern der Zählkammer möglichst blasenfrei mit Probenflüssigkeit gefüllt und mit je einem Deckgläschen abgedeckt. Anschließend wurden in jeder Kammer 40 Quadrate ausgezählt, wobei darauf geachtet wurde, die Quadrate möglichst gleichmäßig in der gesamten Kammer auszuwählen. Die Berechnung der Protozoen pro Milliliter Probe erfolgte nach Gleichung 2:

Protozoen $/ \mathrm{ml}$ Probe $=\frac{\text { Gesamtzahl der gezählten Protozoen * Faktor * Verdünnun } \mathrm{g}}{\text { Anzahl der gezählten Quadrate }}$

\subsubsection{Messung der Fermentationsgase}

Die Bestimmung des Gasvolumens erfolgte bei den RUSITEC-Untersuchungen mit Hilfe eines $2000 \mathrm{ml}$ Polyethylen-Meßzylinders, an dessen Unterseite eine Öffnung mit einem Dreiwegehahn angebracht worden war. Um das Gas quantitativ zu gewinnen, wurde dieser Hahn über einen Schlauch mit dem Gassammelbeutel verbunden. Nachdem der Meßzylinder durch Untertauchen in einer Wanne zunächst vollständig mit Wasser gefüllt worden war, konnte das Gas durch langsames Herausziehen des mit der Unterseite nach oben gehaltenen Zylinders durch den 
Saugdruck des Wassers aus dem Beutel abgesaugt werden. Das Volumen des abgesaugten Gases wurde dann direkt an der Skala des Meßzylinders abgelesen. Die Errechnung dieser Gasvolumina in Mol erhält man durch Umformung der allgemeinen Gasgleichung ( $p{ }^{*} v=n{ }^{*}{ }^{*} T$ ) (Gleichung 3 ):

$$
n=\frac{p^{*} v}{R^{*} T}\left[\frac{\mathrm{Pa}^{*} \mathrm{~m}^{3}}{{ }^{\circ} \mathrm{K}}\right]
$$

wobei

$$
\begin{aligned}
& n=\text { Molanzahl } \\
& \mathrm{p}=\text { Luftdruck in Pascal }(\mathrm{Pa}) \\
& \mathrm{v}=\text { Gasvolumen in } \mathrm{m}^{3} \\
& \mathrm{R}=\text { universelle Gaskonstante } 8,3143 \mathrm{~J}^{*} \mathrm{~K}^{-1}{ }^{*} \mathrm{~mol}^{-1} \\
& \mathrm{~T}=\text { Temperatur in Kelvin }\left({ }^{\circ} \mathrm{K}\right)
\end{aligned}
$$

In der batch-culture konnte das Gasvolumen durch Subtraktion des Flüssigkeitsvolumens vom Gefäßvolumen ermittelt werden. Dem Druckunterschied zwischen Gefäßinneren und der Atmosphäre wurde durch Verwendung einer verschließbaren Gasspritze (Nr. 050033, Fa. Alltech, Unterhaching) zur Probenentnahme Rechnung getragen.

Die Gaszusammensetzung wurde gaschromatographisch unter den folgenden Bedingungen bestimmt (Tab.3):

Tab. 3: Chromatographiebedingungen zur Bestimmung der Gaszusammensetzung des Fermentationsgases.

\begin{tabular}{|l|l|}
\hline \hline Gerät & Shimadzu GC 8A (Shimadzu Europa, Duisburg, D) \\
\hline Detektor & Wärmeleitfähigkeitsdetektor (TCD) \\
\hline Injektortemperatur & $80^{\circ} \mathrm{C}$ \\
\hline Säulenofentemperatur & $40^{\circ} \mathrm{C}$, isotherm \\
\hline Detektortemperatur & $80^{\circ} \mathrm{C}$ \\
\hline Detektorstrom & $80 \mathrm{~mA}$ \\
\hline Säule & Porapak Q $(80 / 100) 3 \mathrm{~m} * 4 \mathrm{~mm}$ \\
\hline Trägergas & Argon $40 \mathrm{ml} /$ min (Einstellung: $180 \mathrm{kPa})$ \\
\hline Probenmenge & $1 \mathrm{ml}$, manuelle Injektion \\
\hline Integrator & Schimadzu CR-1B \\
\hline \hline
\end{tabular}


Die Signale des Wärmeleitfähigkeitsdetektors wurden durch einen Integrator (Shimadzu C-R 1B) in Form von Chromatogrammen aufgezeichnet. Die Flächen unter den Peaks wurden durch das Gerät berechnet und in der dimensionslosen Einheit Area ausgegeben.

Eine Eichung des Geräts erfolgte jeden Morgen nach Inbetriebnahme. Hierzu wurde dreimal $1 \mathrm{ml}$ eines speziell hergestellten Eichgasgemisches (Messer Griesheim, Kassel, D) der Zusammensetzung

$\begin{array}{lr}\text { Kohlendioxid } & 65 \% \\ \text { Methan } & 30 \% \\ \text { Stickstoff } & 4 \% \\ \text { Sauerstoff } & 1 \%\end{array}$

verwendet. Um die Stabilität des Systems zu überprüfen, wurde die Eichung am Ende jeder Meßreihe wiederholt.

Im Rahmen der Methodenvalidierung wurden folgende Variationskoeffizienten ermittelt: Methan: 1,53 \%, Kohlendioxid 1,41\% und Stickstoff 1,94\%. Die Linearität der Messung wurde anhand von Eichgeraden überprüft, die in Abbildung 5 dargestellt sind.

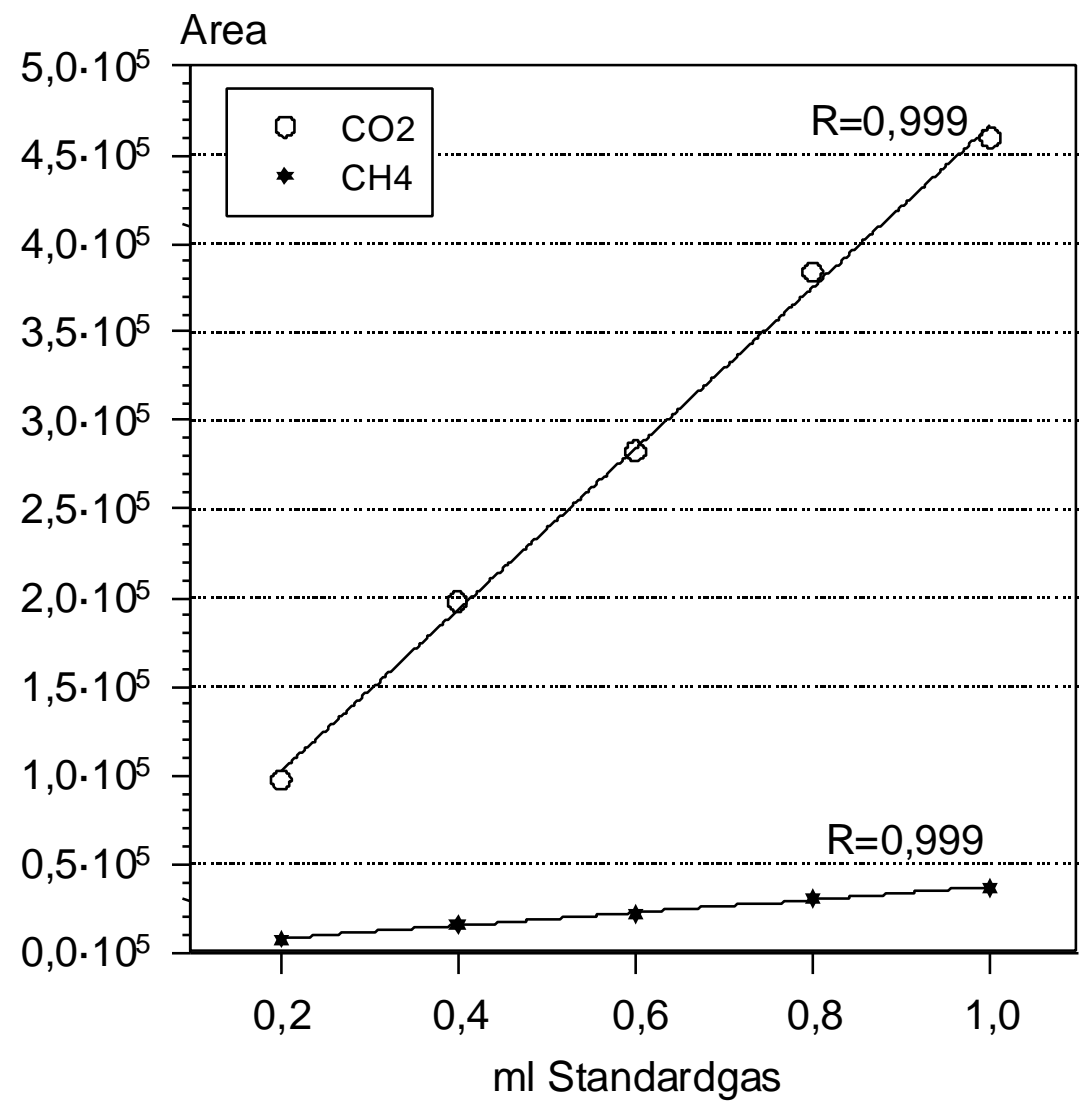

Abb. 5: Darstellung der Linearitätsüberprüfung der Gasanalysen nach GOTTWALD (1995) 


\subsubsection{Messung der flüchtigen Fettsäuren}

Für die im Rahmen dieser Arbeit durchgeführten Messungen der kurzkettigen flüchtigen Fettsäuren (SCFA) wurden zwei Verfahren angewandt. Die beiden Verfahren unterscheiden sich hinsichtlich der gaschromatographischen Bedingungen (Tab. 4 und 5) und der Tatsache, daß die Auswertung der Chromatogramme bei Verfahren 1 nach der Methode des externen Standards und bei Verfahren 2 nach der Methode des internen Standards durchgeführt wurde. Das Verfahren 1 wurde für die Untersuchungen in Versuchsstufe 1 und das Verfahren 2 für diejenigen der Versuchsstufe 2 verwandt.

Tab. 4: $\quad$ Chromatographiebedingungen zur Bestimmung der kurzkettigen flüchtigen Fettsäuren (SCFA) nach Verfahren 1.

\begin{tabular}{|l|l|}
\hline \hline Gerät & Shimadzu GC 14B (Shimadzu Europa, Duisburg, D) \\
\hline Detektor & Flammenionisationsdetektor (FID) \\
\hline Injektortemperatur & $260^{\circ} \mathrm{C}$ \\
\hline Säulenofentemperatur & $\begin{array}{l}\text { Temperaturprogramm } 5 \mathrm{~min} 5^{\circ} \mathrm{C}, \text { Heizrate } 8^{\circ} \mathrm{C} / \mathrm{min}, \\
\text { Endtemperatur } 190^{\circ} \mathrm{C}, 1 \mathrm{~min}\end{array}$ \\
\hline Detektortemperatur & $280^{\circ} \mathrm{C}$ \\
\hline Säule & Kapillarsäule \\
\hline Säulenfüllung & Permabond, FFAP-DF-0,25, $25 \mathrm{~m}^{*} 0,25 \mathrm{~mm} \mathrm{ID}$ \\
\hline Trägergas & Stickstoff $5.0,1,5 \mathrm{~kg} / \mathrm{cm}^{2}$ \\
\hline Probenmenge & $1 \mu \mathrm{l}$, manuelle Injektion, $10 \mu \mathrm{H}$ Hamilton Spritze \\
\hline Integrator & Shimadzu \\
\hline \hline
\end{tabular}

Die Berechnung der Konzentrationen der einzelnen flüchtigen Fettsäuren erfolgte dabei durch den Vergleich der Peakflächen der Standardsubstanzen mit den Peakflächen der Probe. Die Zusammensetzung des Standardgemisches kann Tabelle 6 entnommen werden kann. Bei Verfahren2 wurden die Konzentrationsberechnungen durch den Korrekturfaktor der Methode des internen Standards erweitert. Dabei wurde zu Beginn einer jeden Meßreihe in den drei Kalibrierungsanalysen des Standardgemischs nach folgender Gleichung (4) ein Korrekturfaktor errechnet (ISTD=interner Standard):

$$
\text { Korrekturf aktor }=\frac{\text { Area ISTD }{ }^{*} \text { mol Substanz }}{\text { Area Subst. }{ }^{*} \text { mol ISTD. }}
$$


Tab. 5: Chromatographiebedingungen zur Bestimmung der kurzkettigen flüchtigen Fettsäuren (Verfahren 2).

\begin{tabular}{|c|c|}
\hline Gerät & Shimadzu GC 14B (Shimadzu Europa, Duisburg, D) \\
\hline Detektor & Flammenionisationsdetektor (FID) \\
\hline Injektortemperatur & $200{ }^{\circ} \mathrm{C}$ \\
\hline Säulenofentemperatur & $120^{\circ} \mathrm{C}$, isotherm \\
\hline Detektortemperatur & $200^{\circ} \mathrm{C}$ \\
\hline Synthetische Luft & $50 \mathrm{kPa}$ \\
\hline Säule & Gepackte Glassäule, 2,1m, Shimadzu (221-143668-21) \\
\hline Säulenfüllung & $\begin{array}{l}10 \% \text { Carbowax } 20 \text { MTPA SP1000 mit } 1 \% \mathrm{H}_{3} \mathrm{PO}_{4} \text { auf } \\
\text { Chromosorb WAW, } 80 / 100\end{array}$ \\
\hline Trägergas & $\begin{array}{l}\text { Wasserstoff } 5.0,100 \mathrm{ml} / \mathrm{min} \text { (Einstellung: } 100 \mathrm{kPa} \text { ) } \\
\text { Das Trägergas wurde gleichzeitig als Brenngas für den FID } \\
\text { verwendet! }\end{array}$ \\
\hline Probenmenge & $1 \mu l$ \\
\hline Probenaufbereitung & $\begin{array}{l}5 \mathrm{ml} \text { zentrifugierte Probe }+250 \mu \mathrm{l} \text { Ameisensäure (mit } 4 \% \\
2 \text { Methylvaleriansäure) }+750 \mu \mathrm{l} \text { Metaphosphorsäure }\end{array}$ \\
\hline Integrator & Merk D-2000 (Fa. Merk, Darmstadt, D) \\
\hline
\end{tabular}

Tab. 6: Berechnungsgrundlage zur Herstellung eines SCFA Standardgemischs.

\begin{tabular}{|l|c|c|c|c|c|c|}
\hline \hline Säure & $\begin{array}{c}\mathbf{m m o l} / \\
\mathbf{2 5 0} \mathbf{~ m l} \\
\text { Standard }\end{array}$ & $\begin{array}{c}\boldsymbol{\mu m o l} / \mathbf{~ m l} \\
\text { Standard }\end{array}$ & $\mathbf{g} / \mathbf{~ m o l}$ & $\begin{array}{c}\text { Gehalt } \\
(\%)\end{array}$ & $\mathbf{g} / \mathbf{~ m l}$ & $\begin{array}{c}\boldsymbol{\mu l} / \\
\mathbf{2 5 0} \mathbf{~ m l} \\
\text { Standard }\end{array}$ \\
\hline \hline Essigsäure & 7,50 & 30,000 & 60,05 & 99,5 & 1,050 & 430 \\
Propionsäure & 5,00 & 20,000 & 74,08 & 99,0 & 0,990 & 378 \\
iso Buttersäure & 0,25 & 1,000 & 88,11 & 98,0 & 0,947 & 24 \\
n-Buttersäure & 2,50 & 10,000 & 88,11 & 99,0 & 0,958 & 232 \\
iso-Valeriansäure & 0,50 & 2,000 & 102,13 & 98,0 & 0,925 & 56 \\
n-Valeriansäure & 0,75 & 3,000 & 102,13 & 99,0 & 0,938 & 82 \\
2-Methylvaleriansäure & 3,89 & 15,557 & 116,16 & 98,0 & 0,922 & 500 \\
\hline \hline
\end{tabular}


Die tatsächliche Menge an Substanz (Subst.) in der Probe konnte dann mit den Daten aus den Analysen nach Gleichung 5 berechnet werden (KAISER 1965, MERK 1987).

$$
\text { Subst. inder Probe }=\frac{\text { Korrekturf aktor * AreaSubstanz }}{\text { Area ISTD }}
$$

Dabei steht Area für die Peakfläche, Substanz für die zu berechnende Probensubstanz (z.B. Essigsäure) und ISTD für den internen Standard (2- Methylvaleriansäure).

Die Zuverlässigkeit der Messung wurde anhand einer Überprüfung der Linearität (Abb. 6) und durch die Bestimmung der Variationskoeffizienten (Tab. 7) ermittelt. In Abbildung 6 wird eine Meßungenauigkeit bei Verdünnungsstufe 8/12 deutlich, die durch ein undichtes Septum erklärt werden konnte. Trotz dieses Meßfehlers war der Korrelationskoeffizient bei allen untersuchten Komponenten größer 0,997. Die Linearität der Messung wurde damit als hinreichend gut angenommen.

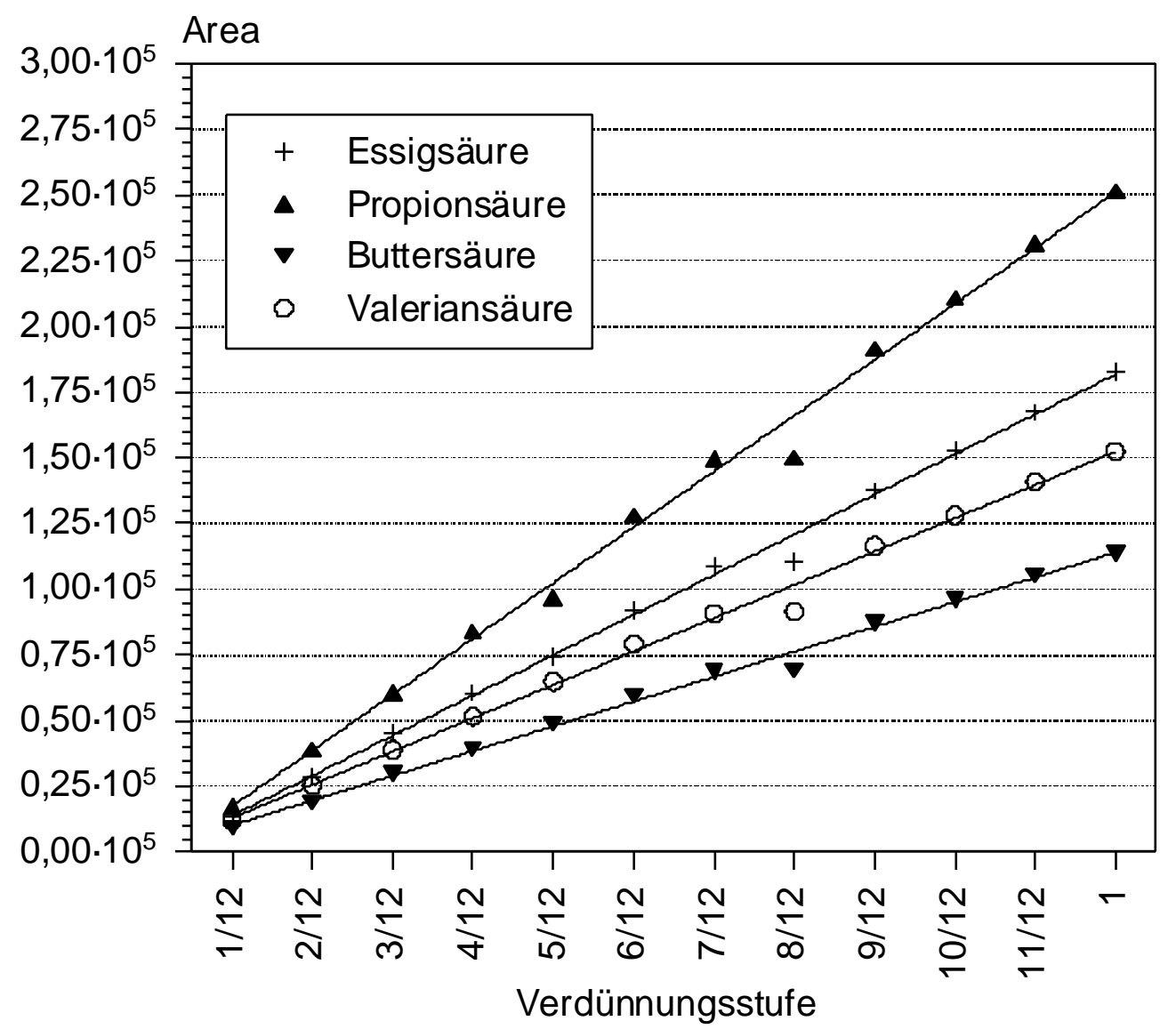

Abb. 6: Darstellung der Linearitätsüberprüfung nach GOTTWALD (1995) 
Tab. 7: Variationskoeffizienten wiederholter Messungen, bestimmt nach GOTTWALD (1995).

\begin{tabular}{|c|c|}
\hline \hline Säure & $\begin{array}{c}\text { Variationskoeffizienten } \\
\%\end{array}$ \\
\hline \hline Essigsäure & 1,3 \\
Propionsäure & 2,5 \\
Buttersäure & 4,9 \\
Valeriansäure & 3,15 \\
\hline \hline
\end{tabular}

\subsubsection{Berechnung der Wasserstoffwiederfindung}

In der vorliegenden Arbeit diente eine besonders niedrige Rate der in Prozent angegebenen Wasserstoffwiederfindung als indirekter Nachweis für die reduktive Acetogenese. Bei der Berechnung der Wasserstoffwiederfindung oder auch Wasserstoffbilanz (WOLIN 1960) geht man davon aus, daß die in den anaeroben Oxidationsprozessen freigesetzten Elektronen zusammen mit Wasserstoffprotonen übertragen werden. Dabei stellt ein Molekül $\mathrm{H}_{2}$ zwei mit je einem Elektron reduzierte Wasserstoffprotonen dar. Da durch den bei der Fermentation der Kohlenhydrate gebildeten Wasserstoff die Fermentation im Pansen gehemmt wird, muß der Wasserstoffpartialdruck durch die Bildung der reduzierten Endprodukte Methan, Propionsäure und Buttersäure niedrig gehalten werden. Stellt man die Menge des bei der Kohlenhydratfermentation freigesetzten Wasserstoffs der Menge des verbrauchten Wasserstoffs gegenüber, so erhält man die Rate der Wasserstoffwiederfindung (WOLIN 1960, DEMEYER und DE GRAEVE 1991):

Die molaren Mengen des aus einem Mol Glucose freigesetzten $\mathrm{H}_{2}$ können den folgenden Reaktionsgleichungen (6) entnommen werden:

Bei der Fermentation von einem Mol Glucose $\left(\mathrm{C}_{6} \mathrm{H}_{12} \mathrm{O}_{6}\right)$ zu 2 Mol Pyruvat $\left(\mathrm{CH}_{3} \mathrm{COCOOH}\right)$ werden $2 \mathrm{H}$ pro mol Pyruvat freigesetzt:

$$
\mathrm{C}_{6} \mathrm{H}_{12} \mathrm{O}_{6} \rightarrow 2 \mathrm{CH}_{3} \mathrm{COCOOH}+4 \mathrm{H}
$$

Beim weiteren Abbau von $1 \mathrm{Mol}$ Pyruvat zu $1 \mathrm{Mol}$ Essigsäure $\left(\mathrm{CH}_{3} \mathrm{COOH}\right)$ werden $2 \mathrm{H}$ Wasserstoff produziert. Im Ganzen sind damit $4 \mathrm{H}$ pro Mol Essigsäure freigesetzt worden:

$$
\mathrm{CH}_{3} \mathrm{COCOOH}+\mathrm{H}_{2} \mathrm{O} \rightarrow \mathrm{CH}_{3} \mathrm{COOH}+\mathrm{CO}_{2}+2 \mathrm{H}
$$


Durch die Umsetzung von $1 \mathrm{Mol}$ Pyruvat zu $1 \mathrm{Mol}$ Propionsäure $\left(\mathrm{CH}_{3} \mathrm{CH}_{2} \mathrm{COOH}\right)$ werden $2 \mathrm{H}$ verbraucht und $2 \mathrm{H}$ reduzieren ein Mol Sauerstoff zu Wasser. Durch den Abbau von $1 / 2 \mathrm{Mol}$ Glucose zu $1 \mathrm{Mol}$ Pyruvat waren vorher aber auch $2 \mathrm{H}$ entstanden:

$$
\mathrm{CH}_{3} \mathrm{COCOOH}+4 \mathrm{H} \rightarrow \mathrm{CH}_{3} \mathrm{CH}_{2} \mathrm{COOH}+\mathrm{H}_{2} \mathrm{O}
$$

$1 \mathrm{Mol}$ Buttersäure $\left(\mathrm{CH}_{3}\left(\mathrm{CH}_{2}\right)_{2} \mathrm{COOH}\right)$ werden aus $2 \mathrm{Mol}$ Essigsäure gebildet. Dabei werden $1 \mathrm{Mol}$ Sauerstoff mit $2 \mathrm{H}$ zu Wasser reduziert. Bei der vorhergehenden Essigsäureentstehung wurden jedoch pro Mol Buttersäure $8 \mathrm{H}$ freigesetzt.

$$
2 \mathrm{CH}_{3} \mathrm{COOH}+4 \mathrm{H} \rightarrow \mathrm{CH}_{3}\left(\mathrm{CH}_{2}\right)_{2} \mathrm{COOH}+\mathrm{H}_{2} \mathrm{O}
$$

Bei der Entstehung von Methan $\left(\mathrm{CH}_{4}\right)$ werden $4 \mathrm{H}$ im Methan und 4 weitere Wasserstoffatome in Form von Wasser gebunden:

$$
\mathrm{CO}_{2}+8 \mathrm{H} \rightarrow \mathrm{CH}_{4}+2 \mathrm{H}_{2} \mathrm{O}
$$

Wenn die molaren Mengen der entstandenen Fermentationsprodukte Essigsäure $(E)$, Propionsäure $(\mathrm{P})$, Buttersäure $(\mathrm{B})$ und Methan $(\mathrm{M})$ vorliegen, können damit die unter normalen Bedingungen entstandenen bzw. verbrauchten Wasserstoffmengen bestimmt werden.

Der freigesetze Wasserstoff $\left(H_{p}=H_{\text {produced }}\right)$ kann dabei nach Gleichung 7,

$$
H_{p}=2{ }^{*} E+P+4{ }^{*} B
$$

der verbrauchte Wasserstoff $\left(\mathrm{H}_{\mathrm{u}}=\mathrm{H}_{\mathrm{used}}\right)$ nach Gleichung 8

$$
H_{u}=2 * P+2 * B+4 * M
$$

berechnet werden.

Aus dem Quotienten (Gleichung 9)

$$
\frac{\mathrm{Hu}{ }^{*} 100}{\mathrm{Hp}}=\text { Wasserstof fwiederfindung } \%
$$

wird dann die Wasserstoffwiederfindung in Prozent bestimmt. Werte im Bereich von $80-98 \%$ sind dabei als normal anzusehen. Wasserstoffwiederfindungsraten von weniger als $80 \%$ geben dagegen einen Hinweis auf alternative Wasserstoffsenken. 
Mit Hilfe der ${ }^{13} \mathrm{C}-\mathrm{NMR}$ (Nuclear Mass Resonance) Spektroskopie kann die ${ }^{13} \mathrm{C}-\mathrm{CO}_{2}$-Anreicherung einzelner Substanzen in einer Probe gemessen werden. Darüber hinaus ist es möglich, die Position des markierten Kohlenstoffs in den einzelnen Molekülen zu bestimmen. Vor allem diese Möglichkeit war für die Anwendung der ${ }^{13} \mathrm{C}-\mathrm{NMR}$ Spektroskopie in der vorliegenden Arbeit ausschlaggebend.

Um mit Hilfe der NMR Spektroskopie die ${ }^{13} \mathrm{C}-\mathrm{CO}_{2}$-Anreicherung zu messen, ist eine Konzentration von mindestens $10 \mu \mathrm{g}{ }^{13} \mathrm{C}$ in der Probe notwendig. Da diese Menge in den unbehandelten batch-culture-Proben nicht erreicht wurden, mußten die Proben aufkonzentriert werden. Dazu wurde die Flüssigkeit der Inkubationsgefäße zunächst mit $5 \mathrm{~N} \mathrm{NaOH}$ auf einen pH-Wert von ca. 9,5 gebracht, um die Fettsäuren in Salze zu überführen. Die stark alkalische Flüssigkeit wurde 10 Minuten bei $5500 \mathrm{~g}$ zentrifugiert, bevor der Überstand im Rotationsverdampfer (Typ SB, Fa. Büchi, Flawi, Schweiz) eingeengt wurde.

Von den so behandelten Proben wurden $390 \mu \mathrm{l}$ in NMR-Röhrchen überführt und mit $\mathrm{D}_{2} \mathrm{O}$ auf $500 \mu \mathrm{l}$ aufgefüllt. Als interner Standard wurden $50 \mu \mathrm{l}$ Dioxan zugegeben. Die ${ }^{13} \mathrm{C}$-NMR Spektren wurden im Institut für Organische Chemie der Georg-August-Universität Göttingen an einem Spektrometer (Varian I500, $125,7 \mathrm{MHz}$ ) bei einer Temperatur von $30^{\circ} \mathrm{C}$ und einer Meßdauer von 9 Stunden analysiert. Die chemische Verschiebung wird in $\sigma$-Werten relativ zu Tetramethylsilan angeben (HESSE ET AL. 1987).

\subsection{Statistische Auswertung}

Das Datenmaterial aus dem balancierten vierfaktoriellen batch-culture-Versuch wurde zunächst mit Hilfe des Statistikprogramms STATISTICA (Version 5.1, Fa. StatSoft Tulsa, OK, USA/Hamburg) auf Normalverteilung und Varianzhomogenität überprüft. Dabei zeigte sich, daß die Ursprungsdaten weder normalverteilt waren, noch die Bedingungen der Varianzhomogenität erfüllten. Um diese beiden Grundvoraussetzungen für eine Varianzanalyse zu schaffen, wurde in STATISTICA mit einer Box-Cox-Transformations-Prozedur die Quadratwurzel als geeignete Transformation für das vorliegende Datenmaterial ermittelt (NETER ET AL. 1996). Die transformierten Daten erfüllten bei erneuter Prüfung auf Normalverteilung und Varianzhomogenität die erforderlichen Bedingungen. Im Anschluß an die statistischen Berechnungen wurden die ermittelten Mittelwerte durch Quadrieren wieder zurücktransformiert. Diese Vorgehensweise führte dazu, daß die in der Arbeit angegebenen Mittelwerte nicht dem arithmetischen Mittel der Originaldaten entsprechen (Anhang 15 und 16). 
Da sich der Versuchstag signifikant auf die untersuchten Parameter auswirkte, wurde dieser als zufälliger Effekt in das Varianzmodell aufgenommen. Es ergab sich somit ein gemischtes Varianzmodell mit den festen Effekten aus Ration (RAT), Nüchterungsdauer (NUE) und in-vitro-Substrat (SUB) sowie dem zufälligen Effekt Versuchstag (TAG). Dieses Modell galt sowohl für die Versuchsreihe mit Protozoen als auch für die ohne Protozoen. Die Modellschätzungen wurden mit der Prozedur MIXED des SAS Systems (Version 6.12) durchgeführt. Nach LITTELL ET AL. (1996) ist diese Prozedur bei gemischten Modellen der Prozedur PROC GLM vorzuziehen.

Die Signifikanz einzelner Effekte wurde mit einer Irrtumswahrscheinlichkeit von $p<0,5 \%$ überprüft. Zur Einhaltung der tatsächlichen Irrtumswahrscheinlichkeit auf dem vorbestimmten Niveau wurden Multiple Mittelwertsvergleiche auf der Grundlage des Tukey-Kramer-Verfahrens durchgeführt.

Ergebnisse, die in Experimenten mit ${ }^{13} \mathrm{C}-\mathrm{CO}_{2}$-Marker ermittelt wurden, konnten aufgrund des geringen Stichprobenumfangs nicht auf Normalverteilung untersucht werden. Die Auswertung der Versuche erfolgte nach dem folgenden allgemeinen Varianzmodell (Gleichung 10):

$Y_{\mathrm{ijl}}=\mu+\mathrm{FAKTOR} 1_{\mathrm{i}}+e_{\mathrm{ij}}$

wobei

$\begin{array}{ll}Y_{\mathrm{ijl}} & =\text { Beobachtungswert des Merkmals } \\ \mu & =\text { Gesamtmittel } \\ \text { FAKTOR } 1_{\mathrm{i}} & =\text { Effekt von Faktor } 1 \\ \mathrm{e}_{\mathrm{ij}} & =\text { Restvarianz } \\ \mathrm{ij} & =\text { Indizes für die jeweiligen Faktorstufen }\end{array}$

Die Bezeichnung Faktor 1 steht hier als Variable für unterschiedliche Faktoren in den einzelnen Versuchen. Die Auswertung dieser einfaktoriellen Versuche wurde mit dem Statistikprogramm Statview (Statview Vers. 4.55, Abacus Concepts, Berkeley, Canada) vorgenommen. Dabei wurde zunächst im Rahmen der Varianzanalyse (ANOVA) zur Prüfung der Nullhypothese $\left(H_{0}\right)$ ein F-Test durchgeführt. Das Kriterium für die Ablehnung von $H_{0}$ war $p<0,05$. Bei abgelehnter $H_{0}$ wurde mit dem Grenzdifferenzen-Test nach Fischer (Fischers PLSD) geprüft, ob die Mittelwertsunterschiede zwischen den Faktorstufen signifikant waren. Die Grenze für die Signifikanz wurde dabei auf $p<0,05$ festgelegt. 
Haupt- sowie Wechselwirkungen der Faktoren Ration, Nüchterungsdauer und in-vitro-Substrat auf die Parameter SCFA, Methan, Wasserstoffwiederfindungsrate und Methan / SCFA-Verhältnis sind in Übersicht 5 dargestellt. In den nachfolgenden Abschnitten werden diese Effekte anhand der Versuchsergebnisse vorgestellt. Auf die Darstellung der Dreifachwechselwirkungen wurde hier verzichtet, da diese keine entscheidenden Informationen für die in der vorliegenden Arbeit zu beantwortenden Fragen lieferten. Die nach den Faktoren Ration, Nüchterungsdauer und in-vitroSubstrat aufgegliederten Versuchsergebnisse können dem Anhang entnommen werden.

Übersicht 5: Überblick über Haupt- und Wechselwirkungen der unabhängigen Faktoren auf die erhobenen Parameter bei nicht defauniertem Pansensaft, F-Test, ${ }^{*}(p<0,05),{ }^{* *}(p<0,01)$, n.s. $=$ nicht signifikant.

\begin{tabular}{|c|c|c|c|c|c|c|c|c|}
\hline \hline & $\mathrm{n}$ & SCFA & Acetat & Propionat & Butyrat & $\mathrm{CH}_{4}$ & $\mathrm{H}_{\mathrm{u}} / \mathrm{H}_{\mathrm{p}}$ & $\mathrm{CH}_{4} / \mathrm{SCFA}$ \\
\hline \hline $\begin{array}{c}\text { Ration } \\
\text { (RAT) }\end{array}$ & 54 & $* *$ & $* *$ & $* *$ & $* *$ & $* *$ & $* *$ & $* *$ \\
\hline $\begin{array}{c}\text { Nüchterungsdauer } \\
\text { (NUE) }\end{array}$ & 54 & $* *$ & $* *$ & $* *$ & n.s. & $* *$ & $* *$ & $* *$ \\
\hline $\begin{array}{c}\text { in-vitro-Substrat } \\
\text { (SUB) }\end{array}$ & 54 & $* *$ & $* *$ & $* *$ & $* *$ & $* *$ & $* *$ & $* *$ \\
\hline RAT * NUE & 27 & $* *$ & $* *$ & $* *$ & $* *$ & $* *$ & $* *$ & $* *$ \\
\hline RAT * SUB & 27 & $*$ & n.s. & $* *$ & n.s. & $* *$ & $* *$ & $* *$ \\
\hline NUE $*$ SUB & 27 & n.s. & n.s. & n.s. & n.s. & $*$ & n.s. & n.s. \\
\hline \hline
\end{tabular}

\subsubsection{Einfluß der Ration des Spendertieres}

Die Fütterung des Spendertieres hatte auf alle gemessenen Parameter einen signifikanten Einfluß. Abbildung 7 zeigt Ergebnisse der batch-culture-Ansätze mit Pansensaft des mit Heu-Kraftfutter- bzw. Stroh-Harnstoff gefütterten Spendertieres, gemittelt über die Faktoren Nüchterungsdauer und Substrat. Die Stroh-HarnstoffRation führte im Vergleich zur Heu-Kraftfutter-Ration zu einer deutlichen Senkung der SCFA- sowie der Methanproduktion. Die Methanmenge verringerte sich dabei stärker als die SCFA-Summe. Dies zeigte sich auch in dem von 0,16 auf 0,13 signifikant verringerten Methan/ SCFA-Verhältnis (Anhang 1). 


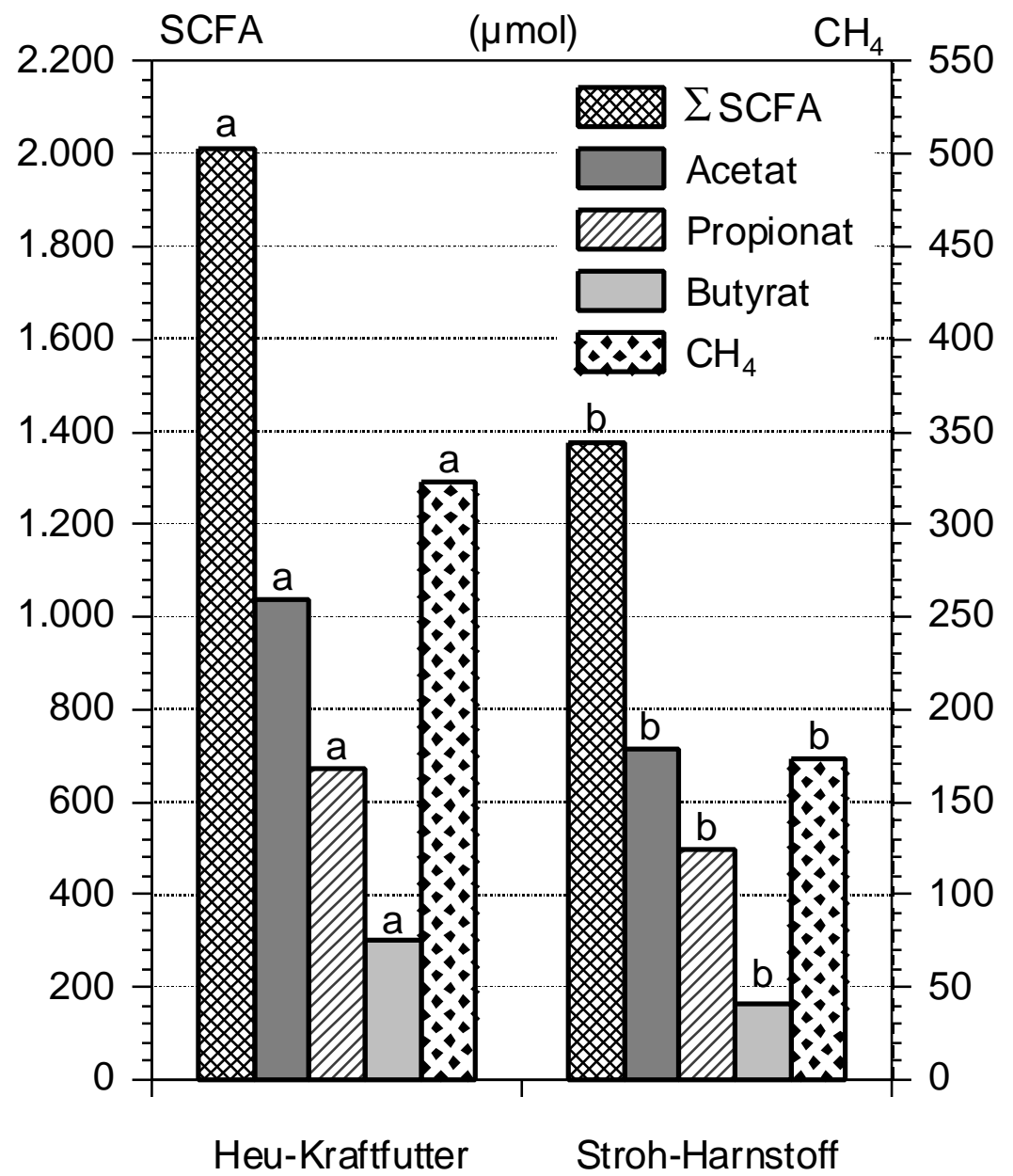

Abb. 7: $\quad$ Einfluß der Ration des Spendertieres auf die Bildung von SCFA und Methan in der batch-culture $(n=54)$. Unterschiedliche Buchstaben an Säulen mit gleichem Muster kennzeichnen signifikante Unterschiede zwischen den Mittelwerten, Tukey-Kramer mit $\mathrm{p}<0,05$.

\subsubsection{Einfluß der Nüchterungsdauer des Spendertieres}

Eine um 8 Stunden verlängerte Nüchterungsdauer des Spendertieres vor der Pansensaftentnahme führte, mit Ausnahme des Butyrats, zu einer signifikanten Verringerung der SCFA- sowie der Methanmengen (Abb. 8). Dabei verschob sich das Methan/ SCFA-Verhältnis signifikant von 0,15 auf 0,13 . Demzufolge hatte die Nüchterungsdauer einen geringeren Einfluß auf die Fermentation als die Ration des Spendertieres (Anhang 1). 


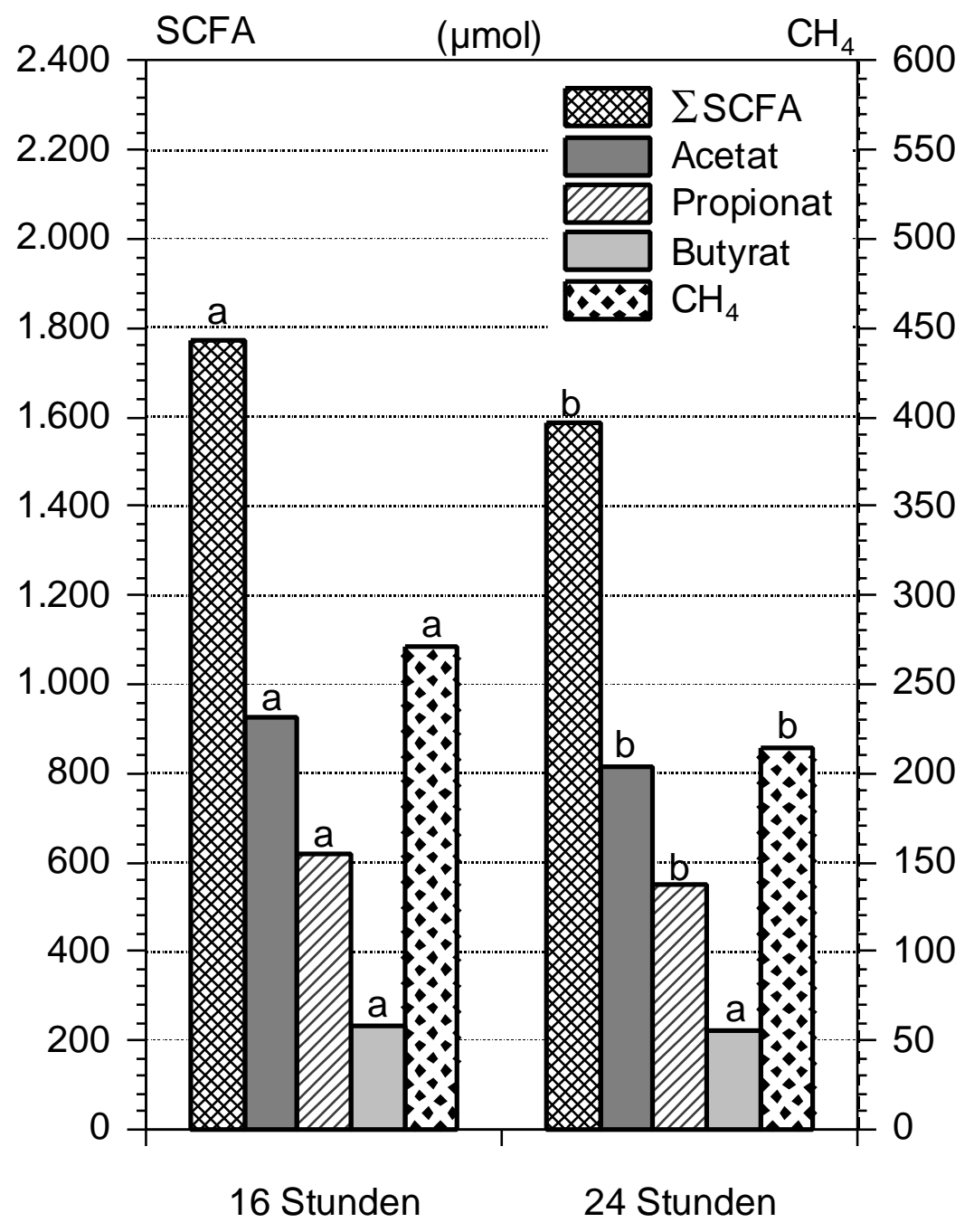

Abb. 8: $\quad$ Einfluß der Nüchterungsdauer des Spendertieres vor der Pansensaftentnahme auf die Bildung von SCFA und Methan in der batch-culture $(n=54)$. Unterschiedliche Buchstaben an Säulen mit gleichem Muster kennzeichnen signifikante Unterschiede zwischen den Mittelwerten, Tukey-Kramer mit $p<0,05$.

\subsubsection{Einfluß des in-vitro-Substrates}

In Abbildung 9 sind die Mengen der einzelnen Fermentationsprodukte in Abhängigkeit der eingesetzten in-vitro-Substrate, gemittelt über Fraktion und Nüchterungsdauer, dargestellt. Es zeigte sich, mit Ausnahme des Butyrats, ein deutlich signifikanter Abfall der entstandenen Fermentationsprodukte von Heu über Stroh zu Blinddarminhalt. Besonders bemerkenswert war das signifikant niedrigere Methan / SCFA-Verhältnis bei der Verwendung des in-vitro-Substrates Blinddarminhalt mit einem Wert von 0,09 (Anhang 1). 


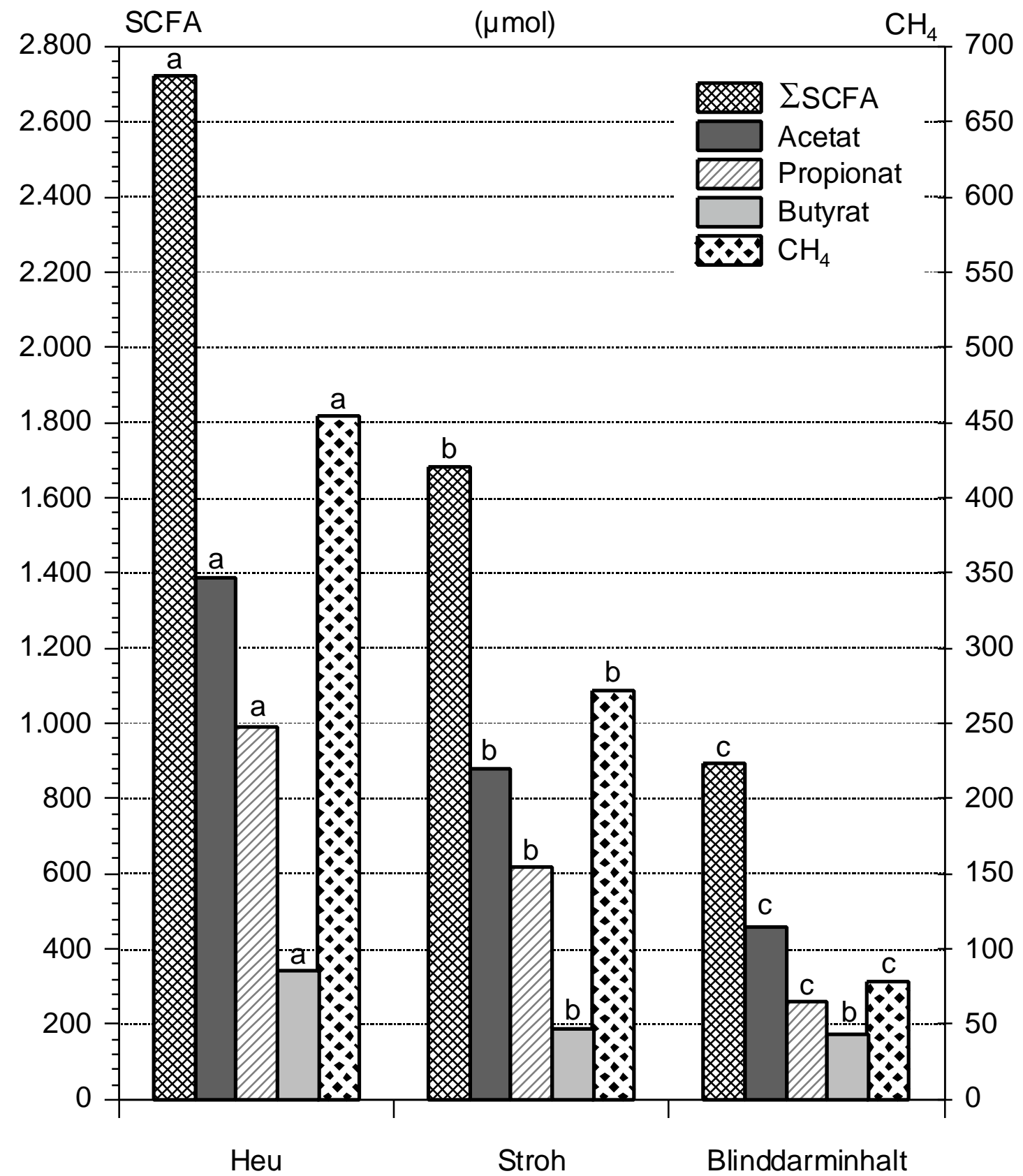

Abb. 9: $\quad$ Einfluß des in-vitro-Substrates auf die Bildung von SCFA und Methan in der batch-culture $(n=54)$. Unterschiedliche Buchstaben an Säulen mit gleichem Muster kennzeichnen signifikante Unterschiede zwischen den Mittelwerten, Tukey-Kramer mit $p<0,05$.

4.1.4 Einfluß der Wechselwirkungen zwischen den Faktoren Ration, Nüchterungsdauer und in-vitro-Substrat

Tabelle 8 zeigt den Einfluß von Ration und Nüchterungsdauer des Spendertieres auf die Fermentationsparameter. Bei der Heu-Kraftfutter-Ration führte die Verlängerung der Nüchterungsdauer vor der Pansensaftentnahme zu keiner Veränderung der SCFA-Produktion. Die Methanmenge stieg bei einer Nüchterungsdauer von 
24 Stunden signifikant von 306 auf $340 \mu \mathrm{mol}$ an. Die Stroh-Harnstoff-Ration bewirkte gegenüber der kraftfutterreichen Ration dagegen eine signifikante Senkung aller gemessenen Parameter. Dabei stieg der Anteil des Propionats an der SCFA-Summe leicht an (von 34 auf $37 \%$ ), während der Butyratanteil geringfügig sank (von 15 auf $12 \%)$.

Bei der Stroh-Harnstoff-Ration führte die Verlängerung der Nüchterungsdauer vor der Pansensaftentnahme zu einer signifikanten Senkung der SCFA-Summe. Die Methanmenge sank um mehr als die Hälfte, von 238 auf $117 \mu \mathrm{mol} / \mathrm{Tag}$, so daß sich das Methan/ SCFA-Verhältnis von 0,15 auf 0,10 verringerte. Bei der Stroh-HarnstoffRation hatte somit die verlängerte Nüchterungsdauer eine stärker senkende Wirkung auf die Methanproduktion als auf die SCFA-Summe. Dieser Effekt konnte bei der Heu-Kraftfutter-Ration nicht nachgewiesen werden.

Tab. 8: $\quad$ Einfluß von Ration und Nüchterungsdauer auf die Bildung von SCFA und Methan in der batch-culture $(n=27)$. Unterschiedliche Buchstaben in gleichen Spalten bezeichnen signifikante Unterschiede zwischen den Mittelwerten, Tukey-Kramer mit $p<0,05$.

\begin{tabular}{|c|c|c|c|c|c|c|c|c|c|c|}
\hline \multicolumn{11}{|c|}{ Pansensaft nicht defauniert } \\
\hline \multirow{2}{*}{ Ration } & \multirow{2}{*}{$\begin{array}{l}\text { Nüchterungs- } \\
\text { dauer }\end{array}$} & \multirow{2}{*}{$\begin{array}{c}\text { SCFA } \\
\mu \mathrm{mol}\end{array}$} & \multicolumn{2}{|c|}{ Acetat } & \multicolumn{2}{|c|}{ Propionat } & \multicolumn{2}{|c|}{ Butyrat } & \multirow{2}{*}{$\begin{array}{r}\mathrm{CH}_{4} \\
\mu \mathrm{mol}\end{array}$} & \multirow[t]{2}{*}{$\mathrm{CH}_{4} / \mathrm{SCFA}$} \\
\hline & & & $\mu \mathrm{mol}$ & $\%$ & $\mu \mathrm{mol}$ & $\%$ & $\mu \mathrm{mol}$ & $\%$ & & \\
\hline \multirow{2}{*}{$\begin{array}{l}\text { Heu- } \\
\text { Kraftfutter }\end{array}$} & 16 Stunden & $1964^{\mathrm{a}}$ & $1022^{a}$ & 52 & $664^{\mathrm{a}}$ & 34 & $277^{\mathrm{a}}$ & 14 & $306^{b}$ & $0,16^{a}$ \\
\hline & 24 Stunden & $2065^{\mathrm{a}}$ & $1051^{\mathrm{a}}$ & 51 & $683^{\mathrm{a}}$ & 33 & $325^{\mathrm{a}}$ & 16 & $340^{\mathrm{a}}$ & $0,17^{\mathrm{a}}$ \\
\hline \multirow{2}{*}{$\begin{array}{l}\text { Stroh- } \\
\text { Harnstoff }\end{array}$} & 16 Stunden & $1609^{b}$ & $831^{b}$ & 52 & $571^{\mathrm{b}}$ & 36 & $194^{b}$ & 12 & $238^{c}$ & $0,15^{\mathrm{a}}$ \\
\hline & 24 Stunden & $1190^{\circ}$ & $605^{\mathrm{c}}$ & 51 & $432^{c}$ & 37 & $140^{\mathrm{c}}$ & 12 & $117^{d}$ & $0,10^{\mathrm{b}}$ \\
\hline
\end{tabular}

Der Einfluß des in-vitro-Substrates bei der Heu-Kraftfutter- sowie der Stroh-HarnstoffRation ist in Tabelle 9 aufgezeigt. Bei beiden Rationen gingen die Mengen an Fermentationsprodukten aus den in-vitro-Substraten von Heu über Stroh zu Blinddarminhalt deutlich zurück. Die prozentualen Anteile der einzelnen Fettsäuren an der SCFA-Summe zeigen, daß beim in-vitro-Substrat Blinddarminhalt der Propionatanteil geringer und der Butyratanteil höher war (Anhang 1). Durch die Umstellung auf die Stroh-Harnstoff-Ration wurde das Methan/SCFA-Verhältnis bei den in-vitroSubstraten Heu und Blinddarminhalt signifikant niedriger. Die in-vitro-Substrate Heu und Stroh hatten jedoch keinen Einfluß auf diesen Parameter. 
Tab. 9: $\quad$ Einfluß von Ration und in-vitro-Substrat auf die Bildung von SCFA und Methan in der batch-culture $(n=27)$. Unterschiedliche Buchstaben in gleichen Spalten kennzeichnen signifikante Unterschiede zwischen den Mittelwerten, Tukey-Kramer mit $\mathrm{p}<0,05$.

\begin{tabular}{|c|c|c|c|c|c|c|c|c|c|c|}
\hline \multicolumn{11}{|c|}{ Pansensaft nicht defauniert } \\
\hline \multirow{2}{*}{ Ration } & \multirow{2}{*}{$\begin{array}{l}\text { in-vitro- } \\
\text { Substrat }\end{array}$} & \multirow{2}{*}{$\begin{array}{l}\text { SCFA } \\
\mu \mathrm{mol}\end{array}$} & \multicolumn{2}{|c|}{ Acetat } & \multicolumn{2}{|c|}{ Propionat } & \multicolumn{2}{|c|}{ Butyrat } & \multirow{2}{*}{$\begin{array}{c}\mathrm{CH}_{4} \\
\mu \mathrm{mol}\end{array}$} & \multirow[t]{2}{*}{$\mathrm{CH}_{4} / \mathrm{SCFA}$} \\
\hline & & & $\mu \mathrm{mol}$ & $\%$ & $\mu \mathrm{mol}$ & $\%$ & $\mu \mathrm{mol}$ & $\%$ & & \\
\hline \multirow{3}{*}{$\begin{array}{l}\text { Heu- } \\
\text { Kraftfutter }\end{array}$} & Heu & $3062^{\mathrm{a}}$ & $1601^{a}$ & 52 & $1017^{\mathrm{a}}$ & 33 & $444^{\mathrm{a}}$ & 14 & $592^{\mathrm{a}}$ & $0,19^{a}$ \\
\hline & Stroh & $1982^{c}$ & $1029^{c}$ & 51 & $709^{b}$ & 36 & $244^{b}$ & 12 & $327^{b}$ & $0,16^{\mathrm{ab}}$ \\
\hline & $\begin{array}{l}\text { Blinddarm- } \\
\text { inhalt }\end{array}$ & $1208^{e}$ & $599^{e}$ & 50 & $374^{d}$ & 31 & $235^{b}$ & 19 & $132^{d}$ & $0,11^{\mathrm{c}}$ \\
\hline \multirow{3}{*}{$\begin{array}{l}\text { Stroh- } \\
\text { Harnstoff }\end{array}$} & Heu & $2412^{b}$ & $1189^{b}$ & 49 & $969^{\mathrm{a}}$ & 40 & $254^{\mathrm{b}}$ & 11 & $335^{\mathrm{b}}$ & $0,14^{\mathrm{b}}$ \\
\hline & Stroh & $1411^{d}$ & $744^{d}$ & 53 & $530^{c}$ & 38 & $137^{c}$ & 10 & $222^{c}$ & $0,16^{\mathrm{ab}}$ \\
\hline & $\begin{array}{l}\text { Blinddarm- } \\
\text { inhalt }\end{array}$ & $625^{\dagger}$ & $338^{f}$ & 54 & $165^{\mathrm{e}}$ & 26 & $121^{\mathrm{c}}$ & 19 & $39^{\mathrm{e}}$ & $0,06^{d}$ \\
\hline
\end{tabular}

Tab. 10: $\quad$ Einfluß von Nüchterungsdauer und in-vitro-Substrat auf die Bildung von SCFA und Methan in der batch-culture $(n=27)$. Unterschiedliche Buchstaben in gleichen Spalten kennzeichnen signifikante Unterschiede zwischen den Mittelwerten, Tukey-Kramer mit $p<0,05$.

\begin{tabular}{|c|c|c|c|c|c|c|c|c|c|c|}
\hline \multirow{3}{*}{$\begin{array}{l}\text { Nüchterungs- } \\
\text { dauer }\end{array}$} & \multicolumn{9}{|c|}{ Pansensaft nicht defauniert } & \multirow{3}{*}{$\mathrm{CH}_{4} / \mathrm{SCFA}$} \\
\hline & \multirow{2}{*}{$\begin{array}{l}\text { in-vitro- } \\
\text { Substrat }\end{array}$} & \multirow{2}{*}{$\begin{array}{l}\text { SCFA } \\
\mu \mathrm{mol}\end{array}$} & \multicolumn{2}{|c|}{ Acetat } & \multicolumn{2}{|c|}{ Propionat } & \multicolumn{2}{|c|}{ Butyrat } & \multirow{2}{*}{$\begin{array}{l}\mathbf{C H}_{4} \\
\mu \mathrm{mol}\end{array}$} & \\
\hline & & & $\mu \mathrm{mol}$ & $\%$ & $\mu \mathrm{mol}$ & $\%$ & $\mu \mathrm{mol}$ & $\%$ & & \\
\hline \multirow{3}{*}{16 Stunden } & Heu & $2816^{a}$ & $1468^{\mathrm{a}}$ & 52 & $1015^{\mathrm{a}}$ & 36 & $333^{a}$ & 12 & $506^{a}$ & $0,18^{\mathrm{a}}$ \\
\hline & Stroh & $1808^{b}$ & $936^{c}$ & 52 & $665^{\mathrm{b}}$ & 37 & $207^{b}$ & 11 & $304^{c}$ & $0,17^{\mathrm{a}}$ \\
\hline & $\begin{array}{l}\text { Blinddarm- } \\
\text { inhalt }\end{array}$ & $955^{d}$ & $496^{\mathrm{e}}$ & 52 & $284^{\mathrm{c}}$ & 30 & $175^{b}$ & 18 & $90^{\mathrm{e}}$ & $0,09^{c}$ \\
\hline \multirow{3}{*}{24 Stunden } & Heu & $2631^{a}$ & $1308^{b}$ & 50 & $971^{\mathrm{a}}$ & 37 & $352^{a}$ & 13 & $405^{b}$ & $0,15^{\mathrm{a}}$ \\
\hline & Stroh & $1554^{c}$ & $828^{d}$ & 53 & $559^{b}$ & 36 & $167^{\mathrm{b}}$ & 11 & $241^{d}$ & $0,15^{\mathrm{a}}$ \\
\hline & $\begin{array}{l}\text { Blinddarm- } \\
\text { inhalt }\end{array}$ & $831^{d}$ & $423^{f}$ & 51 & $236^{c}$ & 28 & $172^{b}$ & 21 & $68^{f}$ & $0,08^{d}$ \\
\hline
\end{tabular}


Die Wechselwirkungen zwischen Nüchterungsdauer und Substrat gehen aus Tabelle 10 hervor. Es konnten für das in-vitro-Substrat Heu bei der SCFA-Summe sowie bei den Propionat- und Butyratmengen keine signifikanten Unterschiede festgestellt werden. Die prozentualen Anteile der einzelnen SCFA wurden durch die Nüchterungsdauer ebenfalls kaum beeinflußt. Das Methan/ SCFA-Verhältnis wurde nur durch das in-vitro-Substrat Blinddarminhalt signifikant erniedrigt. Die verlängerte Nüchterungsdauer senkte das Verhältnis beim in-vitro-Substrat Blinddarminhalt auf 0,08 . Signifikante Wechselwirkung zwischen den Faktoren Nüchterungsdauer und invitro-Substrat wurden nur für den Parameter Methan nachgewiesen (Übersicht 5).

\section{2 batch-culture-Untersuchungen mit defauniertem Pansensaft}

Haupt- sowie Wechselwirkungen der Faktoren Ration, Nüchterungsdauer und in-vitro-Substrat auf die Parameter SCFA, Methan, Wasserstoffwiederfindungsrate und Methan / SCFA-Verhältnis sind in Übersicht 6 dargestellt. In den nachfolgenden Abschnitten werden diese Effekte anhand der Versuchsergebnisse vorgestellt. Auf die Darstellung der Dreifachwechselwirkungen wurde hier verzichtet, da diese keine entscheidenden Informationen für die in der vorliegenden Arbeit zu beantwortenden Fragen lieferten. Die nach den Faktoren Ration, Nüchterungsdauer und in-vitroSubstrat aufgegliederten Versuchsergebnisse können dem Anhang entnommen werden.

Übersicht 6: Überblick über die Haupt- und Wechselwirkungen der unabhängigen Faktoren auf die erhobenen Parameter bei defauniertem Pansensaft, F-Test, ${ }^{*}(p<0,05)$, ${ }^{* *}(p<0,01)$, n.s. $=$ nicht signifikant, n. n. = nicht nachweisbar.

\begin{tabular}{|c|c|c|c|c|c|c|c|c|}
\hline \hline & $\mathbf{n}$ & SCFA & Acetat & Propionat & Butyrat & $\mathrm{CH}_{4}$ & $\mathrm{H}_{\mathrm{u}} / \mathrm{H}_{\mathrm{p}}$ & $\mathrm{CH}_{4} / \mathbf{S C F A}$ \\
\hline \hline $\begin{array}{c}\text { Ration } \\
\text { (RAT) }\end{array}$ & 54 & $* *$ & n.s. & $* *$ & $* *$ & n.n. & $* *$ & - \\
\hline $\begin{array}{c}\text { Nüchterungsdauer } \\
\text { (NUE) }\end{array}$ & 54 & $* *$ & $* *$ & $* *$ & n.s. & n.n. & $* *$ & - \\
\hline $\begin{array}{c}\text { In-vitro-Substrat } \\
\text { (SUB) }\end{array}$ & 54 & $* *$ & $* *$ & $* *$ & $* *$ & n.n. & $* *$ & - \\
\hline RAT *NUE & 27 & $* *$ & $* *$ & $* *$ & n.s & n.n. & n.s. & - \\
\hline RAT .SUB & 27 & $* *$ & $* *$ & $* *$ & $*$ & n.n. & n.s. & - \\
\hline NUE.SUB & 27 & n.s. & n.s. & n.s. & $* *$ & n.n. & n.s. & - \\
\hline \hline
\end{tabular}

Die Defaunierung führte zu einer insgesamt sehr viel geringeren SCFA-Produktion. Dabei verschob sich das Acetat / Propionat-Verhältnis zugunsten des Propionats. Bei keiner der Inkubationen konnte Methan nachgewiesen werden. Daher wurde in den folgenden Abbildungen und Tabellen auf die Darstellung des Methans verzichtet. 


\subsubsection{Einfluß der Ration des Spendertieres}

Die Fütterungsumstellung des Spendertieres von der Heu-Kraftfutter- auf die StrohHarnstoff-Ration führte zu einem signifikanten Rückgang der SCFA-Summe. Dabei blieb die Menge des Acetats nahezu gleich, während die Propionat- und Butyratmengen signifikant um 116 bzw. 18 umol sanken (Anhang 2). Das Verhältnis Acetat zu Propionat wurde durch die Rationsumstellung niedriger (Abb. 10).
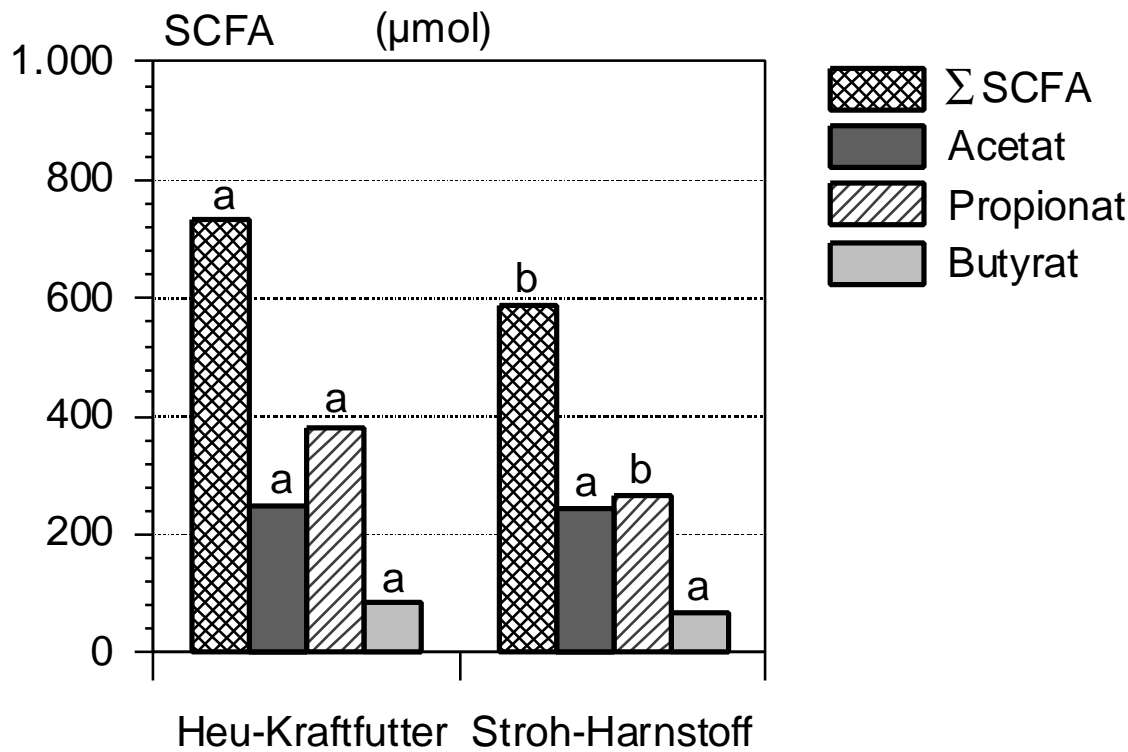

Abb. 10: $\quad$ Einfluß der Ration des Spendertieres auf die Bildung von SCFA in der batchculture unter Verwendung von defauniertem Pansensaft. $(n=54)$. Unterschiedliche Buchstaben an Säulen mit gleichem Muster kennzeichnen signifikante Unterschiede zwischen den Mittelwerten, Tukey-Kramer mit $p<0,05$.

\subsubsection{Einfluß der Nüchterungsdauer des Spendertieres}

Abbildung 11 gibt die Änderung der SCFA-Produktion bei unterschiedlicher Nüchterungsdauer des Spendertieres wieder. Die geringere SCFA-Summe bei einer Nüchterungsdauer von 24 Stunden ist auf die signifikante Reduzierung der Propionatmenge zurückzuführen. Die Veränderungen der Acetat- und Butyratmengen waren dagegen nicht signifikant. Sowohl die SCFA-Summe als auch deren Muster ist denen des Faktors Ration auf den beiden Faktorstufen der Nüchterungsdauer sehr ähnlich. 


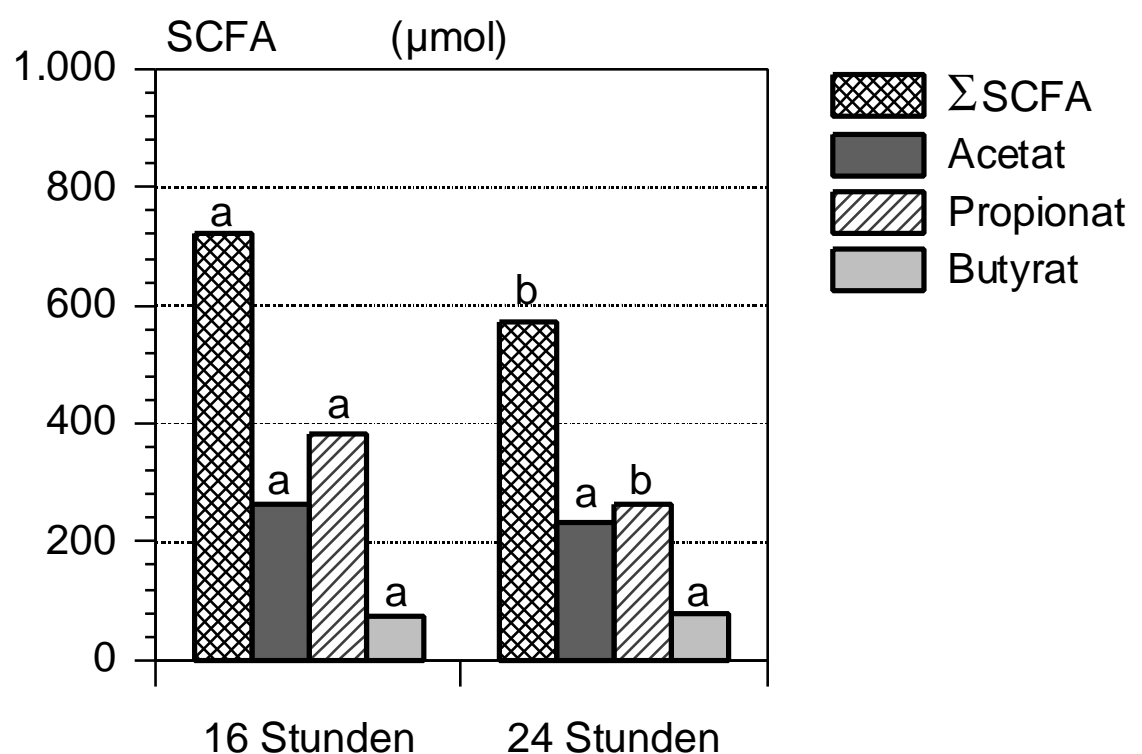

Abb.11: Einfluß der Nüchterungsdauer des Spendertieres auf die Bildung von
SCFA in der batch-culture unter Verwendung von defauniertem
Pansensaft $(n=54)$. Unterschiedliche Buchstaben an Säulen mit gleichem Muster
kennzeichnen signifikante Unterschiede zwischen den Mittelwerten, Tukey-Kramer mit
$p<0,05$.

\subsubsection{Einfluß des in vitro-Substrates}

Alle drei in-vitro-Substrate hatten einen deutlichen Einfluß auf das Fettsäuremuster in der batch-culture (Abb. 12). Die SCFA-Summe war beim in-vitro-Substrat $\mathrm{Heu}$ am höchsten, fiel zum Blinddarminhalt auf die Hälfte ab und erreichte beim Stroh das niedrigste Niveau. Das Fettsäuremuster war bei den in-vitro-Substraten Heu und Stroh durch deutlich höhere Propionat- als Acetatmengen gekennzeichnet.

Beim Blinddarminhalt lag der Propionatanteil im Vergleich zum Acetatanteil um ein Drittel niedriger. Bezüglich des Butyratanteiles waren die Unterschiede zwischen den in-vitro-Substraten $\mathrm{Heu}$ und Blinddarminhalt statistisch nicht abzusichern. Demgegenüber wurde beim in-vitro-Substrat Stroh nur etwa ein Drittel der bei den anderen beiden in-vitro-Substraten gebildeten Butyratmengen synthetisiert. 


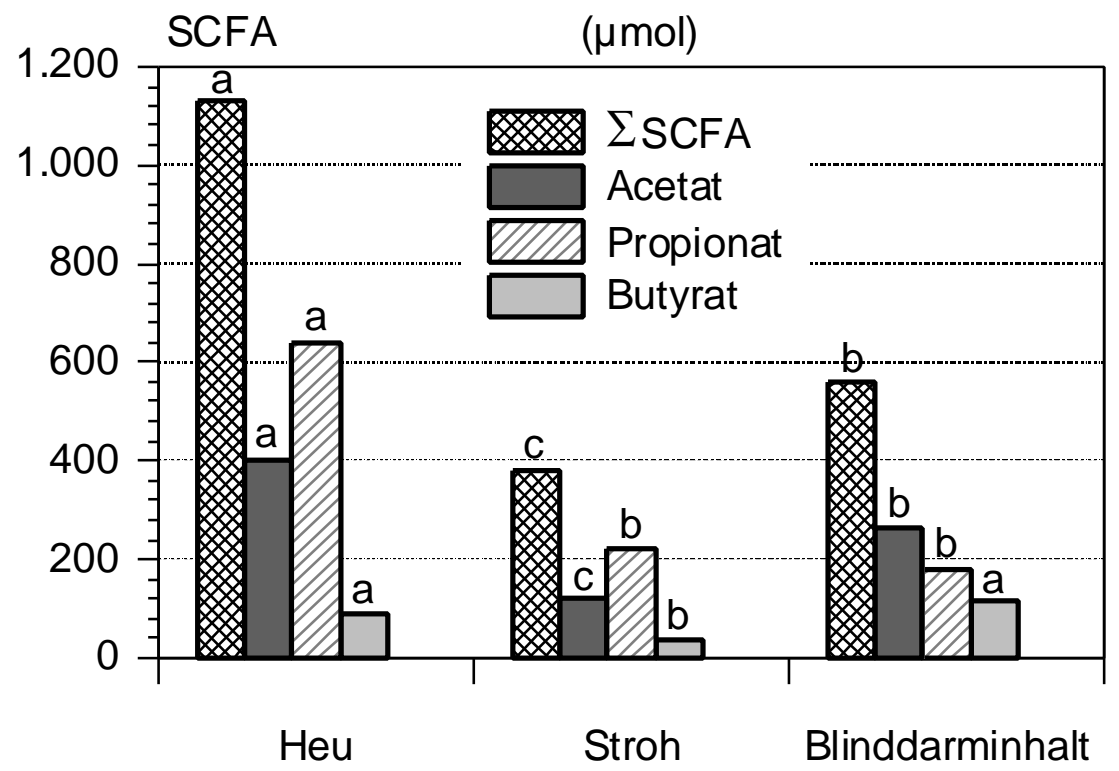

Abb. 12: $\quad$ Einfluß des in-vitro-Substrates auf die Bildung von SCFA in der batch-culture unter Verwendung von defauniertem Pansensaft $(n=54)$. Unterschiedliche Buchstaben an Säulen mit gleichem Muster kennzeichnen signifikante Unterschiede zwischen den Mittelwerten, Tukey-Kramer mit $p<0,05$.

4.2.4 Einfluß der Wechselwirkungen zwischen den Faktoren Ration, Nüchterungsdauer und in vitro-Substrat

Tabelle 11 zeigt den Einfluß von Ration sowie Nüchterungsdauer des Spendertieres auf die Fermentationsparameter. Eine signifikante Änderung der SCFA-Summe und ihrer Zusammensetzung war, mit Ausnahme des Butyratanteils, nur nach verlängerter Nüchterungsdauer bei der Stroh-Harnstoff-Ration festzustellen.

Der schon bei der Betrachtung der Hauptwirkungen deutlich werdende Trend zu einem niedriger werdenden Verhältnis von Acetat zu Propionat bei Rationsumstellung von Heu-Kraftfutter auf Stroh-Harnstoff bzw. bei längerer Nüchterungsdauer bestätigte sich auch bei der Aufgliederung nach Faktorenstufen. Die Kombination Stroh-Harnstoff-Ration * 24 Stunden Nüchterungsdauer führte sogar dazu, daß das Verhältnis Acetat zu Propionat größer 1 wurde.

Betrachtet man den Faktor Ration des Spendertieres in Kombination mit dem Faktor in-vitro-Substrat (Tab. 12) wird deutlich, daß sich die SCFA-Summe bei der StrohHarnstoff-Ration auf einem insgesamt niedrigeren Niveau bewegte und beim in-vitroSubstrat Stroh wiederum am niedrigsten war. 
Tab. 11: Einfluß von Ration sowie Nüchterungsdauer auf die Bildung von SCFA in der batch-culture $(n=27)$. Unterschiedliche Buchstaben in gleichen Spalten kennzeichnen signifikante Unterschiede zwischen den Mittelwerten, Tukey-Kramer mit $\mathrm{p}<0,05$.

\begin{tabular}{|c|c|c|c|c|c|c|c|c|}
\hline \multicolumn{9}{|c|}{ Pansensaft defauniert } \\
\hline \multirow{2}{*}{ Ration } & \multirow{2}{*}{$\begin{array}{l}\text { Nüchterungs- } \\
\text { dauer }\end{array}$} & \multirow{2}{*}{$\begin{array}{l}\text { SCFA } \\
\mu \mathrm{mol}\end{array}$} & \multicolumn{2}{|c|}{ Acetat } & \multicolumn{2}{|c|}{ Propionat } & \multicolumn{2}{|c|}{ Butyrat } \\
\hline & & & $\mu \mathrm{mol}$ & $\%$ & $\mu \mathrm{mol}$ & $\%$ & $\mu \mathrm{mol}$ & $\%$ \\
\hline \multirow{2}{*}{$\begin{array}{l}\text { Heu- } \\
\text { Kraftfutter }\end{array}$} & 16 Stunden & $759^{a}$ & $252^{\mathrm{a}}$ & 33 & $419^{a}$ & 55 & $89^{a}$ & 12 \\
\hline & 24 Stunden & $678^{a}$ & $250^{\mathrm{a}}$ & 37 & $344^{b}$ & 51 & $84^{\mathrm{a}}$ & 12 \\
\hline \multirow{2}{*}{$\begin{array}{l}\text { Stroh- } \\
\text { Harnstoff }\end{array}$} & 16 Stunden & $687^{\mathrm{a}}$ & $272^{\mathrm{a}}$ & 40 & $352^{\mathrm{ab}}$ & 51 & $63^{a}$ & 9 \\
\hline & 24 Stunden & $480^{d}$ & $216^{d}$ & 45 & $191^{d}$ & 40 & $73^{a}$ & 15 \\
\hline
\end{tabular}

Tab. 12: Einfluß von Ration und in-vitro-Substrat auf die Bildung von SCFA in der batch-culture $(n=18)$. Unterschiedliche Buchstaben in gleichen Spalten kennzeichnen signifikante Unterschiede zwischen den Mittelwerten, Tukey-Kramer mit $\mathrm{p}<0,05$.

\begin{tabular}{|c|c|c|c|c|c|c|c|c|}
\hline \multicolumn{9}{|c|}{ Pansensaft defauniert } \\
\hline \multirow{2}{*}{ Ration } & \multirow{2}{*}{ in-vitro-Substrat } & \multirow{2}{*}{$\begin{array}{c}\text { SCFA } \\
\mu \mathrm{mol}\end{array}$} & \multicolumn{2}{|c|}{ Acetat } & \multicolumn{2}{|c|}{ Propionat } & \multicolumn{2}{|c|}{ Butyrat } \\
\hline & & & $\mu \mathrm{mol}$ & $\%$ & $\mu \mathrm{mol}$ & $\%$ & $\mu \mathrm{mol}$ & $\%$ \\
\hline \multirow{3}{*}{$\begin{array}{l}\text { Heu- } \\
\text { Kraftfutter }\end{array}$} & Heu & $1322^{\mathrm{a}}$ & $454^{\mathrm{a}}$ & 34 & $782^{\mathrm{a}}$ & 59 & $86^{a}$ & 7 \\
\hline & Stroh & $386^{d}$ & $103^{e}$ & 27 & $236^{c}$ & 61 & $47^{\mathrm{b}}$ & 12 \\
\hline & Blinddarminhalt & $627^{c}$ & $257^{c}$ & 41 & $231^{\mathrm{c}}$ & 37 & $139^{a}$ & 22 \\
\hline \multirow{3}{*}{$\begin{array}{l}\text { Stroh- } \\
\text { Harnstoff }\end{array}$} & Heu & $955^{b}$ & $349^{b}$ & 37 & $513^{b}$ & 54 & $93^{\mathrm{a}}$ & 10 \\
\hline & Stroh & $374^{d}$ & $137^{d}$ & 37 & $209^{c}$ & 56 & $28^{\mathrm{b}}$ & 8 \\
\hline & Blinddarminhalt & $503^{c}$ & $269^{c}$ & 54 & $139^{d}$ & 28 & $95^{a}$ & 19 \\
\hline
\end{tabular}


Der Anteil des Acetats an der SCFA-Summe wurde bei allen in-vitro-Substraten durch die Stroh-Harnstoff-Ration erhöht. Zudem führte das in-vitro-Substrat Blinddarminhalt bei beiden Rationen zu einem Anstieg des prozentualen Acetatanteils. Die Propionatanteile lagen, wie auch beim Acetat, für die in-vitro-Substrate Heu und Stroh mit 59 und 61 \% (Heu-Kraftfutter) bzw. 54 und 56 \% (Stroh-Harnstoff) bei beiden Rationen nahe beieinander. Das in-vitro-Substrat Blinddarminhalt führte sowohl bei der Heu-Kraftfutter- als auch bei der Stroh-Harnstoff-Ration mit 37 bzw. $28 \%$ zu einem sehr viel geringeren Propionatanteil an der SCFA-Summe. Die Butyratanteile variierten insgesamt zwischen 7 und $22 \%$. Auffällig war, daß der Butyratanteil beim in-vitro-Substrat Blinddarminhalt mit ca. $20 \%$ für beide Rationen am höchsten war.

Tabelle 13 gibt die gemessenen molaren und prozentualen SCFA-Mengen in Abhängigkeit der Faktorvariation Nüchterungsdauer und in-vitro-Substrat wieder. Die absoluten Mengen der Fettsäuren sind größenordnungsmäßig mit denen aus Tabelle 12 vergleichbar. Noch deutlicher wird die Ähnlichkeit des Einflusses der Faktoren Ration und Nüchterungsdauer, wenn die prozentualen Anteile der einzelnen Fettsäuren an der SCFA-Summe zwischen den beiden Tabellen verglichen werden. Signifikante Wechselwirkungen traten nur beim Butyrat auf (Übersicht 6).

Tab. 13: Einfluß von Nüchterungsdauer und in-vitro-Substrat auf die Bildung von SCFA in der batch-culture $(n=18)$. Unterschiedliche Buchstaben in gleichen Spalten kennzeichnen signifikante Unterschiede zwischen den Mittelwerten, Tukey-Kramer mit $\mathrm{p}<0,05$.

\begin{tabular}{|c|c|c|c|c|c|c|c|c|}
\hline \multicolumn{9}{|c|}{ Pansensaft defauniert } \\
\hline \multirow{2}{*}{$\begin{array}{l}\text { Nüchterungs- } \\
\text { dauer }\end{array}$} & \multirow{2}{*}{ in-vitro-Substrat } & \multirow{2}{*}{$\begin{array}{l}\text { SCFA } \\
\mu \mathrm{mol}\end{array}$} & \multicolumn{2}{|c|}{ Acetat } & \multicolumn{2}{|c|}{ Propionat } & \multicolumn{2}{|c|}{ Butyrat } \\
\hline & & & $\mu \mathrm{mol}$ & $\%$ & $\mu \mathrm{mol}$ & $\%$ & $\mu \mathrm{mol}$ & $\%$ \\
\hline \multirow{3}{*}{16 Stunden } & Heu & $1248^{\mathrm{a}}$ & $426^{a}$ & 34 & $749^{a}$ & 60 & $73^{a}$ & 6 \\
\hline & Stroh & $446^{d}$ & $134^{\mathrm{C}}$ & 30 & $273^{c}$ & 61 & $39^{b}$ & 9 \\
\hline & Blinddarminhalt & $618^{\mathrm{c}}$ & $267^{b}$ & 43 & $223^{c}$ & 36 & $128^{\mathrm{a}}$ & 21 \\
\hline \multirow{3}{*}{24 Stunden } & Heu & $1024^{b}$ & $375^{a}$ & 37 & $541^{\mathrm{b}}$ & 53 & $108^{a}$ & 10 \\
\hline & Stroh & $317^{e}$ & $106^{c}$ & 33 & $176^{\mathrm{cd}}$ & 56 & $35^{\mathrm{b}}$ & 11 \\
\hline & Blinddarminhalt & $508^{\mathrm{cd}}$ & $259^{b}$ & 51 & $145^{d}$ & 29 & $104^{\mathrm{a}}$ & 20 \\
\hline
\end{tabular}



Versuchen

In den Abschnitten 4.1 und 4.2 wurden die Ergebnisse aus den in der batch-culture gemessenen Parametern Acetat, Propionat, Butyrat sowie Methan vorgestellt. Aus diesen Parametern wurden die Kenngrößen SCFA-Summe und Methan/SCFAVerhältnis errechnet.

Zur Beurteilung, ob die variierten Faktoren möglicherweise zu einer Initiierung der reduktiven Acetogenese geführt haben und somit mit Hilfe einer ${ }^{13} \mathrm{C}-\mathrm{CO}_{2}$-Markierung weiter untersucht werden sollten, wurden drei Kriterien herangezogen: 1. die Reduktion der Methanmenge, 2. das Methan / SCFA-Verhältnis und 3. die Wasserstoffwiederfindungsrate.

Die absolute Methanmenge wurde am deutlichsten durch die Defaunierung reduziert; nach der Defaunierung konnte in den Inkubationen kein Methan mehr nachgewiesen werden. Das Methan/SCFA-Verhältnis wurde am effektivsten durch die Faktorkombination Stroh-Harnstoff-Ration bei 24 Stunden Nüchterungsdauer gesenkt.

Die Wasserstoffwiederfindung ist für die je 12 Faktorkombinationen mit nicht defauniertem und defauniertem Pansensaft in Abbildung 13 dargestellt. Für die Ansätze mit nicht defauniertem Pansensaft konnte nur bei den Faktorkombinationen mit dem in-vitro-Substrat Blinddarminhalt ein signifikanter Einfluß auf die Wasserstoffwiederfindung festgestellt werden. Für die Ansätze, bei denen das Spendertier mit der Heu-Kraftfutter-Ration gefüttert wurde, lag die Wasserstoffwiederfindung für die Varianten mit dem in-vitro-Substrat Blinddarminhalt bei $70 \%$ und für die Stroh-Harnstoff-Ration mit demselben in-vitro-Substrat bei nur $61 \%$ (16 Stunden Nüchterungsdauer) bzw. 50 \% (24 Stunden Nüchterungsdauer).

Auch bei den Ansätzen mit defauniertem Pansensaft bestätigte sich die signifikante Wirkung des in-vitro-Substrates Blinddarminhalt auf die Wasserstoffwiederfindung (Abb.13). Bei einem insgesamt etwas niedrigeren Niveau der Wasserstoffwiederfindung zeigten sich außerdem beim defaunierten im Vergleich zum nicht defaunierten Pansensaft signifikant niedrigere Wasserstoffwiederfindungsraten für die Faktorkombinationen Stroh-Harnstoff-Ration, 24 Stunden Nüchterungsdauer und in-vitro-Substrat Heu bzw. Stroh sowie in der Heu-Kraftfutter-Ration beim in-vitroSubstrat Blinddarminhalt.

Aufgrund der Ergebnisse aus den batch-culture-Untersuchungen deutete nach den o.g. Kriterien vor allem die Defaunierung des verwendeten Pansensaftes und das Substrat Blinddarminhalt auf eine Initiierung der reduktiven Acetogenese hin. Daher wurden diese Faktoren in den Versuchsplan zum direkten Nachweis der reduktiven Acetogenese mit ${ }^{13} \mathrm{C}-\mathrm{CO}_{2}$-Marker aufgenommen. 

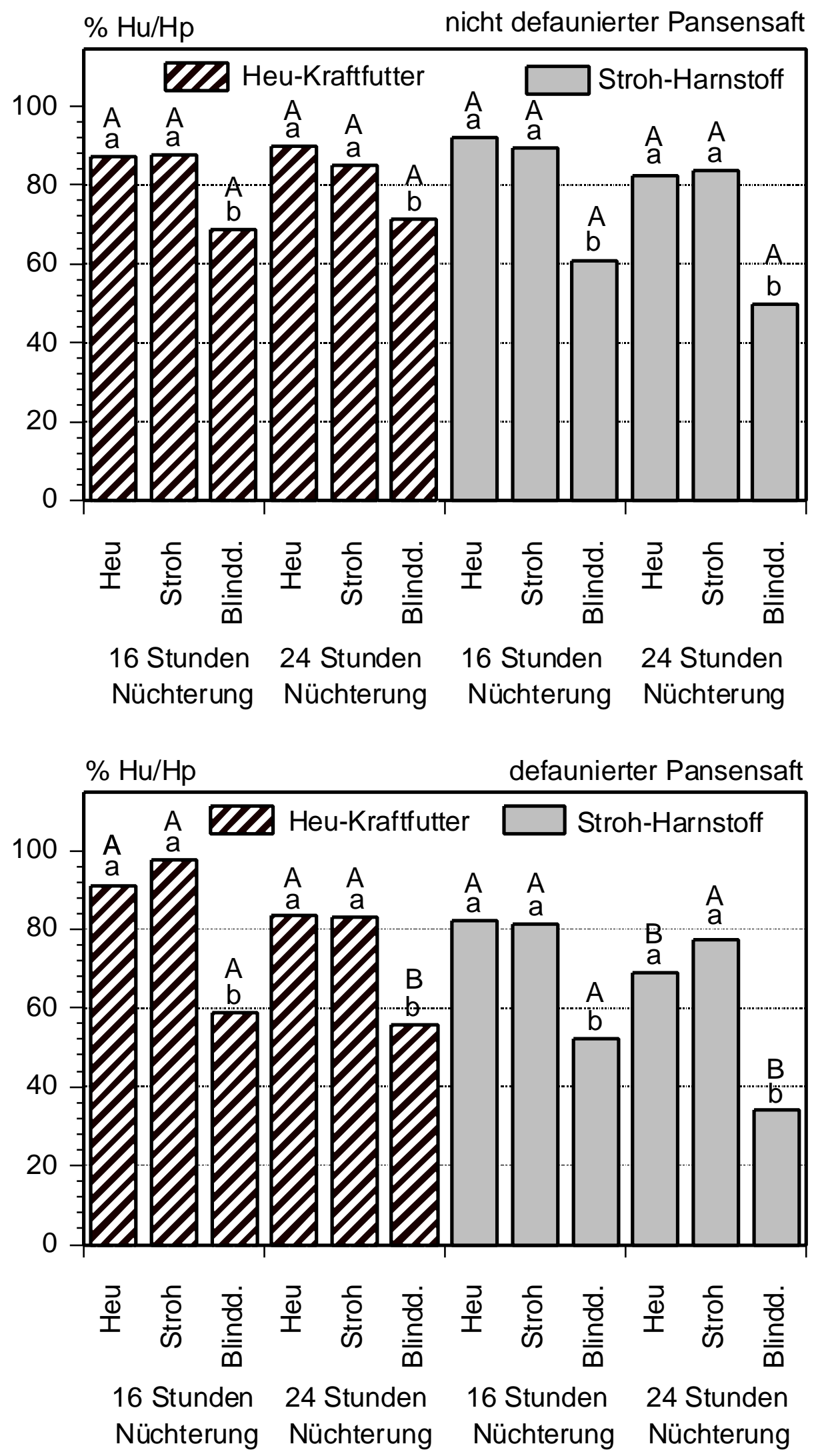

Abb. 13: Wasserstoffwiederfindungsraten der Inkubationen mit nicht defauniertem (A) und defauniertem Pansensaft $(B)(n=9)$. Unterschiedliche Kleinbuchstaben an Säulen mit gleichem Muster kennzeichnen signifikante Unterschiede zwischen den Mittelwerten, Großbuchstaben kennzeichnen signifikante Unterschiede zwischen nicht defauniertem und defauniertem Pansensaft, Tukey-Kramer mit $p<0,05$. 
Der Einsatz der ${ }^{13} \mathrm{C}$-Kernresonanzspektroskopie wurde bereits von DE GRAEVE ET AL. (1994) zum Nachweis der reduktiven Acetogenese im Blind- und Dickdarm des Schweins beschrieben. Um für den direkten Nachweis der reduktiven Acetogenese eine Positivkontrolle zur Verfügung zu haben, wurde vor Beginn der ${ }^{13} \mathrm{C}-\mathrm{CO}_{2}$-Untersuchungen mit Panseninokulum eine Versuchsreihe mit Bakterien aus dem Blindund Dickdarm des Schweins durchgeführt. Nachdem dabei reduktive Acetogenese direkt nachgewiesen werden konnte, wurde in nachfolgenden Untersuchungen mit der gleichen Versuchsanstellung der Effekt der Defaunierung des Panseninokulums, der Einsatz von Blinddarminhalt als in-vitro-Substrat sowie die Entwicklung der mikrobiellen Biozönose in der Pansensimulationstechnik RUSITEC in Gegenwart von Gallensalzen auf das Vorkommen von reduktiver Acetogenese überprüft.

4.4.1

Nachweis der reduktiven Acetogenese durch Mikroben des Schweinedarms

Der Einfluß unterschiedlicher Begasungen mit Argon und Wasserstoff einer aus dem Blind- und Dickdarm des Schweins durch Differentialzentrifugation gewonnenen Bakteriensuspension auf die Synthese von SCFA und Methan ist in Abbildung 14 dargestellt.

Die Begasung mit $80 \%$ Wasserstoff und $20 \%{ }^{13} \mathrm{C}-\mathrm{CO}_{2}$ ließ die SCFA-Summe gegenüber der Begasung mit $80 \%$ Argon und $20 \%{ }^{13} \mathrm{C}-\mathrm{CO}_{2}$ signifikant ansteigen, der Effekt auf die einzelnen Säuren konnte jedoch nur beim Butyrat als signifikant abgesichert werden. Wesentlich eindeutiger war der $30 \%$ ige Anstieg der Methanmenge durch die Wasserstoffbegasung.

Abbildung 15 zeigt, daß in beiden Begasungsvarianten Acetatmoleküle mit einfacher und doppelter Markierung gefunden wurden. Die Begasung mit Wasserstoff bewirkte eine signifikante Steigerung der an der Methylgruppe markierten $\left({ }^{13} \mathrm{CH}_{3}-\mathrm{COOH}\right)$ sowie des doppeltmarkierten Acetats $\left({ }^{3} \mathrm{CH}_{3}{ }^{13} \mathrm{COOH}\right)$ (vgl. Abb. 21, Anhang 14: Spektrum 1 und 2). Aufgrund des geringen Probenumfanges ( $n=2$ bei Argon- und $\mathrm{n}=3$ bei Wasserstoffbegasung) konnte die infolge der Wasserstoffbegasung gesteigerte Menge des an der Carboxylgruppe $\left(\mathrm{CH}_{3^{-}}{ }^{13} \mathrm{COOH}\right)$ markierten Acetats statistisch nicht abgesichert werden. 


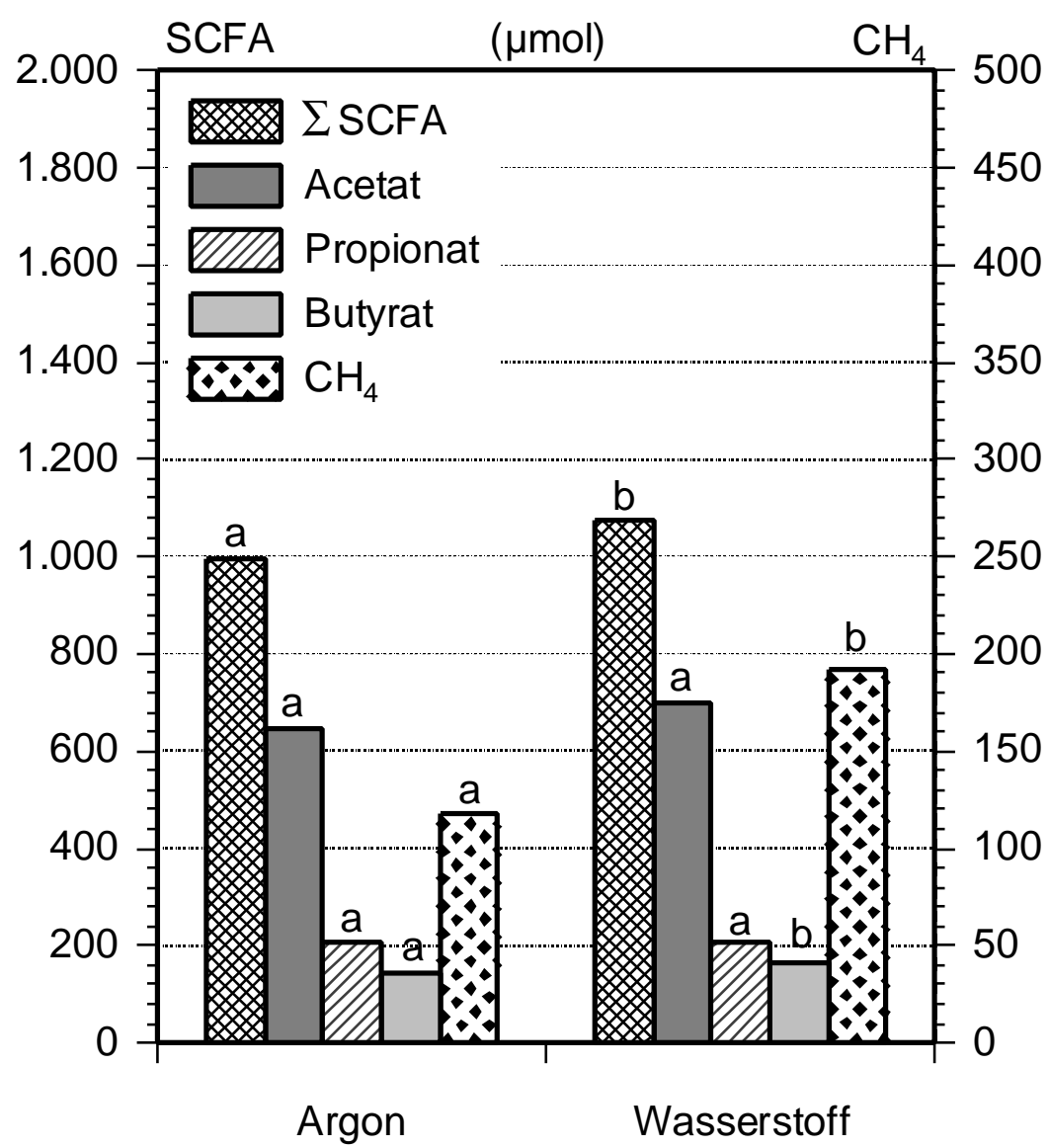

Abb. 14: $\quad$ Einfluß der Begasung mit $80 \%$ Argon $(n=2)$ bzw. $80 \%$ Wasserstoff $(n=3)$ in der Gasatmosphäre einer batch-culture-Inkubation mit Bakterien aus dem Schweinedarm. Unterschiedliche Buchstaben an Säulen mit gleichem Muster kennzeichnen signifikante Unterschiede zwischen den Mittelwerten, Fischers PLSD mit $p<0,05$.

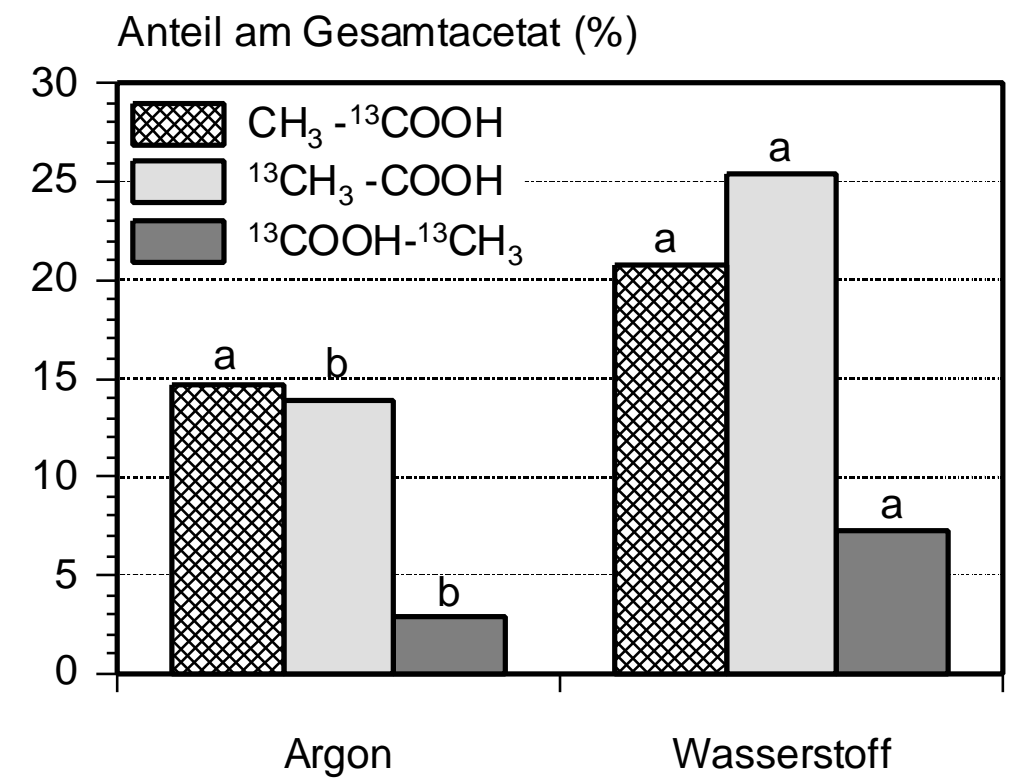

Abb. 15: Einfluß der Begasung mit $80 \%$ Argon $(n=2)$ und $80 \%$ Wasserstoff $(n=3)$ in der Gasatmosphäre der batch-culture Inkubation mit Bakterien aus dem Schweinedarm auf die Entstehung von ${ }^{13} \mathrm{C}-\mathrm{CO}_{2}$-markiertem Acetat. Unterschiedliche Buchstaben an Säulen mit gleichem Muster kennzeichnen signifikante Unterschiede zwischen den Mittelwerten, Fischers PLSD mit $p<0,05$. 


\section{Pansensaft}

Die aufgrund der Ergebnisse aus den vorangegangenen Untersuchungen unter Einsatz des ${ }^{13} \mathrm{C}-\mathrm{CO}_{2}$-Markers wiederholten Inkubationen umfaßten den Einsatz vom in-vitro-Substrat Blinddarminhalt $(n=3)$ sowie die Defaunierung des Pansensaftes $(n=3)$. Als Kontrolle wurden außerdem Inkubationen mit nicht defauniertem Pansensaft und dem in-vitro-Substrat $\mathrm{Heu}(\mathrm{n}=3)$ durchgeführt. Alle Inkubationen erfolgten mit $80 \%$ Wasserstoff und $20 \%{ }^{13} \mathrm{CO}_{2}$ in der Gasatmosphäre, um das reduktiv acetogene Potential zu fördern. In Abbildung 16 fallen die durch die Wasserstoffbegasung hervorgerufenen sehr hohen Methanmengen auf, diese waren nur bei der defaunierten Inkubation signifikant niedriger als bei der Kontrolle mit dem in-vitro-Substrat Heu. Aufgrund des geringen Probenumfanges ließen sich die Unterschiede an SCFA nur in einigen Fällen signifikant absichern. Auffallend war das nach wie vor niedrige Acetat / Propionat-Verhältnis beim Ansatz ohne Protozoen.

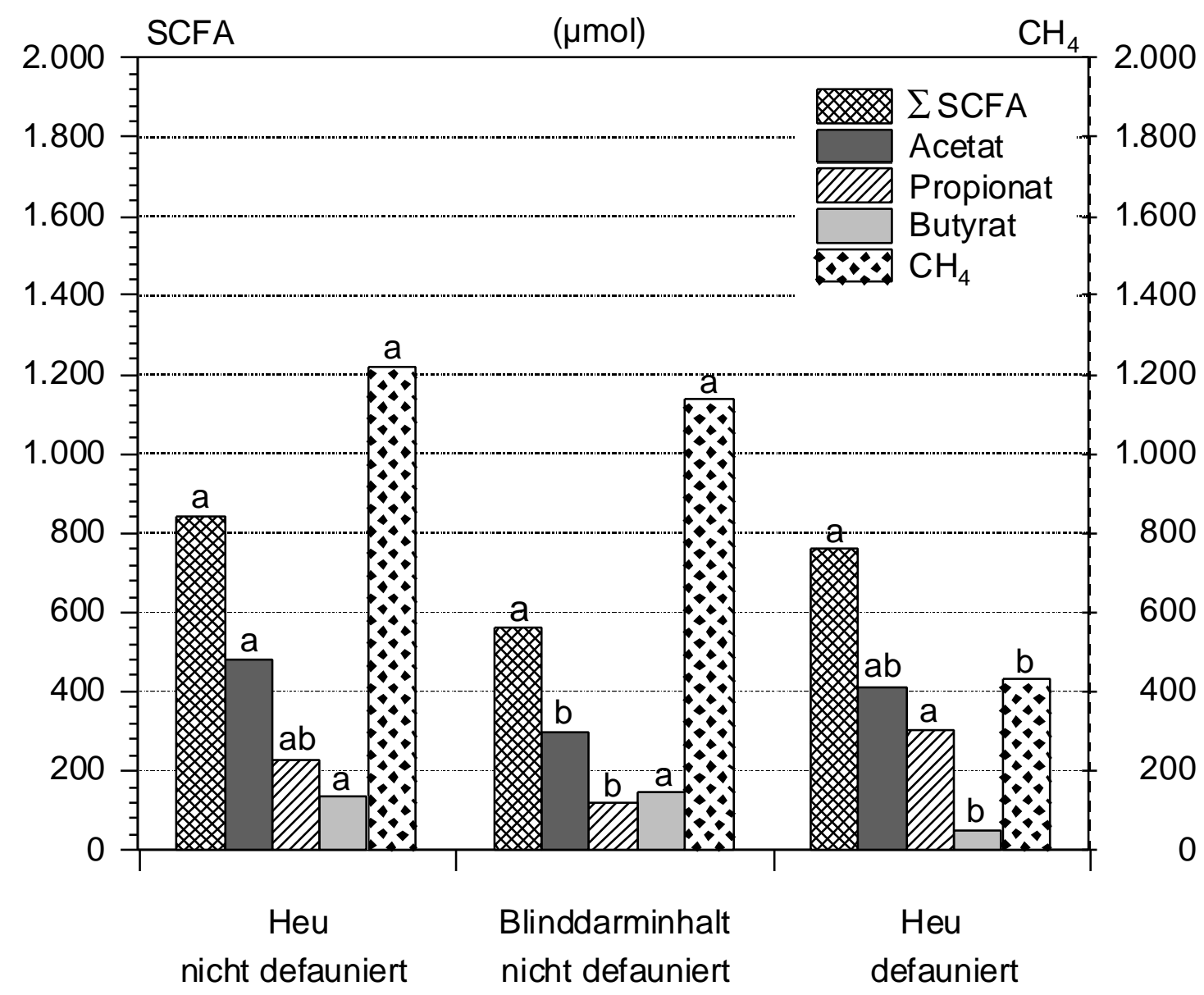

Abb. 16: Einfluß der in-vitro-Substrate $\mathrm{Heu}$ und Blinddarminhalt sowie der Defaunierung auf die Entstehung von SCFA und Methan in der batch-culture $(n=3)$. Unterschiedliche Buchstaben an Säulen mit gleichem Muster kennzeichnen signifikante Unterschiede zwischen den Mittelwerten, Fischers PLSD mit $p<0,05$. 
Die Untersuchungen der Fermentationsprodukte auf das Vorkommen von doppeltmarkiertem Acetat ergaben, daß bei keiner der 9 Inkubationen Acetat reduktiv gebildet wurde ( $\mathrm{vgl}$. Anhang 14, Spektren 3, 4 und 5).

4.4.3

Untersuchungen zum Nachweis einer reduktiven Acetogenese durch pansenstämmige Mikroorganismen aus dem RUSITEC-System

Aufgrund der in der Literatur beschriebenen (IMMIG 1998) und in eigenen RUSITEC Untersuchungen (Anhang 9) bestätigten stark antimethanogenen Wirkung von Gallensalzen wurden auch im Rahmen dieser Arbeit Untersuchungen zum direkten Nachweis der reduktiven Acetogenese unter dem Einfluß von Gallensalzen durchgeführt. Dazu wurde Pansensaft in drei Fermentern des RUSITEC-Systems inkubiert und ab dem vierten Tag in Fermenter zwei und drei 0,4 bzw. 0,6 \% (w/v) Gallensalz infundiert, Fermenter eins blieb als Kontrolle unbehandelt.

Der Einfluß der Gallensalzinfusion auf die Methanogenese ist in Abbildung 17 wiedergegeben. Trotz der methodisch bedingten stark variierenden täglich gebildeten Methanmengen zeigte sich am 5. und 6. Tag, das entspricht dem 2. und 3. Tag der Gallensalzinfusion, eine deutliche Hemmung der Methanogenese. Aufgrund einer Undichtigkeit in dem RUSITEC-System konnte am 5. Tag in dem Fermenter mit der 0,6 \%igen Gallensalzinfusion die Gasmenge nicht bestimmt werden.

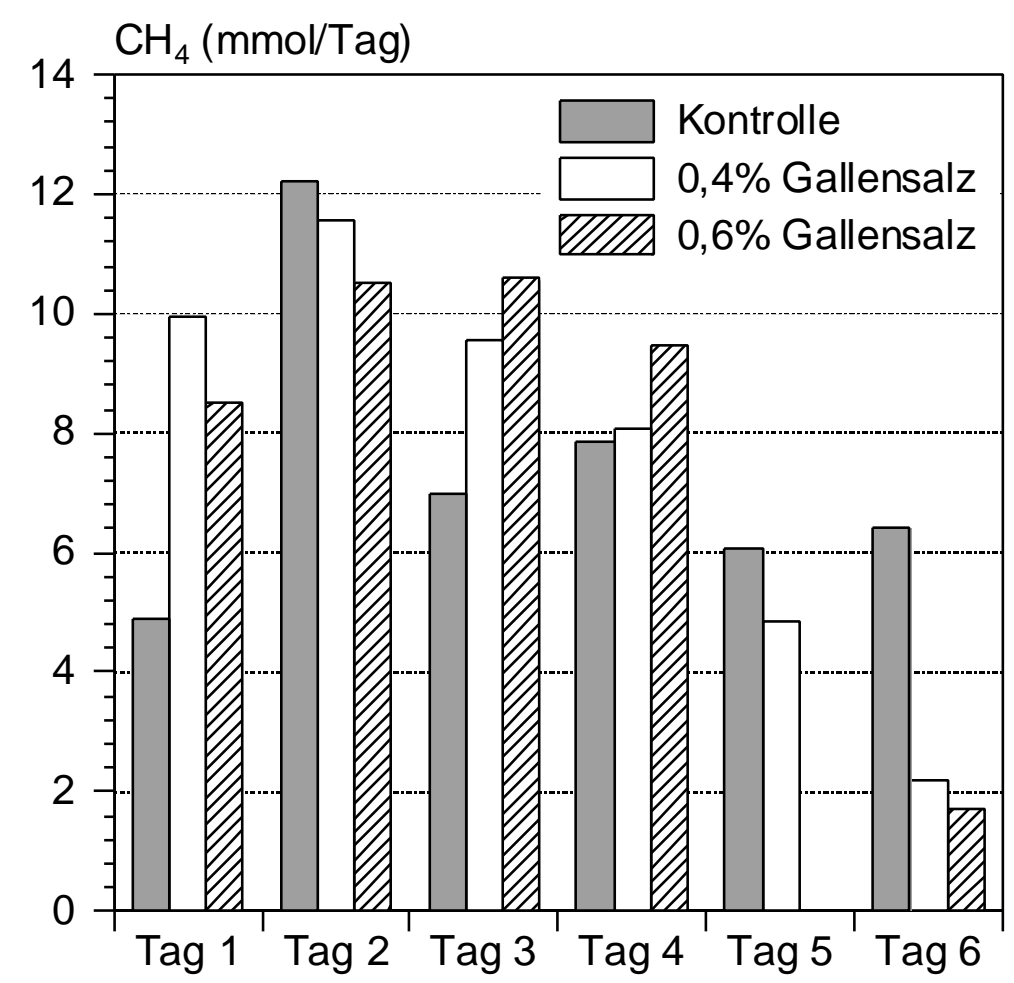

Abb. 17: Einfluß der Infusion von 0,4\% und 0,6\% Gallensalz (w/v) auf die Methanogenese in dem RUSITEC-System. 
Aus Abbildung 18 geht der Einfluß der gleichen Behandlung auf die Protozoenzahl hervor. Hier zeigt sich am 2. und 3. Tag eine Stabilisierung bei einer Anzahl von rund 17000 Protozoen / ml. Nach der Gallensalzzugabe konnten in den behandelten Fermentern am 6. Tag keine Protozoen mehr nachgewiesen werden.

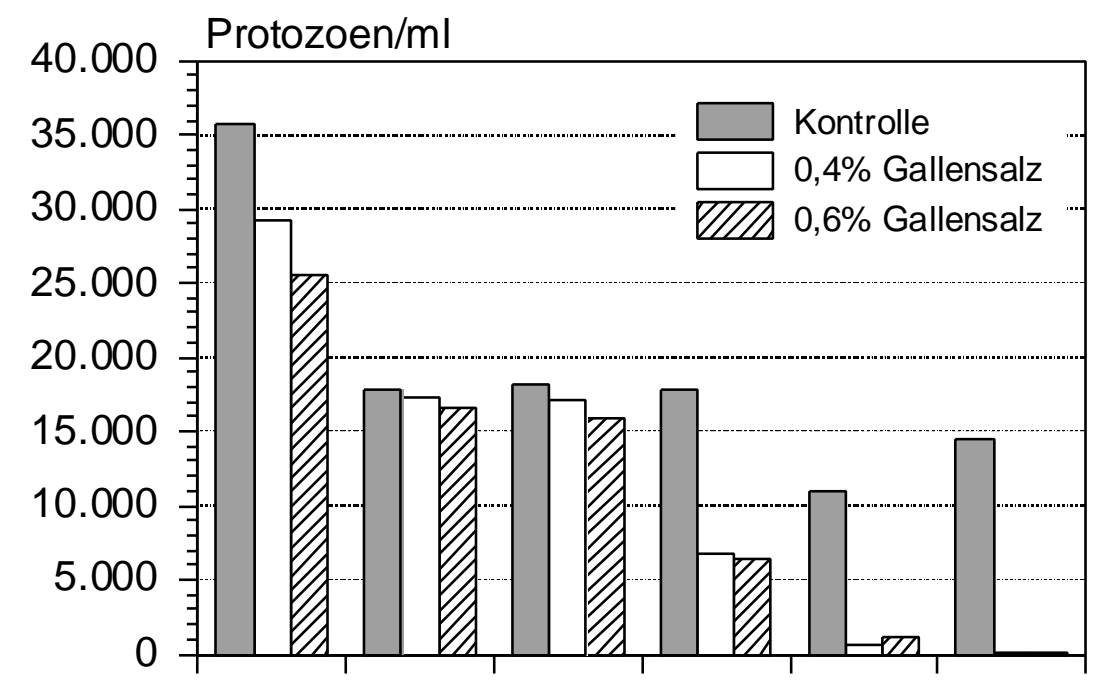

Tag $1 \quad \operatorname{Tag} 2 \quad \operatorname{Tag} 3 \quad \operatorname{Tag} 4 \quad \operatorname{Tag} 5 \quad \operatorname{Tag} 6$

Abb. 18: Einfluß der Infusion von 0,4 und $0,6 \%$ Gallensalz $(\mathrm{w} / \mathrm{v})$ auf die in der Fermentationsflüssigkeit des RUSITEC-Systems vorhandenen Protozoen.

Die Zugabe von Gallensalzen in die Fermenter des RUSITEC-Systems hatte auch eine Wirkung auf die synthetisierten flüchtigen Fettsäuren. In Abbildung 19 sind die Mengen an Butyrat, Propionat und Acetat in Abhängigkeit von Inkubationstag und Behandlung dargestellt. Sowohl bei der Kontrolle als auch bei den ab dem 4. Tag mit Gallensalz infundierten Fermentern zeigt sich ein Abwärtstrend. Dieser wurde aber erst am 6. Tag steiler als bei der Kontrolle. Berechnet man das Methan/SCFAVerhältnis, so erhält man für den 6 . Tag Werte von 0,17 für die Kontrolle und 0,07 bzw. 0,05 für die Fermenter mit den Gallensalzkonzentration 0,4 bzw. 0,6\%.

Nachdem das Inokulum 6 Tage in dem RUSITEC-System auf die beschriebene Weise inkubiert worden war, wurden aus der flüssigen Phase des entsprechenden Fermenters $10 \mathrm{ml}$ entnommen, um diese dann unter Einsatz von ${ }^{13} \mathrm{C}-\mathrm{CO}_{2}$-Marker in der batch-culture zu untersuchen. Die während der sich anschließenden Inkubationsynthetisierten Mengen an SCFA und Methan sind in Abbildung 20 dargestellt. Es fällt auf, daß die Methanmenge, bedingt durch den hohen Anteil von 


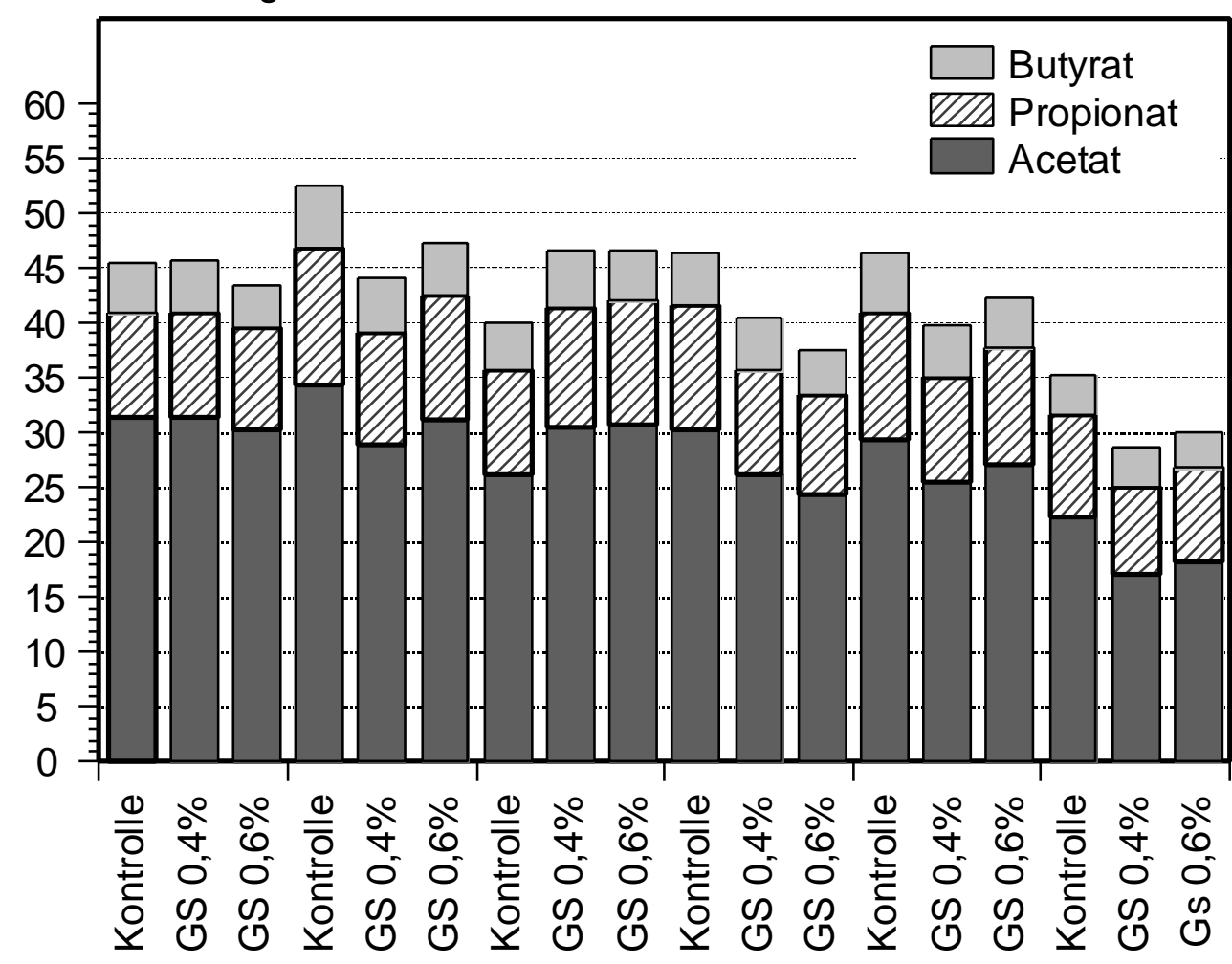

$\begin{array}{llllll}\text { Tag } 1 & \text { Tag } 2 & \text { Tag } 3 & \text { Tag } 4 & \text { Tag } 5 & \text { Tag } 6\end{array}$

Abb. 19: Mengen der in des RUSITEC-Systems pro Tag und Fermenter entstandenen SCFA. Jede Säule stellt das Ergebnis eines Fermenters dar. Die Behandlungen beinhalteten Gallensalzinfusionen von 0,4\% (GS 0,4\%) bzw. 0,6\% (GS 0,6\%) ab dem 4. Tag sowie einen Kontrollfermenter ohne Gallensalz (Kontrolle).

Wasserstoff in der Gasatmosphäre, bei der Kontrolle sehr hoch war, während bei den mit Gallensalz behandelten Inkubationen vergleichsweise geringe Mengen vorlagen. Die SCFA-Summe nahm mit dem Einsatz von Gallensalz um $349(0,4 \%$ Gallensalz) bzw. $485 \mu \mathrm{mol}(0,6 \%$ Gallensalz) signifikant ab. Am Fettsäuremuster war der von der Kontrolle über die 0,4 zur 0,6\%igen Gallensalzkonzentration sinkende Acetatanteil (50, 39 bzw. $22 \%$ ) sowie der in der gleichen Reihenfolge von 27 über 38 zu $54 \%$ ansteigende Butyratanteil an der SCFA-Summe auffallend (Anhang 13). Wie bei den Inkubationen mit defauniertem Pansensaft, war auch bei diesen Inkubationen ein mit zunehmender Gallensalzkonzentration niedriger werdendes Verhältnis von Acetat zu Propionat zu erkennen.

Abbildung 21 zeigt die ${ }^{13} \mathrm{C}$-NMR Spektren A) einer batch-culture-Probe mit Heu als in-vitro-Substrat, B) eines Natriumacetatstandards sowie C) einer batch-cultureProbe mit Inokulum aus dem RUSITEC-System ohne Gallensalzzugabe. In jedem der drei Spektren sind die Banden des an der Methylgruppe $\left(\mathrm{COOH}^{13} \mathrm{CH}_{3}\right)$ und an 


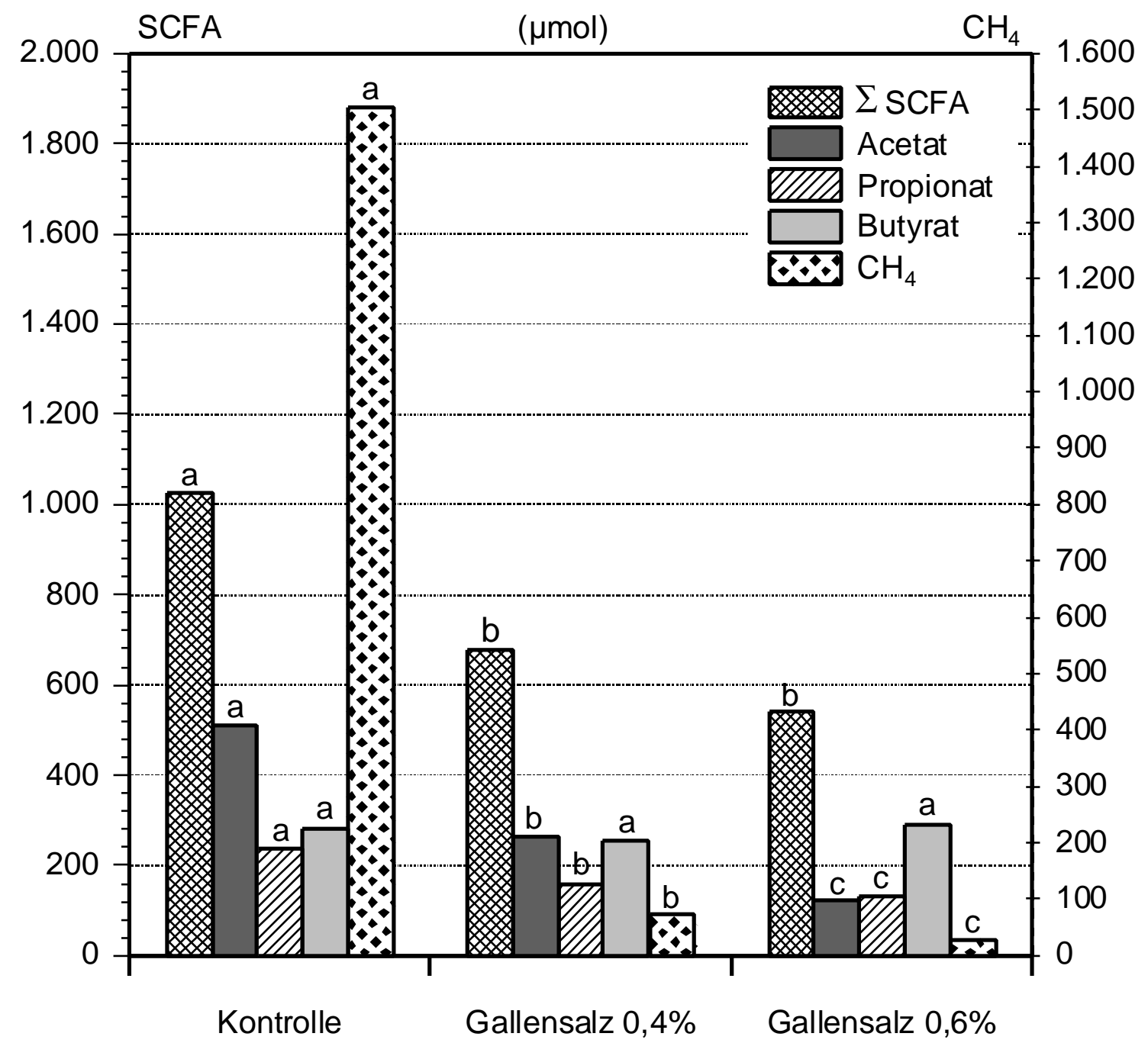

Abb. 20: Einfluß der Entwicklung der Biozönose im RUSITEC auf die Fermentationsprodukte einer 24 stündigen Inkubation in der batch-culture $(n=3)$. Unterschiedliche Buchstaben an Säulen mit gleichem Muster kennzeichnen signifikante Unterschiede zwischen den Mittelwerten, Fischers PLSD mit $p<0,05$.

der Carboxylgruppe $\left({ }^{13} \mathrm{COOH}-\mathrm{CH}_{3}\right){ }^{13} \mathrm{C}$-markierten Acetats durch Pfeile gekennzeichnet. Die Lage dieser Banden konnte anhand der natürlichen ${ }^{13} \mathrm{C}_{-} \mathrm{CO}_{2}-$ Anreicherung $(1,11 \%)$ des Natriumacetats überprüft werden. Bei der Probe mit Doppelmarkierung sind in dem Detailausschnitt neben der $\mathrm{COOH}^{-13} \mathrm{CH}_{3}$ Bande, deren sogenannten Dubletten markiert $\left({ }^{3} \mathrm{COOH}^{13} \mathrm{CH}_{3}\right)$, die den Nachweis für die reduktive Acetogenese liefern.

Die Untersuchungen des Pansensaftes mittels ${ }^{13} \mathrm{C}-\mathrm{NMR}$ ergaben, daß sowohl in der Kontrolle ohne Gallensalz (Anhang 14: Spektrum 6, 7, und 8) als auch im Ansatz mit $0,4 \%$ Gallensalz doppeltmarkiertes Acetat nachgewiesen werden konnte (Anhang 14: Spektrum 9, 10, und 11), während im Ansatz mit 0,6 \% Gallensalz kein doppeltmarkiertes Acetat vorlag (Anhang 14: Spektrum 12). 

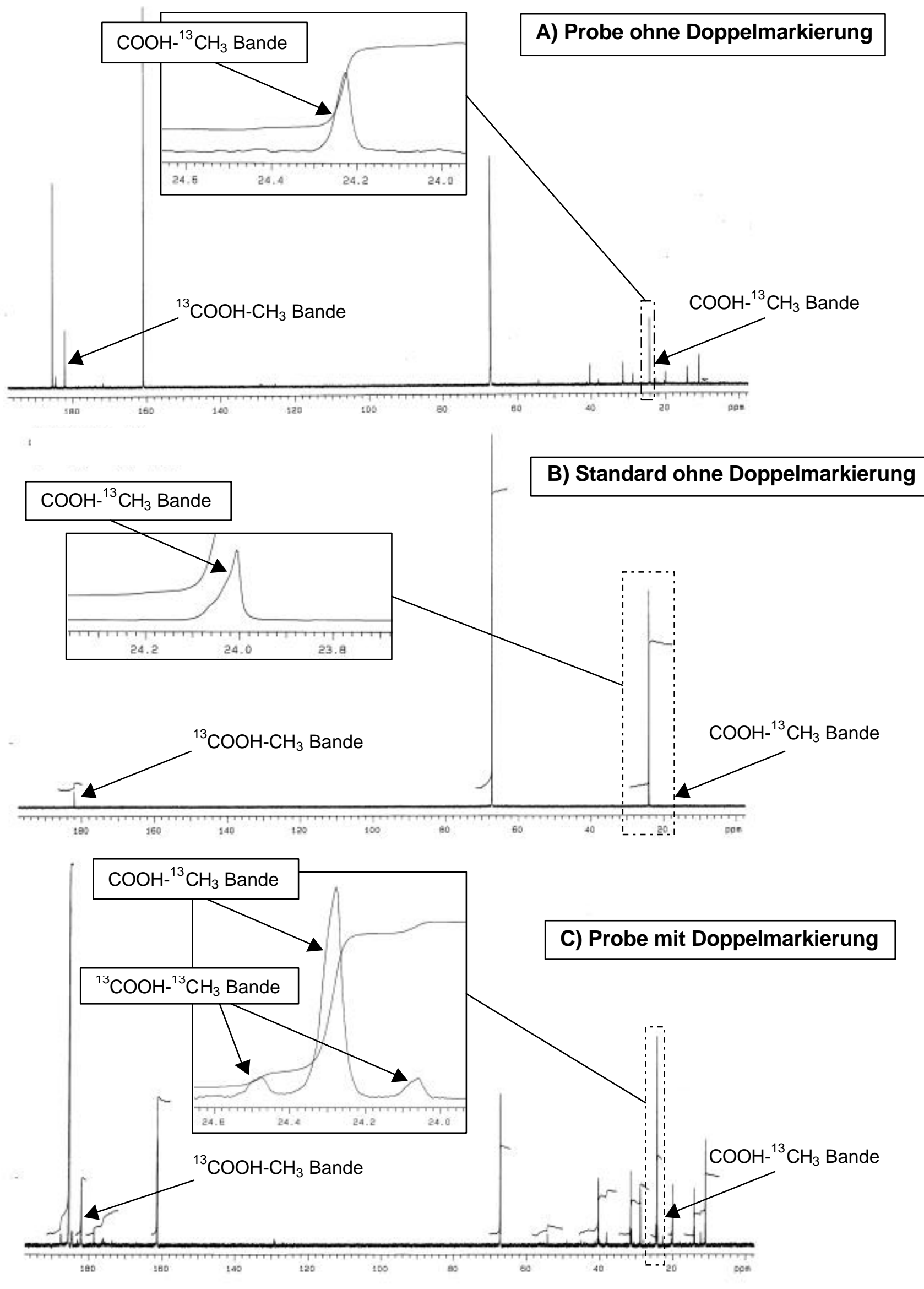

Abb. 21: $\quad{ }^{13} \mathrm{C}-\mathrm{NMR}$ Spektren ohne (A, B) und mit (C) doppeltmarkiertem Acetat 
5.1 Versuchsplan und Versuchskritik

Der Versuchsplan wurde mit dem Ziel aufgestellt, die drei Arbeitshypothesen:

Die reduktive Acetogenese wird gefördert, wenn ...

1. ... Protozoen fehlen,

2. ... weniger leicht abbaubare Kohlenhydrate vorhanden oder

3. ... Substanzen endogenen oder mikrobiellen Ursprungs anwesend sind, zu überprüfen.

In der Versuchsstufe 1 wurden in einem balancierten, vierfaktoriellen Versuch die Faktoren Protozoen, Ration sowie Nüchterungsdauer des Spendertieres und in-vitro-Substrat anhand der Parameter SCFA, Methan, Methan / SCFA-Verhältnis und der Wasserstoffwiederfindung geprüft. Dieses balancierte Versuchsdesign erlaubte die Aufspaltung des Gesamtversuches in nach Faktorstufen getrennte Teilversuche. Da der Einfluß des Faktors Protozoen in den vorliegenden Untersuchungen sehr groß war, wurde in Versuchsstufe 1 der Versuch für die Auswertung und Diskussion in die Teilversuche "nicht defauniert" und "defauniert" gegliedert. Auf die Interpretation der Dreifachwechselwirkungen wurde im Rahmen dieser Arbeit verzichtet, da sich aus den entsprechenden Faktorkombinationen keine für die Versuchsfragen relevanten Erkenntnisse ergaben. Das orthogonale Versuchsdesign ermöglichte, alle Faktoren miteinander zu kombinieren und somit jede Faktorkombination zu testen. Grundsätzlich ist aber die Kombination von mehr als 2 Faktoren nicht sinnvoll, da es schwierig ist, Drei- und Vierfachwechselwirkungen $\mathrm{zu}$ interpretieren. In der vorliegenden Untersuchung konnten trotz der in Versuchsstufe 1 beobachteten Wechselwirkungen für das Vorkommen der reduktiven Acetogenese als relevant erachteten Faktoren identifiziert werden.

In Versuchsstufe 2 erfolgte der direkte Nachweis der reduktiven Acetogenese mit Hilfe der ${ }^{13} \mathrm{C}$-NMR-Methode. Aufgrund der methodenbedingten langen Meßzeiten und des hohen analytischen Aufwandes konnte nur eine begrenzte Anzahl von Proben gemessen werden.

\subsection{Auswahl des verwendeten Defaunierungsverfahrens}

In der vorliegenden Arbeit wurde ein Defaunierungsverfahren benötigt, das es ermöglicht, nicht defaunierten und defaunierten Pansensaft der gleichen Herkunft für parallele Inkubationen zu verwenden. Da für die Versuchsstufe 1 nur eine 
pansenfistulierte Kuh zur Verfügung stand, schied ein Verfahren bei dem zwei Tiere defauniert werden und anschließend eines der beiden wieder mit einer definierten Protozoenpopulation inokuliert wird (DemeYer und VAN NeVEL 1979, Coleman 1985, JOUANY und MARTIN 1997) aus. Da der Versuchsplan zur besseren Vergleichbarkeit eine gleichzeitige Inkubation des nicht defaunierten und defaunierten Pansensaftes vorsah, kam ein Verfahren, daß eine Defaunierung des Spendertieres und eine anschließende Refaunierung in zeitlicher Abfolge impliziert, ebenfalls nicht in Frage. Somit standen noch Zentrifugation, Filtration oder Gefrieren des Pansensaftes sowie der Einsatz einer Detergentienlösung als mögliche Defaunierungsverfahren (LEINMÜLLER und MENKE 1986) zur Auswahl.

Die Zentrifugation erwies sich als ungeeignet, da mit diesem Verfahren neben den Protozoen auch alle Substratpartikel mit anhaftenden Bakterien aus dem Pansensaft entfernt wurden. Bei der Filtration des Pansensaftes treten nach LEINMÜLLER und MENKE (1986) Probleme mit verstopften Filtern auf. Außerdem wird vermutet, daß ebenfalls ein großer Teil der festen Partikel des Pansensaftes mit abfiltriert wird. Vor Beginn der eigenen Untersuchungen wurde die Defaunierung durch Einfrieren des Pansensaftes bei $-20^{\circ} \mathrm{C}$ und $-80^{\circ} \mathrm{C}$ erprobt. Nach dem Gefrieren war zwar keine Protozoenmobilität mehr zu erkennen, dennoch konnte lichtmikroskopisch keine äußerliche Beschädigung der Protozoenzellen festgestellt werden. Inkubationen mit dem so behandelten Pansensaft zeigten kaum eine Einschränkung der Methanproduktion, somit waren die Anzeichen für eine erfolgreiche Defaunierung des Pansensaftes insgesamt nicht hinreichend.

Als viertes Verfahren zur in vitro Defaunierung bot sich der Einsatz einer Detergentienlösung an. Dazu wurde ein von mehreren Autoren BIRD ET AL. 1979, VEIRA ET AL. 1983, KREUZER und KIRCHGEBNER 1986) beschriebenes Verfahren, bei dem das oberflächenaktive Detergens Natrium-lauryl-diethoxy-Sulfat, das in Deutschland unter dem Namen Synperonic (Deutsche ICI, Frankfurt a.M., D.) vertrieben wird, als Wirkstoff zur Protozoeneliminierung eingesetzt. In eigenen Versuchen zeigte sich die Wirkung des Präparates schon nach wenigen Minuten durch ein vollständiges Verschwinden der Protozoen. Damit wurde die gleichzeitige Inkubation von nicht-defauniertem und defauniertem Pansensaft möglich.

\section{3}

\section{Auswahl der verwendeten in-vitro-Methoden}

In-vitro-Methoden bieten die Möglichkeit, die mikrobiellen Umsetzungen im Pansen unter kontrollierten Laborbedingungen zu untersuchen (CZERKAWSKI 1986). In der vorliegenden Arbeit war außerdem die Absicht, extreme, nicht mehr physiologische Bedingungen zu simulieren, für den Einsatz der in-vitro-Systeme ausschlaggebend. 
Für die zu beantwortenden Fragestellungen wurden die nicht kontinuierliche batchculture sowie das kontinuierliche RUSITEC-System (Pansensimulationstechnik) verwendet.

In der Versuchsstufe 1 wurde der Einfluß der 4 Faktoren Protozoen, Ration sowie Nüchterungsdauer des Spendertieres und in-vitro-Substrat mit der batch-cultureMethode (MARTY und DemeYer 1973, Van NeVel und DemeYer 1992, IMmig 1998) untersucht. Diese Methode erlaubte den Einsatz unterschiedlicher Gasatmosphären in den Inkubationsgefäßen und die Prüfung einer hohen Probenanzahl (216 Proben).

Die Nachteile der Methode liegen in der Tatsache begründet, daß die Einflüsse des Spendertieres und der Pansensaftentnahme direkt in das System übernommen werden. Dadurch können die in der vorliegenden Untersuchung als Tageseffekt bezeichneten Phänomene auftreten, die hier zwar durch die Wahl des statistischen Auswertungsverfahrens berücksichtigt wurden, idealerweise aber so gering wie möglich gehalten werden sollten.

Für die Überprüfung des Einflusses der Gallensalze auf die Pansenfermentation wurde das kontinuierliche in-vitro-System RUSITEC (Pansensimulationstechnik) gewählt (CZERKAWSKI und BRECKENRIDGE 1977). Mit diesem Langzeit-in-vitro-System konnte die Wirkung der Gallensalze auf die mikrobielle Biozönose untersucht werden.

Ein besonders hervorzuhebender Unterschied zur batch-culture ist die im RUSITECSystem berücksichtigte, von CZERKAWSKI (1986) beschriebene Kompartimentierung des Pansens. Danach teilen sich die Lebensräume der Mikroorganismen (MO) im Pansen in 4 Kompartimente:

Kompartiment 1: $\quad \mathrm{MO}$ in der flüssigen Phase.

Kompartiment 2: $\quad \mathrm{MO}$ in der flüssigen Phase in der direkten Umgebung von festem Panseninhalt.

Kompartiment 3: MO, die fest an den Partikeln im Pansen anhaften.

Kompartiment 4: $\mathrm{MO}$, die in der direkten Umgebung der Pansenwand leben.

Das RUSITEC-System beinhaltet die Kompartimente 1, 2 und 3, während das Kompartiment 4 naturgemäß nur am Tier selbst untersucht werden kann. Das Kompartiment 2 entspricht den Mikroorganismen, die sich in der flüssigen Phase innerhalb des Nylonbeutels befinden. Bei den hier vorgestellten kombinierten Untersuchungen aus RUSITEC-System und batch-culture wurde das für die batchculture benötigte Inokulum aus der flüssigen Phase des RUSITEC-Systems (Kompartiment 1 und 2) verwendet. 
Da der ${ }^{13} \mathrm{C}-\mathrm{CO}_{2}$-Marker nur in geringen Mengen $(15 \mathrm{~g})$ zur Verfügung stand, wurde es für den direkten Nachweis der reduktiven Acetogenese beim Einsatz von Gallensalzen notwendig, die RUSITEC-Langzeitinkubation mit der batch-culture zu kombinieren. So wurde nach einer 7 tägigen Entwicklung der Biozönose im RUSITEC pro Inkubationsgefäß $10 \mathrm{ml}$ Inokulum entnommen und mit dem ${ }^{13} \mathrm{C}_{-} \mathrm{CO}_{2}-$ Marker inkubiert.

\subsection{Nachweis der reduktiven Acetogenese mittels ${ }^{13} \mathrm{C}$-NMR}

Die ${ }^{13} \mathrm{C}$-Kernresonanzspektroskopie (NMR) hat in den letzten 25 Jahren für die Untersuchung von metabolischen Umsetzungen aerober und anaerober Organismen an Bedeutung gewonnen. Besonders die noch wenig erforschten Fermentationen, an denen einfache organische Verbindungen beteiligt sind, lassen sich mit Hilfe der ${ }^{13} \mathrm{C}$-NMR ohne präparative Isolierungsschritte analysieren. Darüber hinaus wird die praktische Durchführung von Experimenten mit Kohlenstoffmarkern dadurch erleichtert, daß für die NMR-Analytik keine Radioisotope notwendig sind (GRIVET ET AL. 1992).

Der Nachweis der autotroph-reduktiven Acetogenese kann nur eindeutig erbracht werden, wenn gezeigt werden kann, daß beide Kohlenstoffatome des Acetatmoleküls aus dem ${ }^{13} \mathrm{C}$-markierten Kohlendioxidpool stammen. Eine einfache ${ }^{13} \mathrm{C}$-Markierung des Acetats deutet auf den heterotrophen Entstehungsweg hin, da dabei auch Kohlenstoff aus der organischen Ausgangssubstanz (z.B. Hexose) verbraucht wird (DE GraeVe ET AL. 1994). Die ${ }^{13} \mathrm{C}-\mathrm{NMR}$ konnte eine eindeutige Lokalisierung des markierten Kohlenstoffs innerhalb des Acetatmoleküls liefern und wurde deshalb für die im Rahmen dieser Arbeit vorgenommenen ${ }^{13} \mathrm{C}$-Analysen verwendet.

Vor Beginn der Untersuchungen zum direkten Nachweis der reduktiven Acetogenese durch Pansenmikroorganismen mit Hilfe der ${ }^{13} \mathrm{C}-\mathrm{NMR}$ wurde zunächst eine Bakteriensuspension aus dem Schweinedarm als Positivkontrolle der Nachweismethode untersucht (DE GRAEVE ET AL. 1994).

Die Gewinnung dieser Bakteriensuspension und die Inkubationen erfolgten nach Angaben von DE GRAEVE ET AL. (1994). Um die reduktive Acetogenese nicht durch andere Synthesewege zu überlagern, wurde im Gegensatz zu den Arbeiten von $D E$ GRAEVE ET AL. (1994) auf die Zugabe eines Kohlenhydratsubstrates verzichtet. Die Begasung erfolgte bei zwei Inkubationen mit $80 \%$ Argon und $20 \%{ }^{13} \mathrm{C}_{-} \mathrm{CO}_{2}$ als Kontrollvariante und bei drei Inkubationen mit $80 \%$ Wasserstoff und $20 \%{ }^{13} \mathrm{C}-\mathrm{CO}_{2}$. Die Wasserstoffbegasung sollte die reduktive Acetogenese stimulieren und damit die Möglichkeit bieten, unterschiedliche Mengen an reduktiv gebildetem Acetat zu quantifizieren. Die Anwesenheit von Wasserstoff in der Gasatmosphäre hatte auf die 
Summe der flüchtigen Fettsäuren und speziell auf die Butyratmenge eine signifikant steigernde Wirkung (Abb.14, Anhang6). Die Acetatproduktion stieg zwar um $55 \mu \mathrm{mol}$, dieser Anstieg war jedoch nicht signifikant. Dagegen konnte die wasserstoffbedingte Erhöhung der Methanmenge von 74 auf $192 \mu \mathrm{mol}$ statistisch abgesichert werden. DE GRAEVE ET AL. (1994) fanden bei gleicher Behandlung einen wesentlich deutlicheren Zuwachs der Methanmenge von 111 auf $1180 \mu \mathrm{mol}$. Bei ihren Inkubationen wurden, im Gegensatz zu den vorliegenden Ergebnissen, die Mengen an flüchtigen Fettsäuren durch die Wasserstoffbegasung um ca. $50 \%$ gesenkt. Eine Erklärung für diese Unterschiede könnte das in der eigenen Arbeit fehlende Kohlenhydratsubstrat sein.

Die in Abbildung 15 und Anhang 7 dargestellten Ergebnisse belegen, daß in der vorliegenden Arbeit die reduktive Acetogenese mit der ${ }^{13} \mathrm{C}-\mathrm{NMR}$ qualitativ nachgewiesen werden konnte. Darüber hinaus deutete sich an, daß grundsätzlich auch quantitative Aussagen gemacht werden könnten, die vorhandene Anzahl von Kalibrierungsmessungen jedoch nicht zu einer gesicherten Aussage ausreichten.

\subsection{Einfluß der untersuchten Faktoren auf die Fermentation}

In den folgenden Abschnitten werden die Wirkungen der unabhängigen Faktoren Protozoen, Ration, Nüchterungsdauer, in-vitro-Substrat sowie Substanzen endogenen und mikrobiellen Ursprungs diskutiert. Die Faktoren sind je nach Zuordnung zu den drei Arbeitshypothesen (Übersicht1) in den entsprechenden Kapiteln zusammengefaßt. Die mikrobielle Reaktion wird anhand der Fermentationsparameter SCFA, Methan, Methan/SCFA-Verhältnis und der Wasserstoffwiederfindungsrate charakterisiert. Insofern Untersuchungen mit ${ }^{13} \mathrm{C}$ $\mathrm{CO}_{2}$-Marker vorliegen, finden auch diese Ergebnisse in den entsprechenden Kapiteln Berücksichtigung.

\subsection{1 $\quad$ Protozoen}

Der Einfluß der Protozoen wurde durch Inkubationen mit nicht defauniertem und defauniertem Pansensaft vergleichend untersucht. Protozoen gelten als für das Wirtstier nicht essentiell (HUNGATE 1966). Dennoch wurden in der Vergangenheit viele in-vivo- und in-vitro-Untersuchungen mit defauniertem Panseninhalt durchführt, um durch Vergleich mit nicht defauniertem Panseninhalt die Bedeutung der Protozoen zu untersuchen. Dabei wurden zunächst widersprüchliche Ergebnisse erzielt. LEINMÜLLER und MENKE (1986) begründen diese mit verschiedenen Futterrationen für die jeweils untersuchten Tiere. So kann infolge einer Defaunierung bei einem niedrigen Proteinniveau und hohem Energiegehalt in der Ration eine Steigerung der Tierleistung erzielt werden. Dies wird auf eine effizientere mikrobielle 
Proteinsynthese, eine erhöhte Passagerate und damit gesteigerte Proteinanflutung am Dünndarm erklärt. DEMEYER (1981) stellte infolge einer Defaunierung bei einer protein- und cellulosereichen Ration eine verminderte Wachstumsleistung fest. Als Begründung für diese Ergebnisse wird eine abnehmende Verdaulichkeit der organischen Substanz bei nicht limitierender Proteinzufuhr genannt.

Die Wirkung der Defaunierung zeigte sich in den eigenen Untersuchungen bei allen gemessenen Parametern. In keinem der Ansätze mit defauniertem Pansensaft konnte Methan nachgewiesen werden. Über die Reduzierung der Methanogenese durch Entfernung der Protozoen aus dem Pansen wird in der Literatur übereinstimmend berichtet (EADIE und GILL 1971, WHITELAW ET AL. 1984, MATHIEU ET AL. 1996, Williams und Coleman 1997). Da die Ciliaten zu den bedeutendsten Wasserstoffproduzenten im Pansen gehören (USHIDA ET AL. 1997), kann die Reduzierung des entstehenden Methans bei einer Defaunierung mit der Unterdrückung des Interspezies-Wasserstoff-Transfers (ZINDER 1993; WILLIAMS und COLEMAN 1997; SHARP ET AL. 1998) zwischen Ciliaten und methanogenen Bakterien erklärt werden. Die besonders drastische Hemmung der Methanogenese in den vorliegenden Untersuchungen beruht möglicherweise auf der erst kurz vor der Inkubation erfolgten Defaunierung des Pansensaftes. Dadurch konnte sich die mikrobielle Biozönose in ihrer Populationsgröße und -zusammensetzung nicht an die protozoenfreie Situation anpassen. Solche Anpassungsprozesse wurden von BIRD ET AL. (1979) und USHIDA ET AL. (1997) beschrieben. Zudem vermuten VEIRA ET AL. (1983), daß das auch in den vorliegenden Untersuchungen zur Defaunierung eingesetzte Synperonic weitere, jedoch nicht näher beschriebene Nebenwirkungen auf die Biozönose ausübt. Diese werden in der Literatur jedoch nicht näher beschrieben.

Der Einfluß der Defaunierung auf die SCFA-Summe ging, gemittelt über die Faktoren Ration, Nüchterungsdauer und in-vitro-Substrat, mit einer Senkung um mindestens $50 \%$ gegenüber der nicht defaunierten Variante sehr deutlich zurück. Der Acetatanteil sank infolge der Defaunierung des im Mittel von 51 auf $38 \%$. Dabei traten beim in-vitro-Substrat Blinddarminhalt die geringsten Effekte auf, der Anteil des Acetats fiel dort von 51 auf $47 \%$ der SCFA-Summe. Gleichzeitig stieg infolge der Defaunierung der Propionatanteil im Mittel von $34 \%$ auf $49 \%$ deutlich an. Auch hier war der Einfluß des Blinddarminhaltes als in-vitro-Substrat mit einem Anstieg des Propionatanteils von 29 auf $32 \%$ relativ gering. Diese Verschiebung des SCFAMusters läßt sich durch die nur in Bakterien, nicht aber in Protozoen, stattfindende Propionatsynthese (DEMEYER und VAN NEVEL 1979) erklären. Beim Butyrat zeigten sich mit $15 \%$ in der nicht defaunierten und $12 \%$ in der defaunierten Variante weniger deutliche Unterschiede (Anhang 1 und 2). 
Die Umstellung von der Heu-Kraftfutter- auf die Stroh-Harnstoff-Ration sowie die verlängerte Nüchterungsdauer senkten beim defaunierten Pansensaft die Propionatbildung signifikant. Beiden Faktoränderungen ist die geringer werdende Verfügbarkeit an Nährstoffen gemeinsam, die anscheinend einen limitierenden Einfluß auf die propionatbildenden Organsimen hatte, während die anderen Organismen vermutlich Bestandteile des Inokulums verwerteten. Solche Bestandteile könnten z.B. Reste von abgestorbenen Protozoen sein, die für alle Behandlungen in gleichem Maße zur Verfügung standen.

Betrachtet man die Änderung der SCFA-Summe und deren Zusammensetzung bei den in-vitro-Substraten Heu, Stroh und Blinddarminhalt (Abb. 12; Anhang 2) so sind zwischen diesen Faktorstufen deutliche Unterschiede zu erkennen. Dabei zeigt der Vergleich der in-vitro-Substrate Heu und Stroh eine Senkung der SCFA-Summe von 1130 auf $378 \mu \mathrm{mol}$. Das SCFA-Muster blieb dabei nahezu unverändert. Diese Senkung der Fermentationsintensität läßt sich durch den geringeren Nährstoffgehalt und die schlechtere Verfügbarkeit der Nährstoffe im in-vitro-Substrat Stroh erklären. Das Niveau der SCFA-Summe beim in-vitro-Substrat Blinddarminhalt lag mit $561 \mu \mathrm{mol}$ zwischen denen der in-vitro-Substrate Heu und Stroh. Die Zusammensetzung hat sich mit $47 \%$ Acetat, 32\% Propionat und $21 \%$ Butyrat gegenüber den anderen in-vitro-Substraten zugunsten des Acetats verschoben. Dieser Effekt des Blinddarminhaltes liegt vermutlich in dessen Inhaltsstoffen begründet, von denen einige eventuell als Wasserstoffsenken fungieren können. Hierauf wird in dem Kapitel Einfluß von Substanzen endogenen und mikrobiellen Ursprungs ausführlicher eingegangen.

Die in Tabelle 11 wiedergegebenen Ergebnisse, aufgetrennt nach Ration und Nüchterungsdauer, zeigen, daß durch die verlängerte Nüchterungsdauer in der Stroh-Harnstoff-Ration alle Parameter, das Butyrat ausgenommen, signifikant gesenkt wurden. Bei der Heu-Kraftfutter-Ration konnten, mit Ausnahme des Propionats, keine signifikanten Wirkungen der Nüchterungsdauer festgestellt werden. Dieses Ergebnis unterstützt die These, daß die Propionatbildner eher auf die veränderten Bedingungen reagieren und somit vielleicht stärker von dem zur Verfügung stehenden Substrat abhängig sind als die Butyrat- und Acetatbildner. Außerdem scheint die Stroh-Harnstoff-Ration für die Mikroorganismen bei einer längeren Nüchterungsdauer nicht genügend Stickstoffreserven zur Verfügung zu stellen.

Die Kombination der Faktoren Ration und in-vitro-Substrat, wie sie in Tabelle 12 wiedergegeben ist, unterstreicht wiederum den Effekt des in-vitro-Substrates Blinddarminhalt als acetatförderndes und propionathemmendes Substrat. Diese Beobachtung bestätigt sich auch in Tabelle 13, in der die Faktoren 
Nüchterungsdauer und in-vitro-Substrat wiedergeben sind. Die weiter oben gemachte Aussage, daß hier vermutlich endogene Substanzen des Blinddarminhalts auf die SCFA-Zusammensetzung einwirkten, wird dadurch noch einmal bestätigt. Die Ursache für den mit Blinddarminhalt als in-vitro-Substrat im nährstoffärmeren Habitat (Stroh-Harnstoff-Ration, 24 Stunden Nüchterungsdauer) sinkenden Propionat- und steigenden Acetatanteil konnte nicht geklärt werden.

Das in-vitro-Substrat Stroh führt bei allen nach in-vitro-Substrat aufgegliederten Betrachtungen zu den niedrigsten SCFA-Mengen, wobei das in-vitro-Substrat $\mathrm{Heu}$ offensichtlich am meisten fermentierbare Nährstoffe enthält (Tab. 12). Vergleicht man die Reihenfolge in der entstandenen SCFA-Summe von Heu mit der größten SCFAMenge über Blinddarminhalt zu Stroh mit den Ergebnissen der Inkubationen mit nicht defauniertem Pansensaft, fällt auf, daß hier die Reihenfolge zwischen Stroh und Blinddarminhalt vertauscht ist. Ein Erklärungsansatz für dieses Phänomen könnte sein, daß der Blinddarminhalt für die im defaunierten Habitat veränderte Mikrobenpopulation essentielle Nährstoffe liefert, die das Stroh als in-vitro-Substrat nicht enthält.

Für die Beurteilung der Versuchsergebnisse, ob reduktive Acetogenese stattgefunden hat, wurde auch die Rate der Wasserstoffwiederfindung herangezogen. Dabei wurden im Vergleich zu den Untersuchungen mit nicht defauniertem Pansensaft signifikant niedrigere Wasserstoffwiederfindungsraten in den Varianten Heu-Kraftfutter-Ration, 24 Stunden Nüchterungsdauer und in-vitroSubstrat Blinddarminhalt sowie Stroh-Harnstoff-Ration, 24 Stunden Nüchterungsdauer, in-vitro-Substrat Heu bzw. Blinddarminhalt gefunden (Abb.13, Anhang 5). Diese Ergebnisse bestätigen die Bedeutung des in-vitro-Substrates Blinddarminhalt in seiner potentiellen Wirkung auf die reduktive Acetogenese. Außerdem scheint die Nüchterungsdauer besonders in Verbindung mit der StrohHarnstoff-Ration einen Einfluß auf diesen Faktor zu haben.

Aufgrund der absoluten Hemmung der Methanbildung durch die Defaunierung wurde der Faktor Protozoen in Versuchsstufe 2 mit ${ }^{13} \mathrm{C}-\mathrm{CO}_{2}$-Marker auf das Vorkommen von reduktiver Acetogenese untersucht. Die Ergebnisse dieser Inkubationen sind in Abbildung 16 und Anhang 8 wiedergegeben. Hier fällt das gegenüber den Ergebnissen aus Versuchsstufe 1 insgesamt sehr viel geringere Niveau der SCFASumme sowie die sehr viel geringere Wirkung der Defaunierung auf. Ein Grund für das niedrigere SCFA-Niveau könnte der durch die Wasserstoffbegasung $(80 \%$ Wasserstoff, $20 \%$ Argon in der Gasatmosphäre) sehr hohe Wasserstoffpartialdruck mit einer negativen Rückkopplung auf die Fermentation (WOLIN ET AL. 1997) sein. Weiterhin geht aus Abbildung 16 hervor, daß bei diesen Inkubationen im Gegensatz zu den Inkubationen in Versuchsstufe 1, Methan entstanden ist. Auch dies könnte mit 
dem hohen Wasserstoffpartialdruck erklärt werden. Dennoch ist die Wirkung der Defaunierung auf die Methanogenese mit einer Senkung um $64 \%$ gegenüber der nicht defaunierten Variante eindeutig.

Die Untersuchungen der Fermentationsprodukte auf doppeltmarkiertes Acetat erbrachten bei keiner der drei Inkubationen ein positives Ergebnis. Demzufolge wurde die reduktive Acetogenese mit der Defaunierung nicht initiiert.

Zusammenfassend kann gesagt werden, daß durch die Defaunierung in Versuchsstufe 1 die Methanogenese vollständig unterbunden wurde. Die sich in Versuchsstufe 2 anschließende Untersuchung der Fermentationsprodukte auf doppeltmarkiertes Acetat erbrachte keine Hinweise auf das Vorkommen von reduktiver Acetogenese. Hieraus läßt sich schließen, daß die Protozoen nicht ausschlaggebend für diesen Stoffwechselweg sind.

\subsubsection{Verfügbarkeit von Kohlenhydraten}

Der Einfluß der Verfügbarkeit von Kohlenhydraten wurde unter besonderer Berücksichtigung durch die drei Faktoren Ration sowie Nüchterungsdauer des Spendertieres und in-vitro-Substrat überprüft. Als Ration des Spendertieres diente einerseits die Heu-Kraftfutter-, andererseits die Stroh-Harnstoff-Ration. Die Umstellung der Fütterung mindestens eine Woche vor der Inkubation berücksichtigte mögliche Anpassungsprozesse der mikrobiellen Biozönose im Pansen an diese kohlenhydratarme Versorgung. Der Faktor Nüchterungsdauer wurde in den Stufen 16 bzw. 24 Stunden variiert. Dabei sollten durch die längere Nüchterungsdauer Veränderungen der mikrobiellen Population während der Nüchterungszeit erfaßt werden (LeEDLE und GREENING 1988, DeHORITY und ORPIN 1997). Durch die Verwendung der drei in-vitro-Substrate $\mathrm{Heu}$, Stroh und Blinddarminhalt sollten ebenfalls unterschiedliche Niveaus der Kohlenhydratversorgung im Pansen simuliert werden. Die Ergebnisse aus den Untersuchungen mit Blinddarminhalt werden vorrangig im folgenden Kapitel 5.5.3 zum Einfluß von Substanzen endogenen und mikrobiellen Ursprungs diskutiert.

Die Ration des Spendertieres hatte, gemittelt über Nüchterungsdauer und in-vitroSubstrat, auf alle gemessenen Parameter einen signifikanten Einfluß. Dabei verringerte sich mit dem Wechsel von der Heu-Kraftfutter-Ration auf die StrohHarnstoff-Ration die Summe der entstandenen SCFA von $2010 \mu \mathrm{mol}$ um knapp ein Drittel auf $1378 \mu \mathrm{mol}$ (Abb. 7 und Anhang 1). Diese Senkung läßt sich vermutlich durch zwei Faktoren erklären. Zum einen ist davon auszugehen, daß der Gehalt an im Inokulum befindlichen verfügbaren Kohlenhydraten bei der Heu-Kraftfutter-Ration höher ist als bei der Stroh-Harnstoff-Ration und zum anderen ist wahrscheinlich auch 
die Dichte der aktiven Mikroorganismen im Inokulum bei der Heu-Kraftfutter-Ration größer (FAICHNEY ET AL. 1997). Der Gehalt an verfügbaren Kohlenhydraten sowie die im Inokulum befindliche Mikrobenmasse wurden im Rahmen dieser Untersuchungen jedoch nicht bestimmt. Der Einfluß der Ration auf die Mikrobenzusammensetzung im Inokulum und deren Auswirkung wurde von GEIBLER (1995) untersucht. Dabei wurde ein sinkendes cellulolytisches Spaltungsvermögen der Pansenflora bei Fütterung von minderwertigem Heu im Vergleich zu Heu besserer Qualität festgestellt. Die hier vorgestellten Daten bestätigen die Ergebnisse von GEIBLER (1995), wenn der Effekt der Stroh-Harnstoff-Ration mit der Wirkung von minderwertigem Heu als vergleichbar angesehen wird. FAICHNEY ET AL. (1997) untersuchten die Fütterung von Schafen mit und ohne Konzentratzulage. Dabei wurde festgestellt, daß bei der Ration mit Konzentrat mehr stärkeverbrauchende Mikroorganismen aus den Kompartimenten 1 und 2 sowie bei einer reinen Heuration vor allem "transit"-Mikroorganismen aus dem Kompartiment 3 in der flüssigen Phase des Pansensaftes anzutreffen sind. Für die vorliegende Untersuchung könnte dies bedeuten, daß durch die Entnahme von nur flüssigem Panseninhalt bei der Heu-Kraftfutter-Ration vermehrt stärkeverbrauchende Mikroorganismen und bei der Stroh-Harnstoff-Ration vermehrt "transit"Mikroorganismen entnommen wurden.

Für die weitere Beurteilung der Ergebnisse ist die Zusammensetzung der SCFASumme von Bedeutung. Die prozentualen Anteile von Acetat, Propionat und Butyrat an der SCFA-Summe beliefen sich bei der Heu-Kraftfutter-Ration auf 52, 34 bzw. $15 \%$ und bei der Stroh-Harnstoff-Ration auf 52, 36 bzw. $12 \%$ (Abb. 7, Anhang 1). Diese nur geringfügigen Veränderungen in der SCFA-Zusammensetzung deuten darauf hin, daß keine wesentlichen Verschiebungen in der Biozönose stattgefunden haben.

Zudem ist das Methan / SCFA-Verhältnis für die Beurteilung des reduktiv acetogenen Potentials von Bedeutung. Hier ist bei der Umstellung von der Heu-Kraftfutter- auf die Stroh-Harnstoff-Ration eine signifikante Senkung dieses Verhältnisses von 0,16 auf 0,13 festzustellen (Anhang 1). In der Literatur wird im allgemeinen davon ausgegangen, daß die pro fermentierter organischer Substanz entstehenden Methanmengen mit abnehmender Verdaulichkeit des Substrates steigen (McAllister et Al. 1996, van KesSel und Russel 1996). Moss et AL. (1994 a) wiesen dagegen bei niedrigem Fütterungsniveau mit einem abnehmenden Konzentratanteil in der Ration sinkende Methanmengen pro scheinbar verdauter organischer Substanz nach. Eine mögliche Ursache für diesen Effekt wird von Moss ET AL. (1994 a) nicht genannt. Auch KURIHARA ET AL. (1997) berichten von Untersuchungen an Ziegen, die auf dem Energieniveau des Erhaltungsbedarfs gefüttert wurden und keine veränderte Methanproduktion bei unterschiedlichen 
Konzentratanteilen in der Ration zeigten. Da das pansensaftspendende Tier in den eigenen Untersuchungen ebenfalls auf dem Niveau des Erhaltungsbedarfs gefüttert wurde, würden die Ergebnisse von MOSS ET AL. (1994 a) und KURIHARA ET AL. (1997) durch die eigenen bestätigt, wenn man davon ausgeht, daß die Summe der SCFA ein Parameter für die fermentierte organische Substanz ist.

Der zweite Faktor, der hier unter Verfügbarkeit der Kohlenhydrate zusammengefaßt wird, ist die Nüchterungsdauer des Spendertieres. Die in Abbildung 8 und Anhang 1 wiedergegebenen Daten zeigen, daß, abgesehen vom Butyrat, alle gemessenen Parameter infolge der verlängerten Nüchterungsdauer vor der Pansensaftentnahme signifikant gesenkt wurden. Die Abnahme der SCFA-Summe könnte durch eine nach 24 Stunden Nüchterungsdauer verminderte Bakterienpopulation erklärt werden (DEHORITY und ORPIN 1997). Außerdem kann davon ausgegangen werden, daß durch die um 8 Stunden verlängerte Nüchterungsdauer die im Inokulum enthaltene Menge an fermentierbaren Nährstoffen vermindert wurde. Wie GEIBLER (1995) feststellte, werden in den letzten 8 Stunden einer insgesamt 24 stündigen Fermentationsphase $38 \%$ der insgesamt entstandenen SCFA gebildet.

Die prozentualen Anteile der einzelnen Fettsäuren an den SCFA-Summe blieben in den vorliegenden Untersuchungen in Abhängigkeit von der Nüchterungsdauer nahezu unverändert (Anhang 1). Dagegen sank die Methanmenge von 271 auf $214 \mu \mathrm{mol}$ und bewirkte damit ein von 0,15 auf 0,13 signifikant verringertes Methan/SCFA-Verhältnis. Dieses Ergebnis deutet darauf hin, daß nach der längeren Nüchterungsdauer weniger Methan freigesetzt wurde, da auf dem Niveau des Erhaltungsbedarfs gefüttert wurde (MOSS ET AL. 1994 a, KURIHARA ET AL. 1997). Die Senkung der SCFA-Summe durch die verlängerte Nüchterungsdauer lag mit $10,5 \%$ im Vergleich zur Rationsumstellung (31\%) wesentlich niedriger (Anhang 1).

Die in-vitro-Substrate Heu und Stroh beeinflußten sowohl die SCFA-Summe als auch die Methanmenge signifikant (Abb. 9 und Anhang 1). Die Verminderung der SCFASumme von 2722 auf $1683 \mu \mathrm{mol}$ im Vergleich der in-vitro-Substrate Heu und Stroh war sehr viel deutlicher als bei Umstellung von der Heu-Kraftfutter- auf die StrohHarnstoff-Ration. Die Zusammensetzung der SCFA-Summe wurde durch die in-vitroSubstrate Heu und Stroh allerdings nicht wesentlich beeinflußt. Die absolute Methanmenge wurde beim Vergleich der in-vitro-Substrate Heu und Stroh um $40 \%$ gesenkt, trug damit aber nicht signifikant zu einer Änderung des Methan/SCFAVerhältnisses bei. Im Vergleich zum in-vitro-Substrat Heu reduzierte somit das invitro-Substrat Stroh mit seinem relativ hohen Anteil schwer löslicher Kohlenhydrate die mikrobiellen Umsetzungsprozesse erheblich. Die verminderte Fermentation führte jedoch innerhalb der 24 stündigen Inkubationsdauer nicht zu Verschiebungen innerhalb der mikrobiellen Populationen. 
Die in Tabelle 8 wiedergegebenen Einflüsse der Kombination Ration und Nüchterungsdauer zeigen, daß die Nüchterungsdauer bei der Heu-Kraftfutter-Ration keinen Einfluß auf die Menge und Zusammensetzung der SCFA hatte. Dieses Ergebnis deutet darauf hin, daß eine um 8 Stunden verlängerte Nüchterungsdauer bei der Fütterung einer Ration mit leichter verfügbaren Nährstoffen nicht ausreicht, um die Menge der im Inokulum mitgelieferten Nährstoffe entscheidend zu verringern bzw. die mikrobielle Zusammensetzung des Inokulums deutlich zu verändern. Eine Ausnahme könnten die methanogenen Organismen sein, da durch die verlängerte Nüchterungsdauer eine von 306 auf $340 \mu \mathrm{mol}$ signifikant erhöhte Methanmenge festgestellt wurde. Betrachtet man jedoch das Methan/ SCFA-Verhältnis, sind hier keine signifikanten Unterschiede festzustellen. Damit erscheint insgesamt die verlängerte Nüchterungsdauer bei der Heu-Kraftfutter-Ration keine bzw. nur eine sehr geringe Wirkung auf die betrachteten Parameter gehabt zu haben.

Demgegenüber wurden bei der Stroh-Harnstoff-Ration alle gemessenen Parameter durch den Übergang zu einer Nüchterungsdauer von 24 Stunden signifikant vermindert. Die SCFA-Zusammensetzung veränderte sich dabei nicht. Infolge der verlängerten Nüchterungsdauer wurde die entstandene Methanmenge allerdings von 238 um mehr als die Hälfte auf $117 \mu$ mol reduziert. Diese drastische Änderung spiegelte sich auch in dem von 0,15 auf 0,10 signifikant gesenkten Methan/ SCFAVerhältnis wieder.

Diese Ergebnisse belegen die Wechselwirkungen zwischen Ration und Nüchterungsdauer. Als Ursache für diesen Effekt wird vermutet, daß die Aktivität der mikrobiellen Biomasse durch die geringere Nährstoffverfügbarkeit aus der StrohHarnstoff-Ration stark eingeschränkt wurde und mit der zusätzlichen Nüchterungsdauer die Verfügbarkeit von Nährstoffen aus dem Inokulum noch einmal limitiert wurde. Die ebenfalls signifikant verminderte Methanogenese könnte mit einer verringerten Population an methanogenen Bakterien (LEEDLE und GREENING 1988) im Inokulum zusammenhängen.

Die kombinierte Wirkung von Ration des Spendertieres und in-vitro-Substrat sind in Tabelle 9 wiedergegeben. Der Einsatz des in-vitro-Substrates Stroh führte gegenüber dem in-vitro-Substrat $\mathrm{Heu}$ zu einem signifikanten Rückgang der produzierten SCFA-Summe von 3062 auf $1982 \mu \mathrm{mol}$. Auch die einzelnen Fettsäuren nahmen annähernd proportional zur SCFA-Summe ab, so daß man nicht von einer grundlegenden Verschiebung des Fettsäuremusters sprechen kann. Dagegen war der Rückgang der entstandenen Methanmenge mit über $45 \%$ überproportional stärker als die Reduzierung der SCFA-Summe (35\%). Dieser Unterschied spiegelt sich auch in einem höheren Methan/SCFA-Verhältnis wieder, konnte statistisch aber nicht abgesichert werden. Damit scheint das weniger leicht verfügbare in-vitro- 
Substrat Stroh zu einer allgemeinen Senkung der mikrobiellen Aktivität zu führen, ohne dabei jedoch deutliche Verschiebungen der Zusammensetzung der mikrobiellen Biozönose im Pansen hervorzurufen.

Bei der Stroh-Harnstoff-Ration zeigte sich durch die Änderung des in-vitro-Substrates von Heu auf Stroh eine Senkung der SCFA-Summe um $42 \%$, wobei auch hier keine grundlegende Änderung des Fettsäuremusters zu erkennen war. Die Wirkung der in-vitro-Substrate zeigte sich bei der Methanmenge mit einem Rückgang um $34 \%$ beim Übergang von Heu auf Stroh. Im Methan/SCFA-Verhältnis war dieser Rückgang jedoch nicht signifikant. Zwischen den Faktoren Ration und in-vitroSubstrat traten damit keine für die Versuchsfrage relevanten Wechselwirkungen auf.

Die Nüchterungsdauer des Spendertieres hatte eine sehr viel geringere Wirkung auf die Fermentationsparameter als die Ration. Dies zeigte sich am deutlichsten darin, daß die SCFA-Summen für das in-vitro-Substrat Heu bei veränderter Nüchterungsdauer nicht signifikant voneinander abwichen (Tab.10). Bei der kürzeren Nüchterungsdauer ging die SCFA-Summe mit dem Wechsel des in-vitro-Substrates von Heu zu Stroh um $1008 \mu \mathrm{mol}$ (36\%) zurück, ohne daß sich dabei das SCFAMuster um mehr als $1 \%$ änderte. Die Methanmenge ging mit $40 \%$ von 506 auf $304 \mu \mathrm{mol}$ zurück, wodurch sich das Methan/SCFA-Verhältnis jedoch nicht signifikant änderte. Wie schon weiter oben bei dem Einfluß der Faktoren Ration und in-vitro-Substrat abgeleitet, kann diese Änderung durch die geringere Verfügbarkeit der Nährstoffe aus dem in-vitro-Substrat Stroh erklärt werden.

Bei einer um 8 Stunden verlängerten Nüchterungsdauer nahm die SCFA-Summe nach dem Übergang vom in-vitro-Substrat Heu zu Stroh um $41 \%$ ab. Gleichzeitig stieg der Anteil des Acetats um 3 Prozentpunkte auf $53 \%$ an, während der Butyratanteil von 13 auf $11 \%$ abnahm (Tab.10). Die Methanmenge sank von 405 auf $241 \mu \mathrm{mol}$, wodurch sich das Methan / SCFA-Verhältnis jedoch nicht änderte. Daher kann auch hier davon ausgegangen werden, daß die aufgetretenen Verschiebungen durch die veränderte Verfügbarkeit der Nährstoffe verursacht wurden. Diese Ergebnisse belegen, daß zwischen den Faktoren Nüchterung und in-vitro-Substrat keine signifikanten Wechselwirkungen aufgetreten sind.

Für die Beurteilung, ob eine Faktorstufe bzw. eine Kombination verschiedener Faktorstufen für die weitere Untersuchungen mit der ${ }^{13} \mathrm{C}-\mathrm{NMR}$ in Frage kamen, waren die Reduzierung der Methanmenge, das Methan/ SCFA-Verhältnis und die Rate der Wasserstoffwiederfindung ausschlaggebend. Die Reduzierung der absoluten Methanmenge sowie das Methan/SCFA-Verhältnis war in keiner der betrachteten Kombinationen besonders gravierend. Auch die 
Wasserstoffwiederfindung (Abb. 13) war in keiner der Faktorkombinationen so stark abgesenkt, daß sich auf eine Initiierung der reduktiven Acetogenese schließen ließe.

Zusammenfassend ist hinsichtlich der Kohlenhydratverfügbarkeit festzuhalten, daß auch ein vermindertes Angebot leicht abbaubarer Kohlenhydrate die reduktive Acetogenese bei Pansenmikroorganismen nicht zu initiieren vermag.

\subsubsection{Substanzen endogenen und mikrobiellen Ursprungs}

Der Einfluß von Substanzen endogenen und mikrobiellen Ursprungs wurde durch den Einsatz des in-vitro-Substrates Blinddarminhalt untersucht. Dabei wurde davon ausgegangen, daß dieses zuvor autoklavierte in-vitro-Substrat keine lebenden Bakterien oder aktive Enzyme, aber Substanzen endogenen und mikrobiellen Ursprungs aus dem Blinddarm des Schweins enthielt. In Versuchsstufe 2 wurde zusätzlich die Wirkung von Gallensalzen in einem kombinierten RUSITEC - batchculture-Versuch überprüft. Im folgenden werden zunächst die Ergebnisse aus den Inkubationen mit Blinddarminhalt und anschließend diejenigen der Inkubationen mit Gallensalz diskutiert. Da die Inkubationen mit defauniertem Pansensaft eine entscheidende Änderung der Fermentationsprozesse zur Folge hatten, sind die Wirkungen des in-vitro-Substrates Blinddarminhalt im defaunierten Habitat im Kapitel Protozoen diskutiert worden.

Bei allen Inkubationen mit Blinddarminahlt als in-vitro-Substrat trat gegenüber den entsprechenden Inkubationen des in-vitro-Substrates Heu eine signifikante Senkung der SCFA-Summe auf (Abb. 9, Tabelle 9 und 10, Anhang 2). Im Vergleich der Rationen beliefen sich die SCFA-Summen auf 1208 (Heu-Kraftfutter) bzw. $625 \mu \mathrm{mol}$ (Stroh-Harnstoff) und lagen damit um 61 bzw. $74 \%$ unter den entsprechenden Inkubationen des in-vitro-Substrates Heu (Tab.9). Die prozentualen Anteile des Acetats variierten dabei zwischen 50 und $54 \%$, die des Propionats zwischen 31 und $26 \%$, während die des Butyrats konstant blieben. Auch der Faktor Nüchterungsdauer beeinflußte die SCFA-Zusammensetzung nur geringfügig (Tab. 10).

Die niedrigen Werte der gemessenen Parameter, die in allen Faktorkombinationen signifikant größer waren als in den vergleichbaren Inkubationen mit der StrohHarnstoff-Ration, können nicht allein durch den geringeren Anteil an leicht löslichen Kohlenhydraten in diesem Substrat erklärt werden. Geht man davon aus, daß leicht verfügbare Kohlenhydrate bei den in-vitro-Substraten Stroh und Blinddarminhalt in gleichen Anteilen in der Fraktion organischer Rest enthalten war, sind hier mit $12 \%$ der TS beim Stroh und $11 \%$ beim Blinddarminhalt keine wesentlichen Unterschiede zu erkennen (Tab. 2). 
Im Vergleich der in-vitro-Substrate sind beim Blinddarminhalt bemerkenswerte Unterschiede in den Fraktionen Cellulose, Rohprotein, Asche und Rohfett festzustellen. Der Anteil der Cellulose lag mit $16 \%$ der TS um nahezu die Hälfte niedriger als bei dem verwendeten Heu (31\% der TS). Bei einer angenommenen Verdaulichkeit der Cellulose von $50 \%$, würde diese weniger zur Verfügung stehende verdauliche Cellulose einer Menge von $33 \mathrm{mg}$ entsprechen und damit nicht die drastische Senkung der SCFA-Summe erklären können.

Auch der im in-vitro-Substrat Blinddarminhalt enthaltene hohe Rohproteinanteil bewirkt in der mikrobiellen ruminalen Fermentation vermutlich keine deutliche Senkung der SCFA-Produktion. Der Abbau der Rohproteinfraktion führt im Pansen zur Bildung von Aminosäuren und Ammonium, die von den Mikroorganismen zur Proteinsynthese verwendet werden können. Überschüsse von nicht abgebautem Protein fließen unter in-vivo-Bedingungen in den Psalter ab, von den Mikroben nicht verwendete Aminosäuren und Ammonium werden postruminal resorbiert (GÜRTLER 1989). In der batch-culture ist zwar keine Abgabe bzw. Absorption möglich, da aber auch in-vivo starke rationsbedingte Variationen der Ammoniumgehalte auftreten können (GÜRTLER 1989), wird hier davon ausgegangen, daß der vergleichsweise hohe Proteingehalt keine wesentlichen Auswirkungen auf die untersuchten Parameter hatte.

Die Aschefraktion besteht aus Mengen- und Spurenelementen sowie Sand und Ton (KIRCHGESSNER 1987). Es wird angenommen, daß auch der hohe Aschegehalt im invitro-Substrat Blinddarminhalt nicht zu den vorliegenden Effekten geführt hat.

Eine weitere auffallende Eigenschaft des in-vitro-Substrates Blinddarminhalt ist der mit 6,95 \% der TS vergleichsweise hohe Rohfettgehalt. Die Wirkung von Fetten als Bestandteil von Wiederkäuerrationen wird seit vielen Jahren in der Literatur intensiv diskutiert (CZerkaWSKI et AL. 1966, PalmQuist und Jenkins 1980, Coenen 1988, BRINKMANN 1991, ImMIg 1990, JouANY 1994, VAN NeVEL und DemeYER 1996, Dong ET AL. 1997, MACHMÜLLER ET AL. 1998).

Für die hier zu beantwortende Fragestellung ist zunächst die antimikrobielle Wirkung der Fette von Interesse. Bei allen Faktorkombinationen mit dem in-vitro-Substrat Blinddarminhalt wurden ähnliche SCFA-Muster (Acetat $50 \%$, Propionat $30 \%$ und Butyrat $20 \%$ ) festgestellt. Verglichen mit den Inkubationen der in-vitro-Substrate Heu und Stroh fällt auf, daß in den Inkubationen mit Blinddarminhalt als in-vitro-Substrat der Propionatanteil niedriger und der Butyratanteil höher war. Dagegen gab es in den Acetatanteilen keine wesentlichen Unterschiede zwischen den drei in-vitroSubstraten. Für das Methan/SCFA-Verhältnis wurden beim in-vitro-Substrat Blinddarminhalt immer signifikant niedrigere Werte gefunden als bei Heu und Stroh. 
Beim Blinddarminhalt traten zudem signifikante Wechselwirkungen auf, da sowohl bei der Ration als auch bei der Nüchterungsdauer das jeweils nährstoffärmere Habitat zu einem signifikant niedrigeren Methan / SCFA-Verhältnis führte (Tab. 9 und 10).

Die Wirkung von Fetten auf das SCFA-Muster wird von NAGARAJA ET AL. (1997) mit einer Senkung des Acetatanteils bei gleichzeitiger Erhöhung des Propionatanteils an der SCFA-Summe beschrieben. Diese Beobachtung konnte in der vorliegenden Untersuchung nicht gemacht werden. Auch die von einigen Autoren beschriebene Abnahme des Butyrats (DemeYer et AL. 1969, HatCH ET AL. 1972, Jenkins 1987) wurde hier nicht bestätigt. Damit scheint der Fettanteil in der Ration nicht für eine Verschiebung der SCFA bildenden Populationen verantwortlich gewesen zu sein.

NAGARAJA ET AL. (1997) beschreiben als weitere Wirkungen einer fettreichen Fütterung die Defaunierung des Habitats sowie die Toxizität einiger Fette für methanogene Bakterien. Die mit diesen beiden Effekten einhergehende Unterdrückung der Methanogenese führt in der Regel zu einer Wasserstoffanreicherung im Habitat und damit zu einer erhöhten Propionatbildung (JOUANY 1994). Da in keiner der Inkubationen mit Blinddarminhalt als in-vitro-Substrat eine gesteigerte Propionatbildung auftrat, wird vermutet, daß mit dem Einsatz des in-vitroSubstrates Blinddarminhalt keine direkte Hemmung der Methanogenese einherging.

Eine Erklärung für die sehr deutliche Hemmung der Methanbildung beim Einsatz des Blinddarminhalts könnte die Existenz eines mit diesem in-vitro-Substrat eingebrachten Wasserstoffakzeptors sein. Dabei könnte es sich um ungesättigte Fettsäuren handeln, die durch Biohydrogenierung (HARFOOT und HAZLEWOOD 1997) den entstehenden Wasserstoff aufnehmen. Die Frage, ob dies in den vorliegenden Untersuchungen der Fall ist oder andere Inhaltsstoffe des in-vitro-Substrates Blinddarminhalt mögliche Wasserstoffsenken darstellen, wurde im Rahmen der vorliegenden Untersuchungen nicht untersucht.

Aufgrund seiner in allen Faktorkombinationen gegenüber den anderen in-vitroSubstraten eindeutig senkenden Wirkung auf die Wasserstoffwiederfindung (Abb. 13) sowie der ebenso deutlichen Wirkung auf das Methan/ SCFA-Verhältnis, wurde das in-vitro-Substrat Blinddarminhalt mit in den Versuchsplan für die Versuchsstufe 2 aufgenommen.

Die bei den Inkubationen mit ${ }^{13} \mathrm{C}-\mathrm{CO}_{2}$-Marker und Wasserstoffbegasung gemessenen Konzentrationen an SCFA und Methan sind in Abbildung 16 dargestellt. Das in-vitro-Substrat Blinddarminhalt führte gegenüber der Inkubation mit dem in-vitro-Substrat Heu zu einer insgesamt niedrigeren SCFA-Produktion und zu niedrigeren Acetat- und Propionatanteilen sowie höheren Butyratanteilen. Die im 
Vergleich zur Versuchsstufe 1 (Anhang 3 und 8) lassen sich mit der Wasserstoffbegasung in Versuchsstufe 2 erklären. Die in Versuchsstufe 2 sehr viel höhere Methanproduktion belegt, daß der Blilnddarminhalt keine toxische Wirkung auf die methanogenen Organismen hat.

Die Analyse auf doppelt ${ }^{13} \mathrm{C}$-markiertes Acetat erbrachte bei keiner der in Abbildung 16 dargestellten Inkubationen ein positives Ergebnis. Deshalb wird davon ausgegangen, daß keine der im Blinddarminhalt enthaltenen Substanzen endogenen und mikrobiellen Ursprungs zur Initiierung der reduktiven Acetogenese geführt hat.

Als zusätzlicher Faktor wurde in der Versuchsstufe 2 die Wirkung von Gallensalzen auf inr Potential zur Induzierung der reduktiven Acetogenese untersucht. FLORIN und Woods (1995) wiesen in in-vitro-Untersuchungen mit menschlichen Faeces eine gallensalzinduzierte Hemmung der Methanogenese von bis zu $56 \%$ nach. In batchculture-Untersuchungen mit Pansensaft beobachtete IMMIG (1998) durch den Zusatz von $0,5,1,1,5$ und $2 \%(v / v)$ Galle vom Schwein eine Senkung der Methanproduktion von bis zu $80 \%$. Dabei trat eine signifikante Senkung der Methanogenese erst ab einer Konzentration von $1 \%$ Gallensalz in der Fermentationsflüssigkeit auf. Auch die Wasserstoffwiederfindungsrate war in diesen Untersuchungen nur bei der $1 \%$ igen Gallensalzkonzentration signifikant gesenkt. Gleichzeitig wurde in allen Inkubationen mit Gallensalzen die Acetatmenge drastisch vermindert. In einer weiteren Untersuchung wurde der gesamte Wasserstoff aus der Gasatmosphäre, unabhängig von der Gallensalzkonzentration, in Methan umgewandelt. Aus diesen Ergebnissen schloß IMMIG (1998), daß bei Zusatz von Gallensalzen keine reduktive Acetogenese stattgefunden hat.

Gallensalze werden kontinuierlich in der Leber synthetisiert, in der Gallenblase gespeichert und dann schubweise in den Dünndarm abgegeben (GüRTLER 1989). Dort sind sie aufgrund ihrer sowohl hydrophilen als auch hydrophoben Molekülteile entscheidend an der Mizellenbildung beteiligt (YOUNG ET AL. 1996). Die polaren und unpolaren Eigenschaften sowie die schlechte Wasserlöslichkeit der Gallensalzmoleküle ähneln sehr den physikalischen Eigenschaften der langkettigen Fettsäuren. Der Effekt von langkettigen freien Fettsäuren auf die Pansenfermentation zeigt sich vor allem in der Toxizität für methanogene und Gram-positive Bakterien sowie Protozoen. Dadurch wird die Methanogenese und die cellulolytische Aktivität der Pansenfermentation deutlich gesenkt. Diese Veränderungen zeigen sich in einer verringerten Acetat-, Butyrat- und Methanproduktion sowie in einem gesteigerten Propionatanteil an der SCFA-Summe (NAGARAJA ET AL. 1997, IMMIG 1998). Daraus kann gefolgert werden, daß Gallensalz zwar nicht die reduktive Acetogenese initiieren, aber im Dickdarm ein die Methanogenese hemmender Faktor ist. 
In der eigenen Untersuchung begannen die Gallensalzinfusionen am vierten Tag des RUSITEC-Verfahrens und zeigten zuerst eine deutliche Wirkung auf die Protozoenzahl, die bei den beiden mit Gallensalz behandelten Fermentern bereits am ersten Infusionstag von rund 17000 auf 6500 Protozoen/ml (Abb. 18, Anhang 10) zurückging. Am 6. Tag des RUSITEC-Ansatzes waren dann in den beiden behandelten Fermentern keine Protozoen mehr nachzuweisen. Auch die Methanogenese ging an diesen Tagen erkennbar zurück (Abb. 17 und Anhang 11).

Die Effekte des aus dem RUSITEC-System entnommenen Inokulums in der batchculture sind in Abbildung 20 aufgezeigt. Die in der Kontrolle sehr hohe Methankonzentration kann durch den Wasserstoffanteil von $80 \%$ in der Gasatmosphäre erklärt werden. In den beiden mit Gallensalz behandelten Inkubationen wurden bei gleicher Wasserstoffkonzentration nur noch $73(0,4 \%$ Gallensalz) und $26 \mu \mathrm{mol}$ Methan $(0,6 \%$ Gallensalz) gemessen. Dieses Ergebnis unterstützt die These, daß die methanogenen Organismen durch die Wirkung der Gallensalze gehemmt wurden. Auch die SCFA-Summe wurde durch die Gallensalzbehandlung gesenkt. Das SCFA-Muster war bei den batch-cultureInkubationen im Gegensatz zu der Inkubation im RUSITEC-System deutlich verändert. Auffallend war der mit der Gallensalzinfusion von 27 (Kontrolle) über 38 $(0,4 \%$ Gallensalz) auf $54 \%$ (0,6 \% Gallensalz) angestiegene Butyratanteil. Während der Propionatanteil mit 23 und $24 \%$ gleich blieb, fiel der Acetatanteil an der SCFASumme von $50 \%$ bei der Kontrolle auf $39 \%$ bei $0,4 \%$ Gallensalz und $22 \%$ bei 0,6\% Gallensalz ab (Abb.20, Anhang 13). Die durch die Gallensalzinfusion sinkende Acetatmenge in der batch-culture kann durch die protozoeneliminierende Wirkung des Gallensalzes erklärt werden, da Protozoen kein Propionat aber Acetat produzieren (DEMEYER und VAN NEVEL 1979). Für den sehr hohen Anteil an Butyrat konnte keine Erklärung gefunden werden.

Mit Hilfe der ${ }^{13} \mathrm{C}$-NMR-Analyse der Fermentationsflüssigkeit wurde sowohl in der Kontrollinkubation (Abb.21, (C) Probe mit Doppelmarkierung) als auch in einer Inkubation mit 0,4 \% Gallensalz doppeltmarkiertes Acetat nachgewiesen, während in der Inkubation mit 0,6\% Gallensalz kein doppeltmarkiertes Acetat gefunden wurde. Damit wird ausgeschlossen, daß Gallensalz in höherer Konzentration für die Initiierung der reduktiven Acetogenese verantwortlich war.

Dieses Ergebnis legt den Schluß nahe, daß die Inkubation des Pansensaftes in dem Langzeit-in-vitro-System RUSITEC zu einer Förderung des reduktiv acetogenen Potentials führte. Die fördernde Wirkung kann darauf beruht haben, daß aus der flüssigen Phase des RUSITEC-Systems vor allem Mikroben aus den Kompartimenten 1 und 2 entnommen wurden. 
Aus Abbildung 20 geht hervor, daß in beiden Inkubationen, bei denen die reduktive Acetogenese nachgewiesen wurde, gleichzeitig auch Methan gebildet wurde. Dieses Ergebnis entspricht nicht unbedingt den in der Literatur wiedergegebenen Vermutungen, nach denen die reduktiv acetogenen Organismen eine wesentlich niedrigere Affinität für Wasserstoff als methanogene Organismen haben (MORVAN ET AL. 1994).

Zusammenfassend kann über den Einfluß von Substanzen endogenen und mikrobiellen Ursprungs auf die Pansenfermentation festgehalten werden, daß sowohl beim in-vitro-Substrat Blinddarminhalt als auch bei der Zugabe von Gallensalzen eine deutliche die Methanbildung hemmende Wirkung festgestellt wurde. Beim autoklavierten Blinddarminhalt dürfte dieser hemmende Effekt auf eine durch dieses in-vitro-Substrat bereitgestellte Wasserstoffsenke zurückzuführen sein. Die Gallensalze hatten dagegen eine eindeutig toxische Wirkung auf die Protozoen und anscheinend auch auf methanogene Organismen. Weder die mit Blinddarminhalt zugeführten Substanzen endogenen und mikrobiellen Ursprungs noch der Zusatz von Gallensalzen haben jedoch zu einer Initiierung der reduktiven Acetogenese geführt. Die in Versuchsstufe 2 beim Einsatz der Gallensalze gewählte Kombination der Langzeit-in-vitro-Methode RUSITEC mit anschließender batch-culture-Inkubation führte jedoch zur Bildung von doppelt ${ }^{13} \mathrm{C}$-markiertem Acetat. Unter diesen verschärft selektiven Bedingungen ließ sich demnach die reduktive Acetogenese eindeutig nachweisen. 
Die vorliegenden Untersuchungen haben gezeigt, daß durch eine Inkubation von Pansensaft aus dem Langzeit-in-vitro-System RUSITEC in der batch-culture die reduktive Acetogenese initiiert werden kann.

Nun muß der Frage nachgegangen werden, welche der folgenden Einflußfaktoren des RUSITEC-Systems das reduktiv acetogene Potential im Pansen fördern:

Aufgrund einer fehlenden semipermeablen Pansenwand findet keine dynamische Absorption von Fermentationsprodukten statt und es fehlt die ökologische Nische der an der Pansenwand assoziiert lebenden Mikroben (Kompartiment 4).

- Die Zahl der Protozoen ist im RUSITEC-System relativ niedrig, da die relativ hohe Durchflußrate des Puffers zu einem Hinausspülen der Protozoen führt.

- Die Entnahme des Inokulums für die Inkubation erfolgte aus den Kompartimenten 1 und 2, dadurch wurden die fest an den Futterpartikeln anhaftenden Mikroorganismen vermutlich kaum berücksichtigt.

$\mathrm{Da}$ in den kombinierten RUSITEC-batch-culture Untersuchungen die Mikroorganismen aus der flüssigen Phase des Pansensaftes (Kompartimente 1 und 2) besonders unterstützt wurden, sollte in nachfolgenden Untersuchungen zunächst die Bedeutung dieser Kompartimente für die Initiierung der reduktiven Acetogenese genauer untersucht werden. 
Die vorliegenden Untersuchungen haben gezeigt, daß durch eine Inkubation von Pansensaft aus dem Langzeit-in-vitro-System RUSITEC in der batch-culture die reduktive Acetogenese initiiert werden kann.

Nun muß der Frage nachgegangen werden, welche der folgenden Einflußfaktoren des RUSITEC-Systems das reduktiv acetogene Potential im Pansen fördern:

Aufgrund einer fehlenden semipermeablen Pansenwand findet keine dynamische Absorption von Fermentationsprodukten statt und es fehlt die ökologische Nische der an der Pansenwand assoziiert lebenden Mikroben (Kompartiment 4).

- Die Zahl der Protozoen ist im RUSITEC-System relativ niedrig, da die relativ hohe Durchflußrate des Puffers zu einem Hinausspülen der Protozoen führt.

- Die Entnahme des Inokulums für die Inkubation erfolgte aus den Kompartimenten 1 und 2, dadurch wurden die fest an den Futterpartikeln anhaftenden Mikroorganismen vermutlich kaum berücksichtigt.

$\mathrm{Da}$ in den kombinierten RUSITEC-batch-culture Untersuchungen die Mikroorganismen aus der flüssigen Phase des Pansensaftes (Kompartimente 1 und 2) besonders unterstützt wurden, sollte in nachfolgenden Untersuchungen zunächst die Bedeutung dieser Kompartimente für die Initiierung der reduktiven Acetogenese genauer untersucht werden. 
Der mikrobielle Syntheseweg, in dem aus Kohlendioxid und Wasserstoff Acetat gebildet wird, nennt sich reduktive Acetogenese und tritt im Dickdarm von Mensch, Schwein und Kaninchen auf. Seitdem reduktiv acetogene Bakterien auch im Pansen nachgewiesen worden sind, wird die reduktive Acetogenese als mögliche Alternative zur ruminalen Methanogenese diskutiert. Im Pansen bilden acetogene Bakterien Acetat jedoch nicht durch Reduktion von Kohlendioxid mit Wasserstoff sondern durch Oxidation von leicht löslichen Substraten.

Ausgehend von den Unterschieden zwischen den mikrobiellen Habitaten Dickdarm und Pansen wurde in der vorliegenden Arbeit in zwei Versuchsstufen untersucht, welche Faktoren die reduktive Acetogenese im Pansen initiieren können. In Versuchsstufe 1 wurde der Einfluß der Faktoren Anwesenheit von Protozoen, Ration sowie Nüchterungsdauer des Spendertieres und in-vitro-Substrat mit der in-vitroMethode batch-culture überprüft. Die Ergebnisse aus diesem Versuch wurden anschließend anhand der Kriterien Hemmung der Methanbildung, Höhe des Methan / SCFA (flüchtige Fettsäuren)-Verhältnisses und Wasserstoffwiederfindungsrate hinsichtlich ihres Potentials zur Initiierung der reduktiven Acetogenese bewertet.

Basierend auf dieser Bewertung wurden in Versuchsstufe 2 die Effekte der Defaunierung, der endogenen Substanzen in autoklaviertem Blinddarminhalt mit der batch-culture und der Einfluß von einer 0,4 bzw. einer 0,6\%igen Gallensalzkonzentration mit dem RUSITEC-System untersucht. Dazu wurde ein Verfahren unter Verwendung der ${ }^{13} \mathrm{C}-$ Kernresonanzspekroskopie (NMR) zum direkten Nachweis der reduktiven Acetogenese eingesetzt.

Die Ergebnisse der Untersuchungen zeigen, daß die Methanbildung durch Eliminierung der Protozoen im Pansensaft vollständig gehemmt wurde und es zu einer deutlichen Verschiebung des Acetat / Propionat-Verhältnisses zugunsten des Propionats kam. Das ${ }^{13} \mathrm{C}-\mathrm{CO}_{2}-$ Markerverfahren im defaunierten Pansensaft gab jedoch keine Hinweise auf das Vorkommen von reduktiver Acetogenese.

Der Einfluß der Faktoren Ration sowie Nüchterungsdauer des Spendertieres und in-vitro-Substrat Heu bzw. Stroh deutete bei keinem der gemessenen Fermentationsparameter auf eine mögliche Initiierung der reduktiven Acetogenese hin.

Sowohl das in-vitro-Substrat autoklavierter Blinddarminhalt als auch die Gallensalzzugabe führten zu einer deutlichen Hemmung der Methanogenese. Dabei wurde beim Einsatz des in-vitro-Substrates Blinddarminhalt eine deutlich erniedrigte Wasserstoffwiederfindungsrate beobachtet. Die Untersuchungen mit ${ }^{13} \mathrm{C}-\mathrm{CO}_{2}-$ Marker zeigten jedoch, daß die Verwendung von autoklaviertem Blinddarminhalt die 
reduktive Acetogenese nicht initiieren konnte. In der Pansenflüssigkeit, die zur Überprüfung des Langzeiteffektes von Gallensalzen 7 Tage im RUSITEC-System inkubiert worden war, konnte reduktive Acetogenese im Fermenter ohne Gallensalzzugabe (Kontrolle) und in dem mit niedriger Gallensalzkonzentration nachgewiesen werden, nicht aber im Fermenter mit hoher Gallensalzkonzentration.

In der vorliegenden Arbeit werden die Einflüsse aller variierten Faktoren auf die Fermentationsparameter flüchtige Fettsäuren (SCFA), Methan, Methan/ SCFA und Wassserstoffwiederfindungsrate diskutiert. Die Tatsache, daß reduktive Acetogenese bei keiner bzw. geringer, nicht aber bei hoher Gallensalzzugabe auftrat, führte zu der Schlußfolgerung, daß der Einsatz von Gallensalzen nicht zu einer Initiierung der reduktiven Acetogenese im Pansen führt. Dagegen scheint die reduktive Acetogenese vielmehr durch Adaptation der mikrobiellen Biozönose des Pansens an das RUSITEC-System gefördert zu werden. 
The microbial pathway forming acetate from carbon dioxide and hydrogen is called reductive acetogenesis. This pathway occurs in the human colon as well as in the caecum of pigs and rabbits. Reductive acetogenesis is discussed as an alternative pathway to ruminal methanogenesis since reductive acetogene bacteria have been detected in the rumen. In the rumen acetogene bacteria form acetate by oxidation of easily soluble substances instead of the reduction of carbon dioxide with hydrogen.

Starting with the difference between the microbial habitats of the caecum and rumen, the aim of the presented study was to investigate which factors may contribute to an initiation of reductive acetogenesis in two experimental steps. In the first step the influence of the factors presence of protozoa, diet, starving time of the donor animal and in-vitro-substrate were tested by means of the in-vitro-method batch culture. The results of these experiments were evaluated regarding their potential to initiate reductive acetogenesis by the criteria inhibition of methanogenesis, methane / SCFA (short chain fatty acids) ratio level and hydrogen recovery.

Based on this evaluation, in the second step the effects of defaunation and endogenous substances of a sterilised caecum content were tested in batch culture. The influence of 0.4 and $0.6 \%$ bile salt concentrations were screened in the RUSITEC-System. A procedure using the ${ }^{13} \mathrm{C}$-nuclear-mass-resonance spectroscopy (NMR) was employed to prove the presence of reductive acetogenesis directly.

The results show that by eliminating the protozoa in the rumen the methanogenesis has been inhibited completely and the acetate / propionate ratio has been altered clearly in favour of the propionate. The ${ }^{13} \mathrm{C}-\mathrm{CO}_{2}$ marker procedure in the defaunted rumen liquid, did not reveal any indication of the occurrence of reductive acetogenesis.

The influence of the factors diet, starving time of the donor animal and the in-vitosubstrates hay and straw respectively did not point to a possible initiation of reductive acetogenesis by any of the measured fermentation parameters.

The in-vitro-substrate sterilised caecum content and the addition of bile salts led to a significant inhibition of methanogenesis. Using the in-vitro-substrate sterilised caecum content, there was a reduced hydrogen recovery. The analysis with ${ }^{13} \mathrm{C}_{-} \mathrm{CO}_{2}$ marker showed that the use of sterilised caecum content could not initiate the reductive analysis. In the rumen liquid, which was incubated in the RUSITEC-System for 7 days to examine the long term effect of bile salts, reductive acetogenesis could be detected in the control fermenter without bile salts and in the one with $0.4 \%$ bile salt, but not in the fermenters with high bile salt concentration. 
In the presented work the influences of all varied factors on the fermentation parameters SCFA, methane, methane/SCFA ratio and hydrogen recovery are discussed. As reductive acetogenesis occured in the fermenters without or with low bile salt content but not in the ones with high bile salt concentration it can be concluded that the addition of bile salts did not lead to the initiation of reductive acetogenesis in the rumen. However it seems that reductive acetogenesis is promoted by the adaptation of ruminal microbes to the RUSITEC-System. 


\section{Abkürzungen}

$\Sigma$ SCFA

*

**

${ }^{\circ} \mathrm{C}$

${ }^{13} \mathrm{C}$

ADF

$\mathrm{C}$

$\mathrm{C}_{6} \mathrm{H}_{12} \mathrm{O}_{6}$

$\mathrm{CaCl}$

$\mathrm{CH}_{3}\left(\mathrm{CH}_{2}\right)_{2} \mathrm{COOH}$

$\mathrm{CH}_{3} \mathrm{CH}_{2} \mathrm{COOH}$

$\mathrm{CH}_{3} \mathrm{COCOOH}$

$\mathrm{CH}_{3} \mathrm{COOH}$

$\mathrm{CH}_{4}$ / SCFA

$\mathrm{CH}_{4}$

$\mathrm{CO}_{2}$

$\mathrm{CoCl}_{2}$

$\mathrm{CuSO}_{4}$

$\mathrm{D}_{2} \mathrm{O}$

$\mathrm{FeSO}_{4}$

FS

$\mathrm{H}_{0}$

$\mathrm{H}_{2}$

$\mathrm{H}_{2} \mathrm{O}_{\text {dest }}$

$\mathrm{H}_{2} \mathrm{SO}_{4}$

$\mathrm{H}_{3} \mathrm{PO}_{4}$

$\mathrm{HgCl}$

$\mathrm{H}_{\mathrm{p}} / \mathrm{H}_{\mathrm{u}}$

$\mathrm{H}_{\mathrm{p}}$

$\mathrm{H}_{\mathrm{u}}$

$\mathrm{KCl}$

$\mathrm{MgSO}_{4}$

MJ

$\mathrm{MnSO}_{4}$

$\mathrm{N}$

$\mathrm{n}$
Summe der kurzkettigen flüchtigen Fettsäuren

signifikant bei $p<0,05$

signifikant bei $p<0,01$

Grad Celsius

Kohlenstoff der Atommasse $13 \mathrm{u}$

saure Detergentienfaser

Kohlenstoff

Glucose

Calciumchlorid

Buttersäure

Propionsäure

Pyruvat

Essigsäure

Verhältnis von Methan zu kurzkettigen flüchtigen Fettsäuren

Methan

Kohlendioxid

Cobaltchlorid

Kupfersulfat

schweres Wasser

Eisensulfat

Frischsubstanz

Nullhypothese

Wasserstoff

destilliertes Wasser

Schwefelsäure

Phosphorsäure

Quecksilberchlorid

Wasserstoffwiederfindungsrate

produzierter Wasserstoff

verbrauchter Wasserstoff

Kaliumchlorid

Magnesiumsulfat

Mega-Joule

Mangansulfat

Normalität

Stichprobenumfang 


\section{Abkürzungen}

n.n.

nicht nachweisbar

n.s.

nicht signifikant

$\mathrm{N}_{2}$

Stickstoff

$\mathrm{Na}_{2} \mathrm{HPO}_{4}$

Di-Natrium-Hydrogen-Phosphat

$\mathrm{NaCl}$

Natriumchlorid

$\mathrm{NADH}$

reduzierte Form von Nicotinamid-Adenindinucleotid

$\mathrm{NaH}_{2} \mathrm{PO}_{4}$

Natrium-Di-Hydrogen-Phsophat

$\mathrm{NaHCO}_{3}$

Natrium-Hydrogen-Carbonat

$\mathrm{NaOH}$

Natriumhydroxid

NDF

NEL

neutrale Detergentienfaser

$\mathrm{NH}_{4} \mathrm{HCO}_{3}$

Nettoenergie-Laktation

NMR

Ammonium-Hydrogen-Carbonat

NUE

Kernresonanzspektroskopie

$\mathrm{p}$

Nüchterungsdauer des Spendertieres

Wahrscheinlichkeit

PRO

Protozoen

RAT

Ration des Spendertieres

RUSITEC

Pansensimulationstechnik

SCFA

kurzkettige flüchtige Fettsäuren

SUB

in-vitro-Substrat

TAG

Versuchstag

TM

Trockenmasse

$\mathrm{v} / \mathrm{v}$

Mischungsverhältnis pro Volumeneinheit

$w / v$

Mischungsverhältnis Gewicht pro Volumen

Wdh

Wiederholung

$X A$

Rohasche

$X F$

Rohfaser

$\mathrm{XL}$

Rohfett

$X P$

$\mathrm{ZnSO}_{4}$

Rohprotein

Zinksulfat 


\section{Literaturverzeichnis}

Aguilera, J.F. und PRIETO, C. (1991): Methane production in goats given diets based on lucerne hay and barley. Arch. Anim. Nutr., Berlin 41, 77 - 82.

BIRD, S.H., HILL, M.K. und LENG, R.A. (1979): The effects of defaunation of the rumen on the growth of lambs on low-protein-high-energy diets. Br. J. Nutr. 42, 81 - 87.

BLÜMMEL, M. und ØRSKOV, E.R. (1993): Comparison of in vitro gas production and nylon bag degradability of roughages in predicting feed intake in cattle. Anim. Feed Sci. Technol. 40, 109 - 119.

BREZNACK, J.A. und KANE, M.D. (1990): Microbial $\mathrm{H}_{2} / \mathrm{CO}_{2}$ acetogenesis in animal guts: Nature and nutritional significance. FEMS Microbiol. Rev. 87, 309 - 314.

BRINKMANN, J. (1991): Verdauungsphysiologie in vitro und in vivo - Untersuchungen zum Einfluß von freien, veresterten und verseiften Palmfettsäuren. Dissertation, GeorgAugust-Universität Göttingen.

Burroughs, W.N., Frank, A., Gerlaugh, P. und Bethke, R.M. (1950): Preliminary observations upon factors influencing cellulose degestion by rumen microorganisms. J. Nutr. 40, 9 - 24.

Cheng, K.-J. und McAllister, T.A. (1997): Compartmentation in the rumen. In: Hobson, P.N. und Stewart, C.S.: The rumen microbial ecosystem. Blackie Academic \& Professional, London, Weinheim, New York, Tokio, Melbourne, Madras.

COENEN, G. (1988): In vitro-Untersuchungen mit dem RUSITEC-System zum Einfluß unterschiedlicher Fett-Stärke-Kombinationen auf verschiedene Fermentationsparameter von Pansenmikroben. Dissertation, Georg-AugustUniversität Göttingen.

Coleman, F.S. (1985): The cellulase content of 15 species of entodiniomorphid protozoa, mixed bacteria and plant debris isolated from the ovine rumen. J. agric. Sci., Camb. 104, 349 - 360.

Crutzen, P.J., Aselmann, I. und Seiler, W. (1986): Methane production of domestic animals, wild ruminants, other herbivorous fauna and humans. Tellus $38 \mathrm{~B}, 271-274$.

CzerkaWskI, J.W. (1986): An introduction to rumen studies. Pergamon Press, Oxford, New York, Toronto, Sydney, Frankfurt.

CZERKAWSKI, J.W. und BRECKENRIDGE, G. (1972): Fermentation of various glycolytic intermediates and other compounds by rumen micro-organisms, with particular reference to methane production. Br. J. Nutr. 27, 131 - 146.

CZERKAWSKI, J.W. und BRECKENRIDGE, G. (1977): Design and development of a long-term rumen simultation technique (Rusitec). Br. J. Nutr. 38, 371 - 384.

CZERKAWSKI, J.W., BlaXTER, K.L. und WAINMANN, F.W. (1966): The metabolism of oleic, linoleic and linolenic acids by sheep with reference to their effects on methane production. Br. J. Nutr. 20, 349 - 362.

De Graeve, K.G., Grivet, J.P., Durand, M., Beaumatin, P., Cordelet, C., Hannequart, G. und DEMEYER, D.I. (1994): Competition between reductive acetogenesis and methanogenesis in the pig large-intestinal flora. J. Appl. Bacteriol. 76, 55 - 61.

DEHORITY, B.A. und ORPIN, C.G. (1997): Development of, and natural fluctuations in, rumen microbial populations. In: Hobson, P.N. und Stewart, C.S.: The rumen microbial ecosystem. Blackie Academic \& Professional, London, Weinheim, New York, Tokio, Melbourne, Madras. 
DEMEYER, D.I. (1981): Rumen microbes and digestion of plant cell walls. Agric. Environment 6, 295 - 337.

DEMEYER, D.I. und DE GRAEVE, K. (1991): Differences in stoichiometry between rumen and hindgut fermentation. Adv. Anim. Physiol. Anim. Nutr. 22, 50 - 61.

DEMEYER, D.I. und VAN NEVEL, C.J. (1979): Effect of defaunation on the metabolism of rumen micro-organisms. Br. J. Nutr. 42, 515 - 524.

DemeYeR, D.I., FiedLeR, D. und De GraeVe, K.G. (1996): Attempted induction of reductive acetogenesis into the rumen fermentation in vitro. Reprod. Nutr. Dev. 36, 233 - 240.

Dong, Y., Bae, H.D., MtAllister, T.A., Mathison, G.W. und Cheng, K.J. (1997): Lipidinduced depression of methane production and digestibility in the artifical rumen system (Rusitec). Can. J. Anim. Sci. 77, 269 - 278.

Doré, J., Mdrvan, B., Rieu-Lesme, F., Goderel, I., Gouet, P. und Pochart, P. (1995): Most probable number enumeration of $\mathrm{H}_{2}$-utilizing acetogenic bacteria from the digestive tract of animals and man. FEMS Microbiol. Lett. 130, 7 - 12.

Durand, M. und BernAlieR, A. (1993): Reductive acetogenesis in animal and human gut. In: Rombeau, J.H., Cummings, J.L. und Sakata, T.: Physiologial and clinical aspects of short chain fatty acid metabolism. Cambridge University Press.

EADIE, J.M. und Gill, J.C. (1971): The effect of the absence of rumen ciliate protozoa on growing lambs fed on a roughage-concentrate diet. Br. J. Nutr. 26, 155 - 167.

Faichney, G.J., Poncet, C., Lassalas, B., Jouany, J.P., Millet, L., Doré, J. und BROWNLEE, A.G. (1997): Effect of concentrates in a hay diet on the contribution of anaerobic fungi, protozoa and bacteria to nitrogen in rumen and duodenal digesta in sheep. Anim. Feed Sci. Technol. 64, 193 - 213.

FLORIN, T.H.J. und WOODS, H.J. (1995): Inhibition of methanogenesis by human bile. Gut 37, $418-421$.

Garcia-Lopez, P.M., KUnG JR., L. und ODOM, J.M. (1996): In vitro inhibition of microbial methane production by 9,10-Anthraquinone. J. Anim. Sci. 74, 2276 - 2284.

GEIßLER, A. (1995): Radiometrisches in vitro-Verfahren zur Messung des Celluloseabbaues durch die Pansenmikroflora mit Acetobacter-Cellulose als Testsubstrat. Dissertation, Cuvillier, Göttingen.

Gibson, G.G., Cummings, J.H., Macfarlane, G.T., Allison, C., Segal, I., VOrster, H.H. und WALKER, A.R.P. (1990): Alternative pathways for hydrogen disposal during fermentation in the human colon. Gut 31, 679 - 683.

Gibson, G.R., MacFarlane, G.T. und Cummings, J.H. (1993): Sulphate reducing bacteria and hydrogen metabolism in the human large intestine. Gut 34, 437 - 439.

GOTTSCHALK, G. (1986): Bacterial metabolism. Springer, New York, Berlin.

GotTwALD, W. (1995): GC für Anwender. VCH, Weinheim, New York, Basel, Cambridge, Tokio.

GREENING, R.C. und LEEDLE, J.A.Z. (1989): Enrichment and isolation of Acetitomaculum ruminis, gen. nov., sp. nov.: acetogenic bacteria from the bovine rumen. Arch. Microbiol. 151, 399 - 406.

Grivet, J.P., DuRAND, M. und Tholozan, J.L. (1992): ${ }^{13} \mathrm{C}-N M R$ studies of bacterial fermentations. Biochimie 74, 897 - 901.

Grovum, W.L. und WILLIAMS, V.J. (1977): Rate of passage of digesta in sheep. Effects of level of food intake on mathematical predictions of the kinetics of digesta in the reticulo-rumen and intestines. Br. J. Nutr. 38, 435 - 436. 
GÜRTLER, H. (1989): Die Physiologie der Verdauung und Resorption. In: Gürtler, H., Ketz, H.A., Kolb, E., Schröder, L. und Seidel, H.: Lehrbuch der Physiologie der Haustiere. VEB Gustav Fischer, Jena.

HARFOOT, C.G. und HAZLEWOOD, G.P. (1997): Lipid metabolism in the rumen. In: Hobson, P.N. und Stewart, C.S.: The rumen microbial ecosystem. Blackie Academic \& Professional, London, Weinheim, New York, Tokio, Melbourne, Madras.

HARMEYER, J. (1965): Zur Methodik experimenteller Untersuchungen an Pansenprotozoen. Zbl. Vet. Med. (A) 12, 841 - 880.

Hatch, CF., Perri, T.W., Mohler, M.T. und Beeson, W.M. (1972): Effect of added fat with graded levels of calcium to urea-containing rations for beef cattle. J. Anim Sci. 34, 483 - 487.

HeSSE, M., MEIER, H. und ZEEH, B. (1987): Spektroskopische Methoden in der organischen Chemie. Georg Thieme, Stuttgart.

HOOVER, W.H. (1978): Digestion and absorption in the hingut of ruminants. J. Anim. Sci. 46, $1789-1799$.

Hungate, R.E. (1966): The rumen and its microbes. Academic Press, New York und London.

IMMIG, I. (1990): Einfluß von Fetten auf die Fermentation und die Motorik im Pansen von Schafen. Dissertation, Georg-August-Universität Göttingen.

IMMIG, I. (1996): The rumen and hindgut as source of ruminant methanogenesis. Environmental Monitoring and Assessment 42, 57 - 72.

IMMIG, I. (1998): The effect of porcine bile acids on methane production by rumen contents in vitro. Arch. Anim. Nutr. 51, 21 - 26.

JENKINS, TC. (1987): Effekt of fats and fatty acid combinations in ruminal fermentation in semi-continuous in vitro cultures. J. Anim. Sci. 64, 1526 - 1532.

JOHNSON, K.A. und JOHNSON, D.E. (1995): Methane emissions from cattle. J. Anim. Sci. 73, 2483 - 2492.

JOUANY, J.P. (1994): Manipulation of microbial activity in the rumen. Arch. Anim. Nutr. 46, $133-153$.

JOUANY, J.P. und MARTIN, C. (1997): Effect of protozoa in plant cell wall and starch digestion in the rumen. In: Onodera, R., Itabashi, H., Ushida, K., Yano, H. und Sasaki, Y.: Rumen microbes and digestive physiology in ruminants. Japan Sci. Soc. Press, Tokio/S. Karger, Basel.

KAISER, R. (1965): Chromatographie in der Gasphase. Bibliographisches Institut, Mannheim.

KAMLAGE, B., GRUHL, B. und BlaUt, M. (1997): Isolation and characterization of two new homoacetogenic hydrogen-utilizing bacteria from the human intestinal tract that are closely related to Clostridium coccoides. Appl. Environ. Microbiol. 63, 1732 - 1738.

KIRCHGEBNER, M. (1987): Tierernährung. DLG, Frankfurt (Main).

KolB, E. (1989): Die Physiologie der Ernährung. In: Gürtler, H., Ketz, H.-A., Kolb, E., Schröder, L. und Seidel, H.: Lehrbuch der Physiologie der Haustiere. VEB Gustav Fischer, Jena.

Kreuzer, M. und KIRCHGebNeR, M. (1986): Die Bedeutung der Protozoen im Pansen von Hammeln für Verdaulichkeit, N-Bilanz und N-Fraktionen in Kot und Harn bei unterschiedlichen Gehalten und Arten von Stärke in der Ration. J. Anim. Physiol. a. Anim. Nutr. 56, 217 - 231. 
KRUMHOLZ, L.R., Forsberg, C.W. und VerA, D.M. (1983): Association of methanogenic bacteria with rumen protozoa. Can. J. Microbiol. 29, 676 - 680.

Kurihara, M., Shibata, M., Nishida, T., Purnomoadi, A. und Terada, F. (1997): Methane production and its dietary manipulation in ruminants. In: Onodera, R., Itabashi, H., Ushida, K., Yano, H. und Sasaki, Y.: Rumen microbes and digestive physiology in ruminants. Japan Sci. Soc. Press, Tokio/S. Karger, Basel.

LAJOIE, S.F., BANK, S., MilleR, T.L. und WoliN, M.J. (1988): Acetate production from hydrogen and $\left({ }^{13} \mathrm{C}\right)$ carbon dioxide by the microflora of human feces. Appl. Environ. Microbiol. 54, 2723 - 2727.

Le Van, T.D., Robinson, J.A., RalPh, J., GReEning, R.C., SMOlenski, W.J., LeEdLe, J.A.Z. und SCHAEFER, D.M. (1998): Assessment of reductive acetogenesis with indigenous ruminal bacterium populations and Acetitomaculum ruminis. Appl. Environ. Microbiol. 64, 3429 - 3436.

LeClerc, M., Bernalier, A., Donadille, G. und Lelait, M. (1997): $\mathrm{H}_{2} / \mathrm{CO}_{2}$ metabolism in acetogenic bacteria isolated from the human colon. Anaerobe 3, 307-315.

LeedLe, J.A.Z. und GreenING, R.C. (1988): Postprandial changes in methanogenic and acidogenic bacteria in the rumens of steers fed high - or low - forage diets once daily. Appl. Environ. Microbiol. 54, 502 - 506.

LEINMÜLLER, E. und MENKE, K.H. (1986): Wirkung einer Defaunierung des Panseninhalts. Übers. Tierernährg. 14, 75 - 100.

LENG, R.A. (1988): Dynamics of protozoa in the rumen. In: Nolan, J.V., Leng, R. A. und Demeyer, D. I.: The roles of protozoa and fungi in ruminant digestion. Pernambul Books, Armidale, Australia, 51 - 58.

LitTel, R.C., MLliken, G.A., Stroup, W.W. und Wolfinger, R.D. (1996): SAS system for mixed models. SAS Institute Inc.,Cary.

Machmüller, A., Ossowski, D.A., W ANNER, M. und KREUZER, M. (1998): Potential of various fatty feeds to reduce methane release from rumen fermentation in vitro (RUSITEC). Anim. Feed Sci. Technol. 71, 117 - 130.

MACKIE, R.I. und BRYANT, M.P. (1994): Acetogenesis and the rumen: Syntrophic relationsships. In: Drake, H.L.: Acetogenesis, Chapman \& Hall, New York, 331 - 364.

MARTY, R.J. und DEMEYER, D.I. (1973): The effect of inhibitors of methane production on fermentation pattern and stoichiometry in vitro using rumen contents from sheep given molasses. Br. J. Nutr. 30, 369 - 376.

Mathieu, F., Jouany, J.P., Sénaud, J., Bohatier, J., Bertin, G. und Mercier, M. (1996): The effect of Saccaharomyces cerevisiae and Aspergillus oryzae on fermentations in the rumen of faunated and defaunated sheep; protozoal and probiotic interactions. Reprod. Nutr. Dev. 36, 271 - 287.

McAllister, T.A., OKine, E.K., Mathison, G.W. und Cheng, K-J. (1996): Dietary, environmental and microbiological aspects of methane production in ruminants. Can. J. Anim. Sci. 76, 231 - 243.

MERCK (1987): Handbuch Chromato Integrator D 2000. Fa. Merck, Darmstadt.

MILLER, T.L. (1995): Ecology of methane production and hydrogen sinks in the rumen. In: Ruminant Physiology: Digestion, Metabolism, Growth and Reproduction: Proceedings of the VIII International Symposium on ruminant physiology. Ferdinand Enke, Stuttgart. 
Morvan, B., Doré, J., Rieu-lesme, F., Foucat, L., Fonty, G. und Gouet, P. (1994): Establishment of hydrogen-utilizing bacteria in the rumen of the newborn lamb. FEMS Microbiol. Lett. 117, 249 - 256.

Morvan, B., Rieu-Lesme, F., Fonty, G. und Gouet, P. (1996): In vitro interactions between rumen $\mathrm{H}_{2}$-producing cellulolytic microorganisms and $\mathrm{H}_{2}$-utilizing acetogenic and sulfate-reducing bacteria. Anaerobe 2, 175 - 180.

Moss, A.R. (1993): Methane-Global warming and production by animals, Chalcombe Publications, Kingston, Canterbury, Kent, GB.

Moss, A.R. (1994 a): Methane production by ruminants - Literature review of I. Dietary manipulation to reduce methane production and II. Laboratroy procedures for estimating methane potential of diets. Nutrition abstracts and reviews (Series B) 64, 785 - 806.

Moss, A.R., Givens, D.I. und Garnsworthy, P.C. (1994): The effect of alkali treatment of cereal straws on degestibility and methane production by sheep. Anim. Feed Sci. Technol. 49, 254 - 259

Nagaraja, T.G., Newbold, C.J., van NeVEL, C.J. und Demeyer, D.I. (1997): Manipulation of ruminal fermentation. In: Hobson, P.N. und Stewart, C.S.: The rumen microbial ecosystem. Blackie Academic \& Professional, London, Weinheim, New York, Tokio, Melbourne, Madras.

Neter, J., Kutner, M.H., Nachtsheim, C.J. und WassermanN, W. (1996): Applied linear statistical models. Irwin, Chicago.

NolLET, L. und VeRSTRAETE, W. (1996): Gastro-enteric methane versus sulphate and volatile fatty acid production. Environmental Monitoring and Assessment 42, 113 - 131.

Nollet, L., DemeYer, D.I. und Verstraete, W. (1997): Effect of 2-bromoethanesulfonic acid and Peptostreptococcus productus ATCC 35244 addition on stimulation of reductive acetogenesis in the ruminal ecosystem by selective inhibition of methanogenesis. Appl. Environ. Microbiol. 63, 194 - 200.

Nollet, L., Mbanzaminigo, L., Demeyer, D.I. und Verstraete, W. (1998): Effect of the addition of Peptostreptococcus productus ATCC 35244 on reductive acetogenesis in the ruminal ecosystem after inhibition of methanogenesis by cell-free supernatant of Lactobacillus plantarum 80. Anim. Feed Sci. Technol. 71, 49 - 66.

PALMQUIST, D.L. und JENKINS, T.C. (1980): Fat in lactation rations. J. Dairy Sci. 63, 1 - 14.

Piattoni, F., Demeyer, D.I. und MaERTENS, L. (1996): In vitro study of the age dependent caecal fermentation pattern and methanogenesis in young rabbits. Reprod. Nutr. Dev. 36, 253-261.

Rieu-lesme, F., Mbrvan, B., Collins, M.D., Fonty, G. und Willems, A. (1996): A new $\mathrm{H}_{2} / \mathrm{CO}_{2}$-using acetogenic bacterium from the rumen: Description of Ruminococcus schinkii sp. nov.. FEMS Microbiol. Lett. 140, 281 - 286.

ShARP, R., ZEMER, C.J., StERN, M.D. und STAHL, D.A. (1998): Taxon-specific associations between protozoal and methanogen populations in the rumen and a model rumen system. FEMS Microbiol. Ecology 26, 71 - 78.

Stevani, J., Durand, M., De Graeve, K., Demeyer, D.I. und Grivet, J.P. (1991): Degradative abilities and metabolisms of rumen and hindgut microbial ecosystems. In: Sakata, T. und Snipes, R. L. : Hindgut '91. Senshu University Press,Tokio, $123-135$. 
USHidA, K., TOKuRA, M., TAKEnAKA, A. und ITABASHI, H. (1997): Ciliate protozoa and ruminal methanogenesis. In: Onodera, R., Itabashi, H., Ushida, K., Yano, H. und Sasaki, Y.: Rumen microbes and digestive physiology in ruminants. Japan Sci. Soc. Press, Tokio / S. Karger, Basel.

VAN KESSEL, J.A.S. und RUSSELL, J.B. (1996): The effect of pH on ruminal methanogenesis. FEMS Microbiol. Ecology 20, 205 - 210.

VAN NEVEL, C.J. und DEMEYER, D.I. (1992): Influence of antibiotics and a deaminase inhibitor on volatile fatty acids and methane production from detergent washed hay and soluble starch by rumen microbes in vitro. Anim. Feed Sci. Technol. 37, 21 - 31.

VAN NeVEL, C.J. und DemeYER, D.I. (1996): Effect of $\mathrm{pH}$ on biohydrogenation of polyunsaturated fatty acids and their $\mathrm{Ca}$-salts by rumen microorganisms. Arch. Anim. Nutr. 49, 151 - 157.

VEIRA, D.M., INAN, M. und JUI, P.Y. (1983): Rumen ciliate protozoa: Effects on digestion in the stomach of sheep. J. Dairy Sci. 66, 1015 - 1022.

WetZEL, R. (1951): Verbesserte McMaster-Zählkammer zum Auszählen von Wurmeiern. Tierärtzl. Umsch. 6, 209 - 210.

Whitelaw, F.G., EAdiE, J.M., BRuCE, L.A. und ShAND, W.J. (1984): Methane formation in faunated and ciliate-free cattle and its relationship with rumen volatile fatty acid proportions. Br. J. Nutr. 52, 261 - 275.

Willams, A.G. und Coleman, G.S. (1997): The rumen protozoa. In: Hobson, P.N. und Stewart, C.S.: The rumen microbial ecosystem. Blackie Academic \& Professional, London, Weinheim, New York, Tokio, Melbourne, Madras.

Wolin, M.J. (1960): A theoretical rumen fermentation balance. J. Dairy Sci. 40, 1452 - 1459.

WOLIN, M.J. und MILLER, T.L. (1993): Bacterial strains from Human Feces that reduce $\mathrm{CO}_{2}$ to acetic acid. Appl. Environ. Microbiol 59, 3551 - 3556.

Wolin, M.J., MilleR, T.L. und SteWART, C.S. (1997): Microbe-microbe interactions. In: Hobson, P.N. und Stewart, C.S.: The rumen microbial ecosystem. Blackie Academic \& Professional, London, Weinheim, New York, Tokio, Melbourne, Madras.

Young, J.A., CoOK, D.I. LINGARD, J.M., VAN LENNEP, E.W. und WEGMAN, E. (1996): Funktion des Magen-Darm-Trakts. In: Klinke, R. und Silbernagel, S.: Lehrbuch der Physiologie. Georg Thieme, Suttgart und New York. 


\section{Verzeichnis der Abbildungen, Tabellen, Übersichten und des Anhangs}

\section{Abbildungen}

$\mathrm{Nr}$ :

Titel

Seite

1 Schematische Darstellung der Fermentationsvorgänge im Pansen.

2 Schematische Darstellung der Fermentationsprozesse im Pansen unter Einbeziehung einer autotrophen reduktiven Acetogenese.

3 Inkubationsgefäß für batch-culture.

4 Schematischer Aufbau eines RUSITEC-Fermenters (CZERKAWSKI und BRECKENRIDGE 1977).

5 Darstellung der Linearitätsüberprüfung der Gasanalysen nach GOTTWALD (1995).

6 Darstellung der Linearitätsüberprüfung nach GOTTWALD (1995).

7 Einfluß der Ration des Spendertieres auf die Bildung von SCFA und Methan in der batch-culture $(n=54)$.

Einfluß der Nüchterungsdauer des Spendertieres vor der

8 Pansensaftentnahme auf die Bildung von SCFA und Methan in der batchculture $(n=54)$.

9 Einfluß des in-vitro-Substrates auf die Bildung von SCFA und Methan in der batch-culture $(n=54)$.

10 Einfluß der Ration des Spendertieres auf die Bildung von SCFA in der batchculture unter Verwendung von defauniertem Pansensaft $(n=54)$.

11 Einfluß der Nüchterungsdauer des Spendertieres auf die Bildung von SCFA in der batch-culture unter Verwendung von defauniertem Pansensaft $(n=54)$.

12 Einfluß des in-vitro-Substrates auf die Bildung von SCFA in der batch-culture unter Verwendung von defauniertem Pansensaft $(n=54)$.

13 Wasserstoffwiederfindungsraten der Inkubationen mit nicht defauniertem (A) und defauniertem Pansensaft $(B)(n=9)$.

Einfluß der Begasung mit $80 \%$ Argon $(n=2)$ bzw. $80 \%$ Wasserstoff $(n=3)$ in

14 der Gasatmosphäre einer batch-culture-Inkubation mit Bakterien aus dem Schweinedarm.

Einfluß der Begasung mit Argon $(n=2)$ und Wasserstoff $(n=3)$ in der

15 Gasatmosphäre der batch-culture Inkubation mit Bakterien aus dem Schweinedarm auf die Entstehung von ${ }^{13} \mathrm{C}-\mathrm{CO}_{2}$-markiertem Acetat.

16 Einfluß der in-vitro-Substrate Heu und Blinddarminhalt sowie der Defaunierung auf die Entstehung von SCFA und Methan in der batch-culture $(n=3)$.

17 Einfluß der Infusion von $0,4 \%$ und $0,6 \%$ Gallensalz (w/v) auf die Methanogenese in dem RUSITEC-System. 


\section{Abbildungen}

Nr:

Titel

Seite

18 Einfluß der Infusion von 0,4 und 0,6\% Gallensalz (w/v) auf die in der Fermentationsflüssigkeit des RUSITEC-Systems vorhandenen Protozoen. Mengen der in dem RUSITEC-Systems pro Tag und Fermenter
entstandenen SCFA.

Einfluß der Entwicklung der Biozönose im RUSITEC-System auf die

20 Fermentationsprodukte einer 24 stündigen Inkubation in der batch-culture $(n=3)$.

$21{ }^{13} \mathrm{C}-\mathrm{NMR}$ Spektren ohne (A, B) und mit (C) doppeltmarkiertem Acetat.

\section{Tabellen}

Nr:

Titel

Seite

1 Ration 1 und 2 für die HF-Kuh.

2 Inhaltsstoffe der verwendeten in-vitro-Substrate.

3 Chromatographiebedingungen zur Bestimmung der Gaszusammensetzung des Fermentationsgases.

4 Chromatographiebedingungen zur Bestimmung der kurzkettigen flüchtigen Fettsäuren (SCFA) nach Verfahren 1.

5 Chromatographiebedingungen zur Bestimmung der kurzkettigen flüchtigen Fettsäuren (Verfahren 2).

6 Berechnungsgrundlage zur Herstellung eines SCFA Standardgemischs.

7 Variationskoeffizienten wiederholter Messungen, bestimmt nach GOTTWALD (1995).

8 Einfluß von Ration und Nüchterungsdauer auf die Bildung von SCFA und Methan in der batch-culture $(n=27)$.

9 Einfluß von Ration und in-vitro-Substrat auf die Bildung von SCFA und Methan in der batch-culture $(n=27)$.

10 Einfluß von Nüchterungsdauer und in-vitro-Substrat auf die Bildung von SCFA und Methan in der batch-culture $(n=27)$.

11 Einfluß von Ration sowie Nüchterungsdauer auf die Bildung von SCFA in der batch-culture $(n=27)$.

12 Einfluß von Ration und in-vitro-Substrat auf die Bildung von SCFA in der batch-culture $(n=18)$.

13 Einfluß von Nüchterungsdauer und in-vitro-Substrat auf die Bildung von SCFA in der batch-culture $(n=18)$. 


\section{Übersichten}

Nr:

Titel

Seite

1 Zuordnung der Arbeitshypothesen zu den unabhängigen Faktoren und deren Faktorstufen.

Versuchsdesign für in-vitro-Untersuchungen mit insgesamt 9 Faktorstufen

2 der Faktoren Protozoen, Ration sowie Nüchterungsdauer des Spendertieres und in-vitro-Substrat.

3 Übersicht über die mit ${ }^{13} \mathrm{C}-\mathrm{CO}_{2}$-Marker durchgeführten Versuche sowie deren Behandlungen und Zuordnung zu den unabhängigen Faktoren.

4 Versuchsplan für in-vitro-Untersuchungen zum Nachweis der reduktiven Acetogenese

5 Überblick über Haupt- und Wechselwirkungen der unabhängigen Faktoren auf die erhobenen Parameter bei nicht defauniertem Pansensaft.

6 Überblick über die Haupt- und Wechselwirkungen der unabhängigen Faktoren auf die erhobenen Parameter bei defauniertem Pansensaft.

\section{Anhang}

Nr:

Titel

Einfluß von Ration, Nüchterungsdauer und in-vitro-Substrat auf SCFA,

1 Methan, Wasserstoffwiederfindungsrate $\left(\mathrm{H}_{\mathrm{u}} / \mathrm{H}_{\mathrm{p}}\right)$ und Methan / SCFAVerhältnis im nicht defaunierten Pansensaft (Ration und Nüchterungsdauer $n=54$, in-vitro-Substrat $n=36$ ).

Einfluß von Ration, Nüchterungsdauer und in-vitro-Substrat auf SCFA und

2 Wasserstoffwiederfindungsrate $\left(\mathrm{H}_{u} / \mathrm{H}_{\mathrm{p}}\right)$ im defaunierten Pansensaft (Ration und Nüchterungsdauer $n=54$, in-vitro-Substrat $n=36$ ).

Einfluß von Ration, Nüchterungsdauer und in-vitro-Substrat auf SCFA, Methan und Methan/SCFA-Verhältnis im nicht defauniertem Pansensaft $(n=9)$.

Einfluß von Ration, Nüchterungsdauer und in-vitro-Substrat auf SCFA im

4 defauniertem Pansensaft $(n=9)$.

Wasserstoffwiederfindungsraten $(\mathrm{Hu} / \mathrm{Hp})$ aller 24 möglichen Faktor-

5 kombinationen $(n=9)$.

Einfluß der Begasung mit $80 \%$ Argon bzw. $80 \%$ Wasserstoff in der Gasatmosphäre einer batch-culture-Inkubation mit Bakterien aus dem

6 Schweinedarm auf SCFA und Methan ( $n=2$ bei Argon, $n=3$ bei Wasserstoff).

Anteile einfach und doppelt ${ }^{13} \mathrm{C}-\mathrm{CO}_{2}$-markierter Essigsäure in mit Argon bzw.

7 Wasserstoff begasten Inkubationsgefäßen. 


\section{Anhang}

Nr:

Titel

Seite

8 Einfluß der in-vitro-Substrate $\mathrm{Heu}$ und Blinddarminhalt sowie der 85 Defaunierung des Inokulums mit Synperonic auf SCFA und Methan $(n=3)$.

9 Einfluß unterschiedlicher Gallensalzkonzentrationen auf SCFA, Methan und 85 Methan / SCFA-Verhältnis in den einzelnen Fermentern des RUSITECSystems.

10 Einfluß unterschiedlicher Gallensalzkonzentrationen auf die Protozoenzahl im RUSITEC-System.

11 Einfluß unterschiedlicher Gallensalzkonzentrationen auf SCFA, Methan, Wasserstoff-wiederfindungsrate $(\mathrm{Hu} / \mathrm{Hp})$ und Methan / SCFA-Verhältnis im RUSITEC-System.

12 Einfluß unterschiedlicher Gallensalzkonzentrationen auf SCFA und deren prozentuale Zusammensetzung im RUSITEC-System.

13 Einfluß unterschiedlicher Gallensalzkonzentrationen im RUSITEC-System auf SCFA und Methan in der batch-culture.

$14{ }^{13} \mathrm{C}-\mathrm{NMR}$ Spektren von Kohlenstoffatomen des Acetats einiger in-vitroInkubationen.

15: Originaldaten der batch-culture-Untersuchungen mit nicht defauniertem Pansensaft.

16 Originaldaten der batch-culture-Untersuchungen mit defauniertem 96 Pansensaft.

17 Codierung zu Anhang 15 und 16. 
Anhang 1: Einfluß von Ration, Nüchterungsdauer und in-vitro-Substrat auf SCFA, Methan, Wasserstoffwiederfindungsrate $\left(\mathrm{H}_{u} / \mathrm{H}_{\mathrm{p}}\right)$ und Methan / SCFAVerhältnis im nicht defaunierten Pansensaft (Ration und Nüchterungsdauer $\mathrm{n}=54$, in-vitro-Substrat $\mathrm{n}=36$ ).

\begin{tabular}{|c|c|c|c|c|c|c|c|c|c|c|}
\hline $\begin{array}{c}\text { nicht } \\
\text { defaunierter } \\
\text { Pansensaft }\end{array}$ & $\begin{array}{l}\text { SCFA } \\
\mu \mathrm{mol}\end{array}$ & $\begin{array}{r}\text { Ace } \\
\mu \mathrm{mol}\end{array}$ & $\%$ & $\begin{array}{l}\text { Propi } \\
\mu \mathrm{mol}\end{array}$ & nat & $\begin{array}{l}\text { Buty } \\
\mu \mathrm{mol}\end{array}$ & $\%$ & $\begin{array}{l}\mathrm{CH}_{4} \\
\mu \mathrm{mol}\end{array}$ & $\begin{array}{c}\mathbf{H}_{\mathbf{u}} / \mathbf{H}_{\mathbf{p}} \\
\%\end{array}$ & $\mathrm{CH}_{4} / \mathrm{SCFA}$ \\
\hline \multicolumn{11}{|l|}{ Ration } \\
\hline Heu-Kraftfutter & 2010 & 1036 & 52 & 674 & 34 & 301 & 15 & 323 & 81 & 0,16 \\
\hline Stroh-Harnstoff & 1378 & 713 & 52 & 499 & 36 & 166 & 12 & 173 & 75 & 0,13 \\
\hline \multicolumn{11}{|c|}{ Nüchterungsdauer } \\
\hline 16 Stunden & 1774 & 924 & 52 & 617 & 35 & 234 & 13 & 271 & 80 & 0,15 \\
\hline 24 Stunden & 1586 & 813 & 51 & 550 & 35 & 223 & 14 & 214 & 76 & 0,13 \\
\hline \multicolumn{11}{|l|}{ in-vitro-Substrat } \\
\hline $\mathrm{Heu}$ & 2722 & 1387 & 50 & 993 & 36 & 342 & 24 & 454 & 88 & 0,17 \\
\hline Stroh & 1683 & 880 & 52 & 616 & 36 & 186 & 21 & 272 & 87 & 0,16 \\
\hline Blinddarminhalt & 891 & 459 & 51 & 259 & 29 & 173 & 37 & 78 & 62 & 0,09 \\
\hline Mittel & 1721 & 887 & 51 & 601 & 34 & 232 & 19 & 255 & 78 & 0,14 \\
\hline
\end{tabular}

Anhang 2: Einfluß von Ration, Nüchterungsdauer und in-vitro-Substrat auf SCFA und Wasserstoffwiederfindungsrate $\left(\mathrm{H}_{\mathrm{u}} / \mathrm{H}_{\mathrm{p}}\right)$ im defaunierten Pansensaft (Ration und Nüchterungsdauer $n=54$, in-vitro-Substrat $n=36$ ).

\begin{tabular}{|c|c|c|c|c|c|c|c|c|}
\hline \multirow{2}{*}{$\begin{array}{l}\text { defaunierter } \\
\text { Pansensaft }\end{array}$} & \multirow{2}{*}{$\begin{array}{l}\text { SCFA } \\
\mu \mathrm{mol}\end{array}$} & \multicolumn{2}{|c|}{ Acetat } & \multicolumn{2}{|c|}{ Propionat } & \multicolumn{2}{|c|}{ Butyrat } & \multirow{2}{*}{$\begin{array}{c}\mathbf{H}_{\mathrm{u}} / \mathbf{H}_{\mathrm{p}} \\
\%\end{array}$} \\
\hline & & $\mu \mathrm{mol}$ & $\%$ & $\mu \mathrm{mol}$ & $\%$ & $\mu \mathrm{mol}$ & $\%$ & \\
\hline \multicolumn{9}{|l|}{ Ration } \\
\hline $\mathrm{Heu}$ & 718 & 251 & 35 & 381 & 53 & 86 & 12 & 77 \\
\hline Stroh & 576 & 243 & 42 & 265 & 46 & 68 & 12 & 65 \\
\hline \multicolumn{9}{|c|}{ Nüchterungsdauer } \\
\hline 16 Stunden & 722 & 262 & 36 & 384 & 53 & 76 & 10 & 76 \\
\hline 24 Stunden & 573 & 233 & 41 & 262 & 46 & 78 & 14 & 66 \\
\hline \multicolumn{9}{|l|}{ in-vitro-Substrat } \\
\hline $\mathrm{Heu}$ & 1130 & 400 & 35 & 640 & 57 & 89 & 8 & 81 \\
\hline Stroh & 378 & 120 & 32 & 222 & 59 & 37 & 10 & 85 \\
\hline Blinddarminhalt & 561 & 264 & 47 & 182 & 32 & 116 & 21 & 50 \\
\hline Mittel & 665 & 253 & 38 & 334 & 49 & 79 & 12 & 71 \\
\hline
\end{tabular}


Anhang 3: Einfluß von Ration, Nüchterungsdauer und in-vitro-Substrat auf SCFA, Methan und Methan / SCFA-Verhältnis im nicht defauniertem Pansensaft $(n=9)$.

\begin{tabular}{|c|c|c|c|c|c|c|c|c|c|c|}
\hline \multicolumn{11}{|c|}{ nicht defaunierter Pansensaft } \\
\hline \multicolumn{11}{|c|}{ Ration Heu-Kraftfutter } \\
\hline \multirow{2}{*}{$\begin{array}{c}\text { Nüchterungs- } \\
\text { dauer }\end{array}$} & \multirow{2}{*}{ in-vitro-Substrat } & \multirow{2}{*}{$\begin{array}{l}\text { SCFA } \\
\mu \mathrm{mol}\end{array}$} & \multicolumn{2}{|c|}{ Acetat } & \multicolumn{2}{|c|}{ Propionat } & \multicolumn{2}{|c|}{ Butyrat } & \multirow{2}{*}{$\begin{array}{l}\mathrm{CH}_{4} \\
\mu \mathrm{mol}\end{array}$} & \multirow[t]{2}{*}{$\mathrm{CH}_{4} / \mathrm{SCFA}$} \\
\hline & & & $\mu \mathrm{mol}$ & $\%$ & $\mu \mathrm{mol}$ & $\%$ & $\mu \mathrm{mol}$ & $\%$ & & \\
\hline \multirow{3}{*}{16 Stunden } & $\mathrm{Heu}$ & 2944 & 1582 & 54 & 970 & 33 & 392 & 13 & 561 & 0,19 \\
\hline & Stroh & 1949 & 996 & 51 & 726 & 37 & 227 & 12 & 311 & 0,16 \\
\hline & Blinddarminhalt & 1201 & 605 & 50 & 369 & 31 & 227 & 19 & 125 & 0,10 \\
\hline \multirow{3}{*}{24 Stunden } & $\mathrm{Heu}$ & 3185 & 1621 & 51 & 1065 & 33 & 499 & 16 & 623 & 0,20 \\
\hline & Stroh & 2017 & 1063 & 53 & 692 & 34 & 262 & 13 & 344 & 0,17 \\
\hline & Blinddarminhalt & 1215 & 594 & 49 & 379 & 31 & 242 & 20 & 139 & 0,11 \\
\hline \multicolumn{11}{|c|}{ Ration Stroh-Harnstoff } \\
\hline \multirow{2}{*}{$\begin{array}{l}\text { Nüchterungs- } \\
\text { dauer }\end{array}$} & \multirow{2}{*}{ in-vitro-Substrat } & SCFA & \multicolumn{2}{|c|}{ Acetat } & \multicolumn{2}{|c|}{ Propionat } & \multicolumn{2}{|c|}{ Butyrat } & \multirow{2}{*}{$\begin{array}{l}\mathrm{CH}_{4} \\
\mu \mathrm{mol}\end{array}$} & \multirow[t]{2}{*}{$\mathrm{CH}_{4} / \mathrm{SCFA}$} \\
\hline & & $\mu \mathrm{mol}$ & $\mu \mathrm{mol}$ & $\%$ & $\mu \mathrm{mol}$ & $\%$ & $\mu \mathrm{mol}$ & $\%$ & & \\
\hline \multirow{3}{*}{16 Stunden } & $\mathrm{Heu}$ & 2699 & 1359 & 50 & 1061 & 39 & 278 & 10 & 454 & 0,17 \\
\hline & Stroh & 1671 & 878 & 53 & 606 & 36 & 187 & 11 & 297 & 0,18 \\
\hline & Blinddarminhalt & 739 & 398 & 54 & 210 & 28 & 130 & 18 & 61 & 0,08 \\
\hline \multirow{3}{*}{24 Stunden } & $\mathrm{Heu}$ & 2141 & 1029 & 48 & 882 & 41 & 230 & 11 & 234 & 0,11 \\
\hline & Stroh & 1194 & 611 & 52 & 459 & 38 & 113 & 9 & 158 & 0,13 \\
\hline & Blinddarminhalt & 502 & 282 & 56 & 126 & 25 & 94 & 19 & 22 & 0,04 \\
\hline
\end{tabular}


Anhang 4: Einfluß von Ration, Nüchterungsdauer und in-vitro-Substrat auf SCFA im defauniertem Pansensaft $(n=9)$.

\begin{tabular}{|c|c|c|c|c|c|c|c|c|}
\hline \multicolumn{9}{|c|}{ defaunierter Pansensaft } \\
\hline \multicolumn{9}{|c|}{ Ration Heu-Kraftfutter } \\
\hline \multirow{2}{*}{$\begin{array}{c}\text { Nüchterungs- } \\
\text { dauer }\end{array}$} & \multirow{2}{*}{ in-vitro-Substrat } & \multirow{2}{*}{$\begin{array}{l}\text { SCFA } \\
\mu \mathrm{mol}\end{array}$} & \multicolumn{2}{|c|}{ Acetat } & \multicolumn{2}{|c|}{ Propionat } & \multicolumn{2}{|c|}{ Butyrat } \\
\hline & & & $\mu \mathrm{mol}$ & $\%$ & $\mu \mathrm{mol}$ & $\%$ & $\mu \mathrm{mol}$ & $\%$ \\
\hline \multirow{3}{*}{16 Stunden } & Heu & 1419 & 459 & 32 & 858 & 60 & 102 & 7 \\
\hline & Stroh & 434 & 105 & 24 & 282 & 65 & 46 & 11 \\
\hline & Blinddarminhalt & 616 & 253 & 41 & 234 & 38 & 130 & 21 \\
\hline \multirow{3}{*}{24 Stunden } & $\mathrm{Heu}$ & 1229 & 448 & 36 & 710 & 58 & 71 & 6 \\
\hline & Stroh & 341 & 101 & 30 & 193 & 57 & 47 & 14 \\
\hline & Blinddarminhalt & 639 & 262 & 41 & 229 & 36 & 147 & 23 \\
\hline \multicolumn{9}{|c|}{ Ration Stroh-Harnstoff } \\
\hline \multirow{2}{*}{$\begin{array}{l}\text { Nüchterungs- } \\
\text { dauer }\end{array}$} & \multirow{2}{*}{ in-vitro-Substrat } & SCFA & \multicolumn{2}{|c|}{ Acetat } & \multicolumn{2}{|c|}{ Propionat } & \multicolumn{2}{|c|}{ Butyrat } \\
\hline & & $\mu \mathrm{mol}$ & $\mu \mathrm{mol}$ & $\%$ & $\mu \mathrm{mol}$ & $\%$ & $\mu \mathrm{mol}$ & $\%$ \\
\hline \multirow{3}{*}{16 Stunden } & Heu & 1089 & 393 & 36 & 647 & 59 & 49 & 4 \\
\hline & Stroh & 460 & 165 & 36 & 264 & 57 & 32 & 7 \\
\hline & Blinddarminhalt & 622 & 283 & 45 & 213 & 34 & 126 & 20 \\
\hline \multirow{3}{*}{24 Stunden } & Heu & 854 & 308 & 36 & 394 & 46 & 152 & 18 \\
\hline & Stroh & 297 & 112 & 38 & 160 & 54 & 25 & 8 \\
\hline & Blinddarminhalt & 403 & 225 & 63 & 80 & 20 & 68 & 17 \\
\hline
\end{tabular}


Anhang 5: Wasserstoffwiederfindungsraten $\left(\mathrm{H}_{u} / \mathrm{H}_{\mathrm{p}}\right)$ aller 24 möglichen Faktorkombinationen $(n=9)$. Unterschiedliche Buchstaben kennzeichnen signifikante Unterschiede zwischen den in-vitro-Substraten bei gleicher Ration und Nüchterungsdauer, Tukey-Kramer-Test, $p<0,05$.

\begin{tabular}{|c|c|c|c|}
\hline \multicolumn{4}{|c|}{ Ration Heu-Kraftfutter } \\
\hline \multirow{2}{*}{ Nüchterungsdauer } & \multirow{2}{*}{ in-vitro-Substrat } & \multicolumn{2}{|c|}{$\mathbf{H}_{\mathrm{u}} / \mathrm{H}_{\mathrm{p}}(\%)$} \\
\hline & & nicht defauniert & Defauniert \\
\hline \multirow{3}{*}{16 Stunden } & $\overline{\text { Heu }}$ & $87^{a}$ & $91^{\mathrm{a}}$ \\
\hline & Stroh & $88^{\mathrm{a}}$ & $98^{\mathrm{a}}$ \\
\hline & Blinddarminhalt & $69^{b}$ & $59^{b}$ \\
\hline \multirow{3}{*}{24 Stunden } & $\mathrm{Heu}$ & $90^{\mathrm{a}}$ & $83^{a}$ \\
\hline & Stroh & $85^{\mathrm{a}}$ & $83^{\mathrm{a}}$ \\
\hline & Blinddarminhalt & $72^{b}$ & $56^{\mathrm{b}}$ \\
\hline \multicolumn{4}{|c|}{ Ration Stroh-Harnstoff } \\
\hline \multirow{2}{*}{ Nüchterungsdauer } & \multirow{2}{*}{ in-vitro-Substran } & \multicolumn{2}{|c|}{$H_{u} / H_{p}(\%)$} \\
\hline & & nicht defauniert & Defauniert \\
\hline \multirow{3}{*}{16 Stunden } & Heu & $92^{\mathrm{a}}$ & $82^{\mathrm{a}}$ \\
\hline & Stroh & $89^{a}$ & $81^{a}$ \\
\hline & Blinddarminhalt & $61^{b}$ & $52^{b}$ \\
\hline \multirow{3}{*}{24 Stunden } & Heu & $83^{\mathrm{a}}$ & $69^{\mathrm{a}}$ \\
\hline & Stroh & $84^{\mathrm{a}}$ & $77^{\mathrm{a}}$ \\
\hline & Blinddarminhalt & $50^{b}$ & $34^{b}$ \\
\hline
\end{tabular}

Anhang 6: Einfluß der Begasung mit $80 \%$ Argon bzw. $80 \%$ Wasserstoff in der Gasatmosphäre einer batch-culture-Inkubation mit Bakterien aus dem Schweinedarm auf SCFA und Methan $(n=2$ bei Argon, $n=3$ bei Wasserstoff).

\begin{tabular}{|c|c|c|c|c|c|}
\hline \multirow{2}{*}{ Begasung } & \multicolumn{5}{|c|}{$\mu \mathrm{mol}$} \\
\hline & SCFA & Acetat & Propionat & Butyrat & $\mathrm{CH}_{4}$ \\
\hline Argon & 997,18 & 646,450 & 207,200 & 143,530 & 117,828 \\
\hline Wasserstoff & 1072,50 & 701,333 & 208,267 & 162,927 & 192,253 \\
\hline
\end{tabular}

Anhang 7: Anteile einfach und doppelt ${ }^{13} \mathrm{C}-\mathrm{CO}_{2}$-markierter Essigsäure in mit Argon bzw. Wasserstoff begasten Inkubationsgefäßen.

\begin{tabular}{|c|c|c|c|}
\hline \multirow{2}{*}{ Begasung } & \multicolumn{3}{|c|}{$\%$ an Gesamtacetat } \\
\hline & $\mathrm{CH}_{3}+{ }^{13} \mathrm{COOH}$ & ${ }^{13} \mathrm{CH}_{3}+\mathrm{COOH}$ & ${ }^{13} \mathrm{COOH}+{ }^{13} \mathrm{CH}_{3}$ \\
\hline Argon & 15,89 & 14,53 & 2,96 \\
\hline Argon & 13,32 & 13,22 & 2,79 \\
\hline $\mathrm{H}_{2}$ & 23,26 & 26,92 & 8,42 \\
\hline $\mathrm{H}_{2}$ & 17,91 & 22,55 & 6,74 \\
\hline $\mathrm{H}_{2}$ & 21,07 & 26,78 & 6,47 \\
\hline
\end{tabular}


Anhang 8: Einfluß der in-vitro-Substrate $\mathrm{Heu}$ und Blinddarminhalt sowie der Defaunierung des Inokulums mit Synperonic auf SCFA und Methan $(n=3)$.

\begin{tabular}{|c|c|c|c|c|c|}
\hline \hline \multirow{2}{*}{ in-vitro-Substrat } & \multicolumn{5}{|c|}{$\mu$ mol } \\
& SCFA & Acetat & Propionat & Butyrat & $\mathbf{C H}_{\mathbf{4}}$ \\
\hline \hline Heu & 841,67 & 478,76 & 226,98 & 135,93 & 1221,75 \\
\hline Blinddarminhalt & 560,13 & 296,18 & 118,50 & 145,45 & 1136,47 \\
\hline Synperonic & 763,41 & 413,23 & 302,65 & 47,53 & 430,01 \\
\hline \hline
\end{tabular}

Anhang 9: Einfluß unterschiedlicher Gallensalzkonzentrationen auf SCFA, Methan und Methan / SCFA-Verhältnis in den einzelnen Fermentern des RUSITEC.

\begin{tabular}{|c|r|r|r|r|r|r|}
\hline \hline \multirow{2}{*}{ Fermenter } & \multicolumn{6}{|c|}{$\mu \mathrm{mol}$} \\
& $\mathbf{F ~ 1}$ & $\mathbf{F ~ 2}$ & $\mathbf{F ~ 3}$ & $\mathbf{F ~ 4}$ & $\mathbf{F ~ 5}$ & F 6 \\
\hline \hline Gallensalz (\%) (w/v) & 0,00 & 0,25 & 0,50 & 1,00 & 1,50 & 2,00 \\
\hline SCFA & 28,27 & 24,95 & 21,45 & 16,89 & 15,94 & 12,87 \\
\hline Acetat & 15,40 & 13,30 & 11,73 & 9,05 & 8,29 & 6,61 \\
\hline Propionat & 6,31 & 5,50 & 5,95 & 6,37 & 6,49 & 5,33 \\
\hline Butyrat & 3,06 & 3,12 & 2,61 & 1,40 & 1,11 & 0,89 \\
\hline $\mathbf{C H}_{4}$ & 3,50 & 3,03 & 1,16 & 0,07 & 0,05 & 0,04 \\
\hline $\mathbf{C H}_{\mathbf{4}}$ / SCFA & 0,12 & 0,12 & 0,05 & 0,00 & 0,00 & 0,00 \\
\hline \hline
\end{tabular}

Anhang 10: Einfluß unterschiedlicher Gallensalzkonzentrationen auf die Protozoenzahl im RUSITEC.

\begin{tabular}{|c|c|c|c|}
\hline \hline \multirow{2}{*}{ Tag } & \multicolumn{3}{|c|}{ Protozoen / ml Fermenterflüssigkeit } \\
& Kontrolle & $\mathbf{0 , 4} \%$ Gallensalz & $\mathbf{0 , 6} \%$ Gallensalz \\
\hline \hline $\mathbf{1}$ & 35714 & 29337 & 25510 \\
\hline $\mathbf{2}$ & 17857 & 17219 & 16582 \\
\hline $\mathbf{3}$ & 18160 & 17114 & 15937 \\
\hline $\mathbf{4}$ & 17857 & 6803 & 6378 \\
\hline $\mathbf{5}$ & 11054 & 638 & 1063 \\
\hline $\mathbf{6}$ & 14541 & 38 & 38 \\
\hline \hline
\end{tabular}


Anhang 11: Einfluß unterschiedlicher Gallensalzkonzentrationen auf SCFA, Methan, Wasserstoffwiederfindungsrate $\left(\mathrm{H}_{\mathrm{u}} / \mathrm{H}_{\mathrm{p}}\right)$ und Methan/SCFA-Verhältnis im RUSITEC.

\begin{tabular}{|c|c|c|c|c|c|c|c|c|}
\hline \multirow{2}{*}{ Tag } & \multirow{2}{*}{$\begin{array}{c}\text { Gallensalz- } \\
\text { konzentration }\end{array}$} & \multicolumn{5}{|c|}{$\mathrm{mmol}$} & \multirow{2}{*}{$\begin{array}{c}\% \\
\mathbf{H}_{\mathrm{u}} / \mathbf{H}_{\mathrm{p}}\end{array}$} & \multirow[b]{2}{*}{$\mathrm{CH}_{4} / \mathrm{SCFA}$} \\
\hline & & SCFA & Acetat & Propionat & Butyrat & $\mathrm{CH}_{4}$ & & \\
\hline \multirow{3}{*}{1} & Kontrolle & 45,53 & 31,34 & 9,50 & 4,69 & 4,89 & 53 & 0,11 \\
\hline & kein Gallensalz & 45,78 & 31,41 & 9,57 & 4,80 & 9,94 & 75 & 0,22 \\
\hline & kein Gallensalz & 43,37 & 30,18 & 9,32 & 3,87 & 8,53 & 71 & 0,20 \\
\hline \multirow{3}{*}{2} & Kontrolle & 52,58 & 34,45 & 12,34 & 5,79 & 12,2 & 81 & 0,23 \\
\hline & kein Gallensalz & 44,11 & 28,85 & 10,37 & 4,89 & 11,58 & 88 & 0,26 \\
\hline & kein Gallensalz & 47,21 & 31,23 & 11,23 & 4,75 & 10,52 & 80 & 0,22 \\
\hline \multirow{3}{*}{3} & Kontrolle & 40,06 & 26,23 & 9,43 & 4,40 & 7 & 70 & 0,17 \\
\hline & kein Gallensalz & 46,59 & 30,53 & 10,85 & 5,21 & 9,55 & 76 & 0,20 \\
\hline & kein Gallensalz & 46,67 & 30,78 & 11,19 & 4,70 & 10,6 & 81 & 0,23 \\
\hline \multirow{3}{*}{4} & Kontrolle & 46,46 & 30,33 & 11,34 & 4,79 & 7,86 & 70 & 0,17 \\
\hline & Gallensalz $0,4 \%$ & 40,41 & 26,18 & 9,44 & 4,79 & 8,06 & 75 & 0,20 \\
\hline & Gallensalz $0,6 \%$ & 37,44 & 24,42 & 9,02 & 4,00 & 9,46 & 86 & 0,25 \\
\hline \multirow{3}{*}{5} & Kontrolle & 46,45 & 29,28 & 11,73 & 5,44 & 6,05 & 64 & 0,13 \\
\hline & Gallensalz $0,4 \%$ & 39,75 & 25,60 & 9,45 & 4,70 & 4,85 & 60 & 0,12 \\
\hline & Gallensalz $0,6 \%$ & 42,36 & 27,02 & 10,64 & 4,70 & 0 & 37 & 0,00 \\
\hline \multirow{3}{*}{6} & Kontrolle & 35,36 & 22,40 & 9,33 & 3,63 & 6,41 & 75 & 0,18 \\
\hline & Gallensalz $0,4 \%$ & 28,61 & 17,17 & 7,89 & 3,55 & 2,18 & 56 & 0,08 \\
\hline & Gallensalz 0,6 \% & 30,08 & 18,29 & 8,49 & 3,30 & 1,72 & 52 & 0,06 \\
\hline
\end{tabular}


Anhang 12: Einfluß unterschiedlicher Gallensalzkonzentrationen auf SCFA und deren prozentuale Zusammensetzung im RUSITEC.

\begin{tabular}{|c|c|c|c|c|c|}
\hline Tag & $\begin{array}{c}\text { Gallensalz- } \\
\text { konzentration }\end{array}$ & $\begin{array}{l}\text { umol } \\
\text { SCFA }\end{array}$ & Acetat & $\begin{array}{l}\% \text { an SCFA } \\
\text { Propionat }\end{array}$ & Butyrat \\
\hline \multirow{3}{*}{1} & Kontrolle & 45,53 & 69 & 21 & 10 \\
\hline & kein Gallensalz & 45,78 & 69 & 21 & 10 \\
\hline & kein Gallensalz & 43,37 & 70 & 21 & 9 \\
\hline \multirow{3}{*}{2} & Kontrolle & 52,58 & 66 & 23 & 11 \\
\hline & kein Gallensalz & 44,11 & 65 & 24 & 11 \\
\hline & kein Gallensalz & 47,21 & 66 & 24 & 10 \\
\hline \multirow{3}{*}{3} & Kontrolle & 40,06 & 65 & 24 & 11 \\
\hline & kein Gallensalz & 46,59 & 66 & 23 & 11 \\
\hline & kein Gallensalz & 46,67 & 66 & 24 & 10 \\
\hline \multirow{3}{*}{4} & Kontrolle & 46,46 & 65 & 24 & 10 \\
\hline & Gallensalz 0,4\% & 40,41 & 65 & 23 & 12 \\
\hline & Gallensalz 0,6\% & 37,44 & 65 & 24 & 11 \\
\hline \multirow{3}{*}{5} & Kontrolle & 46,45 & 63 & 25 & 12 \\
\hline & Gallensalz 0,4\% & 39,75 & 64 & 24 & 12 \\
\hline & Gallensalz 0,6\% & 42,36 & 64 & 25 & 11 \\
\hline \multirow{3}{*}{6} & Kontrolle & 35,36 & 63 & 26 & 10 \\
\hline & Gallensalz 0,4\% & 28,61 & 60 & 28 & 12 \\
\hline & Gallensalz 0,6\% & 30,08 & 61 & 28 & 11 \\
\hline
\end{tabular}

Anhang 13: Einfluß unterschiedlicher Gallensalzkonzentrationen im RUSITEC auf SCFA und Methan in der batch-culture.

\begin{tabular}{|c|c|c|c|c|c|c|c|c|}
\hline $\begin{array}{c}\text { Gallensalz- } \\
\text { konzentration }\end{array}$ & $\begin{array}{l}\text { SCFA } \\
\mu \mathrm{mol}\end{array}$ & $\begin{array}{c}\text { Acetat } \\
\mu \mathrm{mol}\end{array}$ & $\%$ & $\begin{array}{c}\text { Propionat } \\
\text { umol }\end{array}$ & $\%$ & $\begin{array}{c}\text { Butyrat } \\
\mu \mathrm{mol}\end{array}$ & $\%$ & $\begin{array}{l}\mathrm{CH}_{4} \\
\mu \mathrm{mol}\end{array}$ \\
\hline Kontrolle & 1025 & 509 & 50 & 236 & 23 & 280 & 27 & 1503 \\
\hline Gallensalz $0,4 \%$ & 676 & 264 & 39 & 158 & 23 & 254 & 38 & 73 \\
\hline Gallensalz $0,6 \%$ & 540 & 120 & 22 & 130 & 24 & 290 & 54 & 26 \\
\hline
\end{tabular}


Anhang 14: ${ }^{13} \mathrm{C}-\mathrm{NMR}$ Spektren von Kohlenstoffatomen des Acetats einiger in-vitro Inkubationen.

Spektrum 1: ${ }^{13} \mathrm{C}$-Banden der Methylgruppe des Acetats aus einer Inkubation mit Bakteriensuspension aus dem Schweinedarm ohne Wasserstoffbegasung, $16^{*} 10^{4}$ fache Vergrößerung.

Spektrum 2: ${ }^{13} \mathrm{C}$-Banden der Methylgruppe des Acetats aus einer Inkubation mit Bakteriensuspension aus dem Schweinedarm mit Wasserstoffbegasung, $8^{*} 10^{4}$ fache Vergrößerung
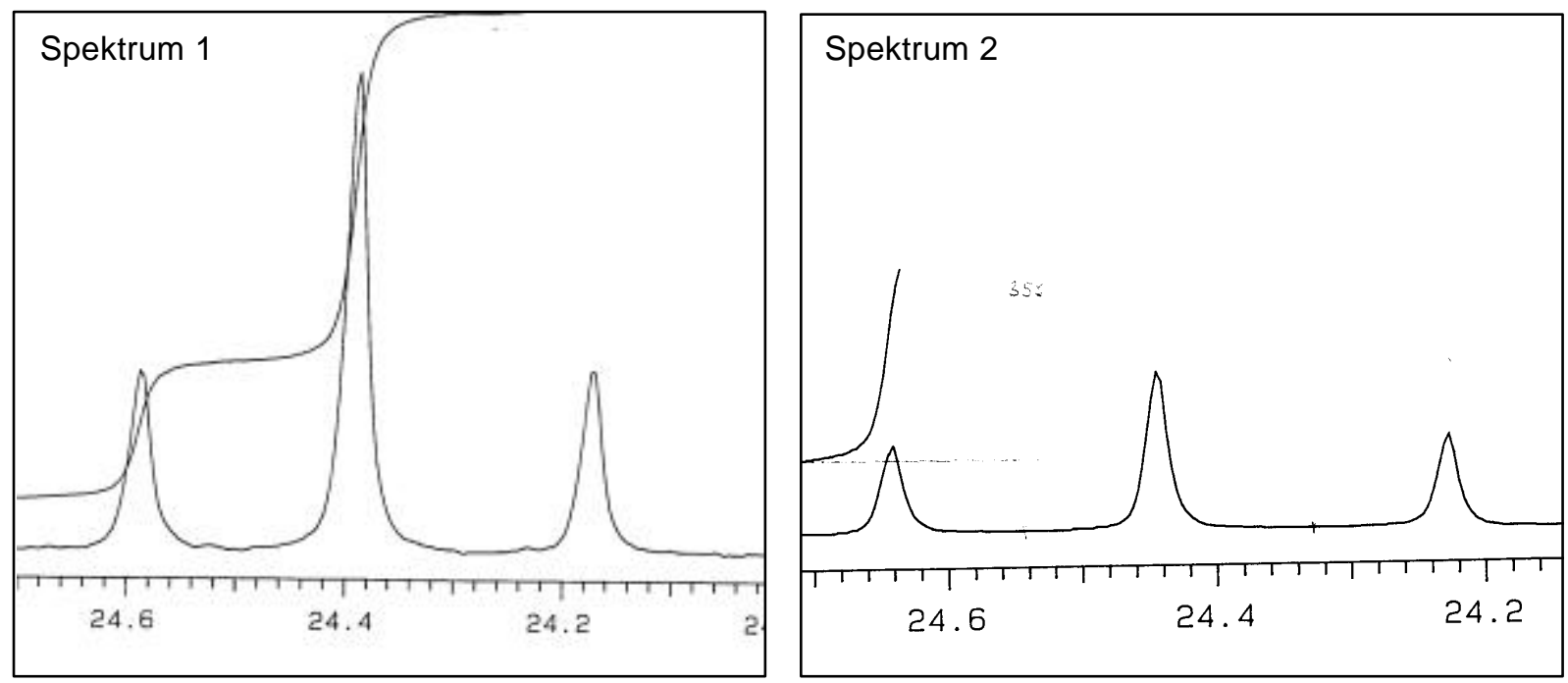

Spektrum 3: ${ }^{13} \mathrm{C}$-Banden der Methylgruppe des Acetats aus einer Inkubation mit Pansensaft einer batch-culture Inkubation mit dem in-vitro-Substrat $\mathrm{Heu}, 16^{\star} 10^{4}$ fache Vergrößerung.

Spektrum 4: ${ }^{13} \mathrm{C}$-Banden der Methylgruppe des Acetats aus einer Inkubation mit Pansensaft einer batch-culture Inkubation mit dem in-vitro-Substrat Blinddarminhalt, $32^{*} 10^{4}$ fache Vergrößerung.
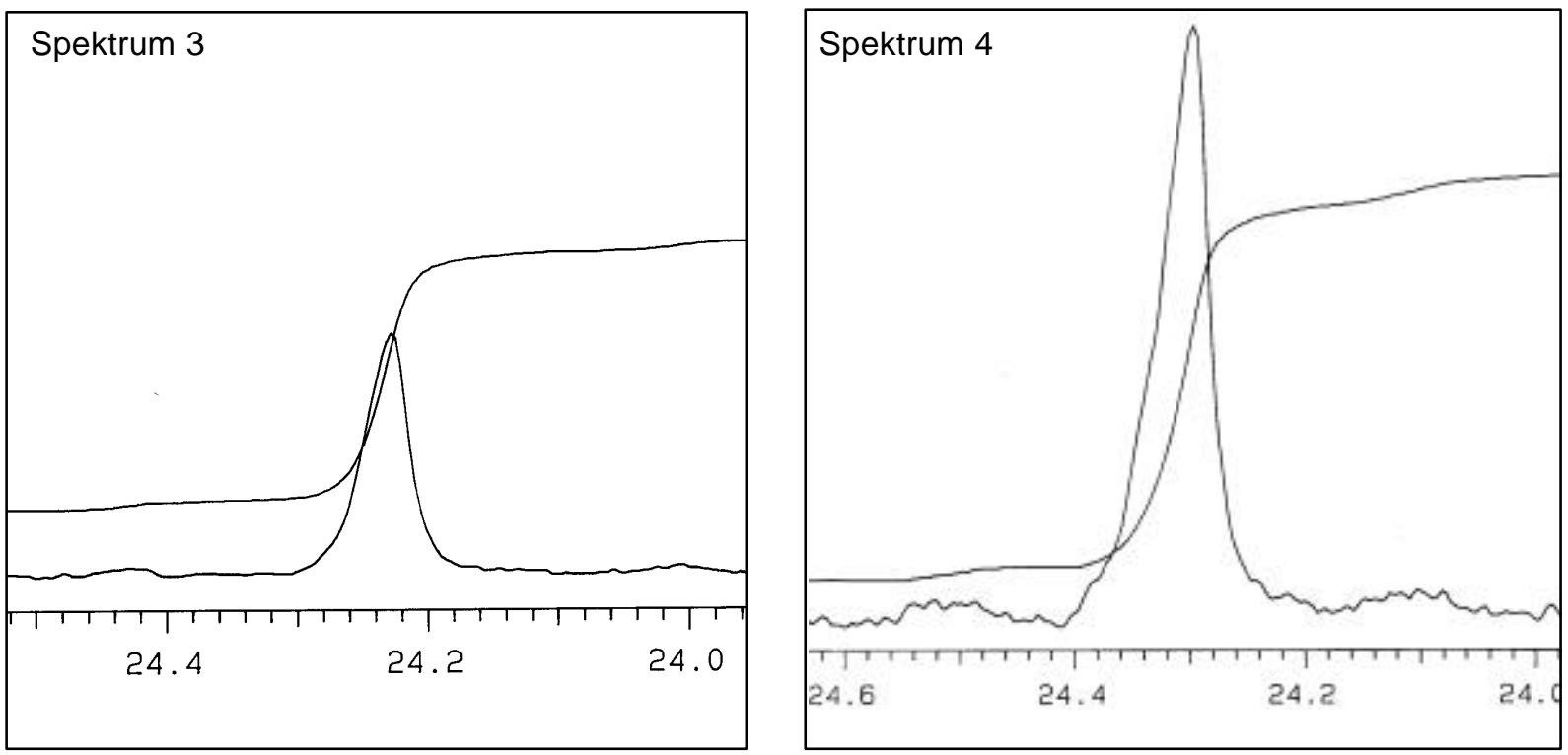
Anhang 14: ${ }^{13} \mathrm{C}-\mathrm{NMR}$ Spektren von Kohlenstoffatomen des Acetats einiger in-vitro Inkubationen (Fortsetzung 1).

Spektrum 5: ${ }^{13} \mathrm{C}$-Banden der Methylgruppe des Acetats aus einer Inkubation mit Pansensaft einer batch-culture Inkubation mit defauniertem Pansensaft, $64^{*} 10^{4}$ fache Vergrößerung.

Spektrum 6: ${ }^{13} \mathrm{C}$-Banden der Methylgruppe des Acetats aus einer Inkubation mit Pansensaft einer batch-culture Inkubation mit im RUSITEC-System vorinkubiertem Pansensaft (1. Wdh.), $64^{*} 10^{4}$ fache Vergrößerung
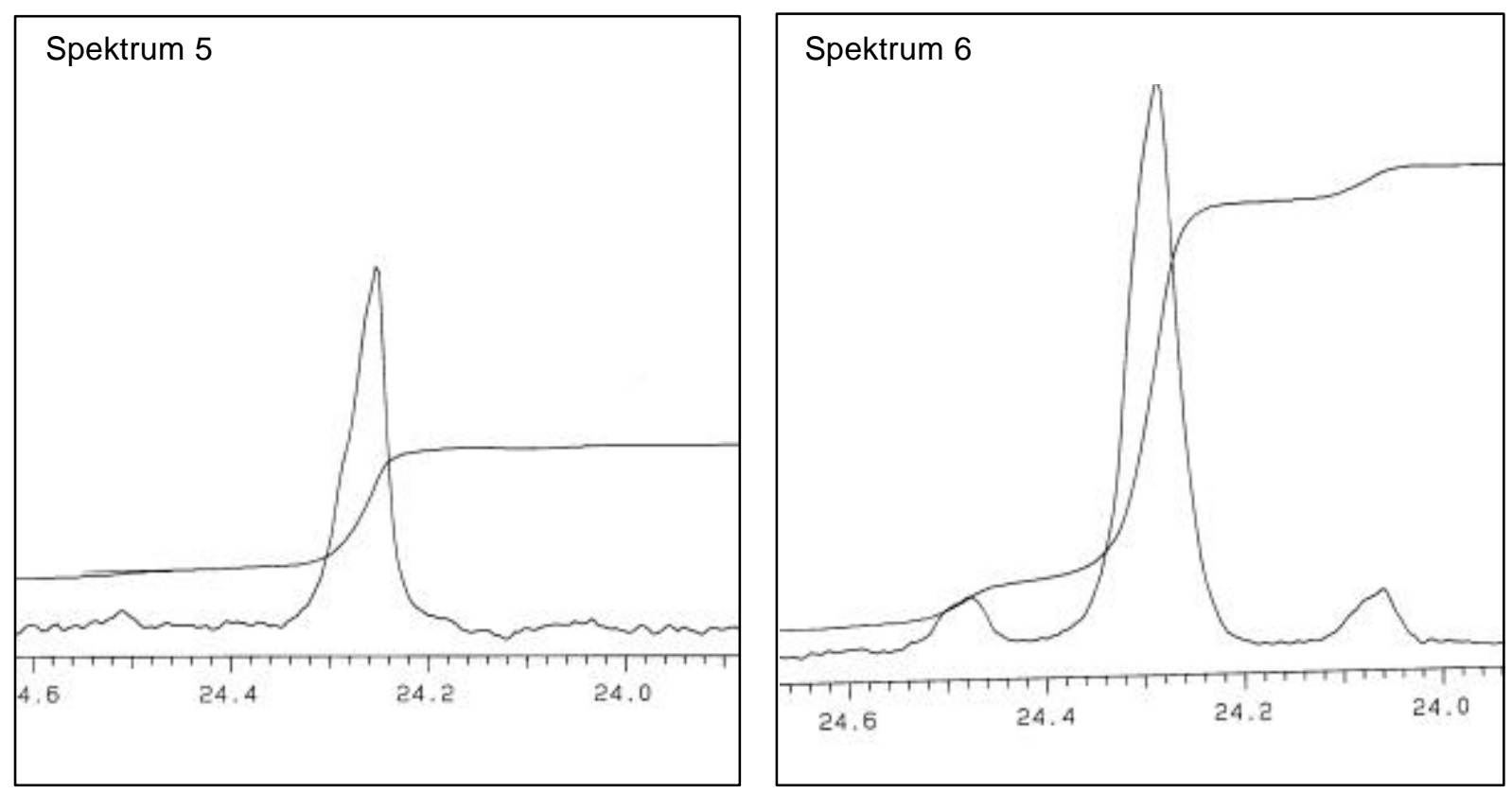

Spektrum 7: ${ }^{13} \mathrm{C}$-Banden der Methylgruppe des Acetats aus einer Inkubation mit Pansensaft einer batch-culture Inkubation mit im RUSITEC-System vorinkubiertem Pansensaft (2. Wdh.), $16^{*} 10^{4}$ fache Vergrößerung.

Spektrum 8: ${ }^{13} \mathrm{C}$-Banden der Methylgruppe des Acetats aus einer Inkubation mit Pansensaft einer batch-culture Inkubation mit im RUSITEC-System vorinkubiertem Pansensaft (3. Wdh.), $32^{*} 10^{4}$ fache Vergrößerung.
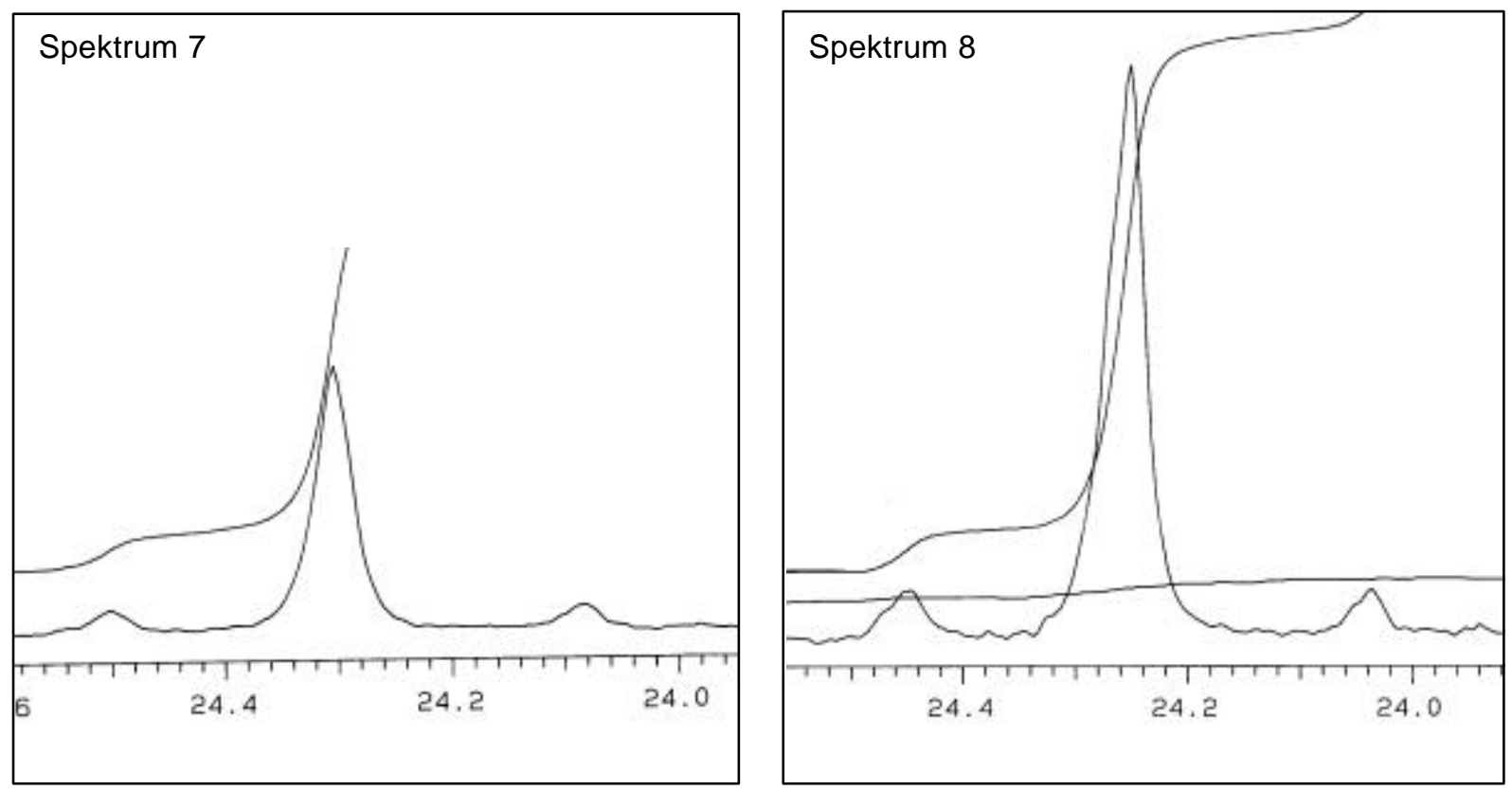
Anhang 14: ${ }^{13} \mathrm{C}-\mathrm{NMR}$ Spektren von Kohlenstoffatomen des Acetats einiger in-vitro Inkubationen (Fortsetzung 2).

Spektrum 9: ${ }^{13} \mathrm{C}$-Banden der Carboxylgruppe des Acetats aus einer Inkubation mit Pansensaft aus einer batch-culture Inkubation mit im RUSITEC-System bei 0,4\% Gallensalzkonzentration vorinkubiertem Pansensaft (1. Wdh.), $32 * 10^{4}$ fache Vergrößerung.

Spektrum 10: ${ }^{13} \mathrm{C}$-Banden der Carboxylgruppe des Acetats aus einer Inkubation mit Pansensaft aus einer batch-culture Inkubation mit im RUSITEC-System bei 0,4\% Gallensalzkonzentration vorinkubiertem Pansensaft (2. Wdh.), $16^{*} 10^{4}$ fache Vergrößerung.
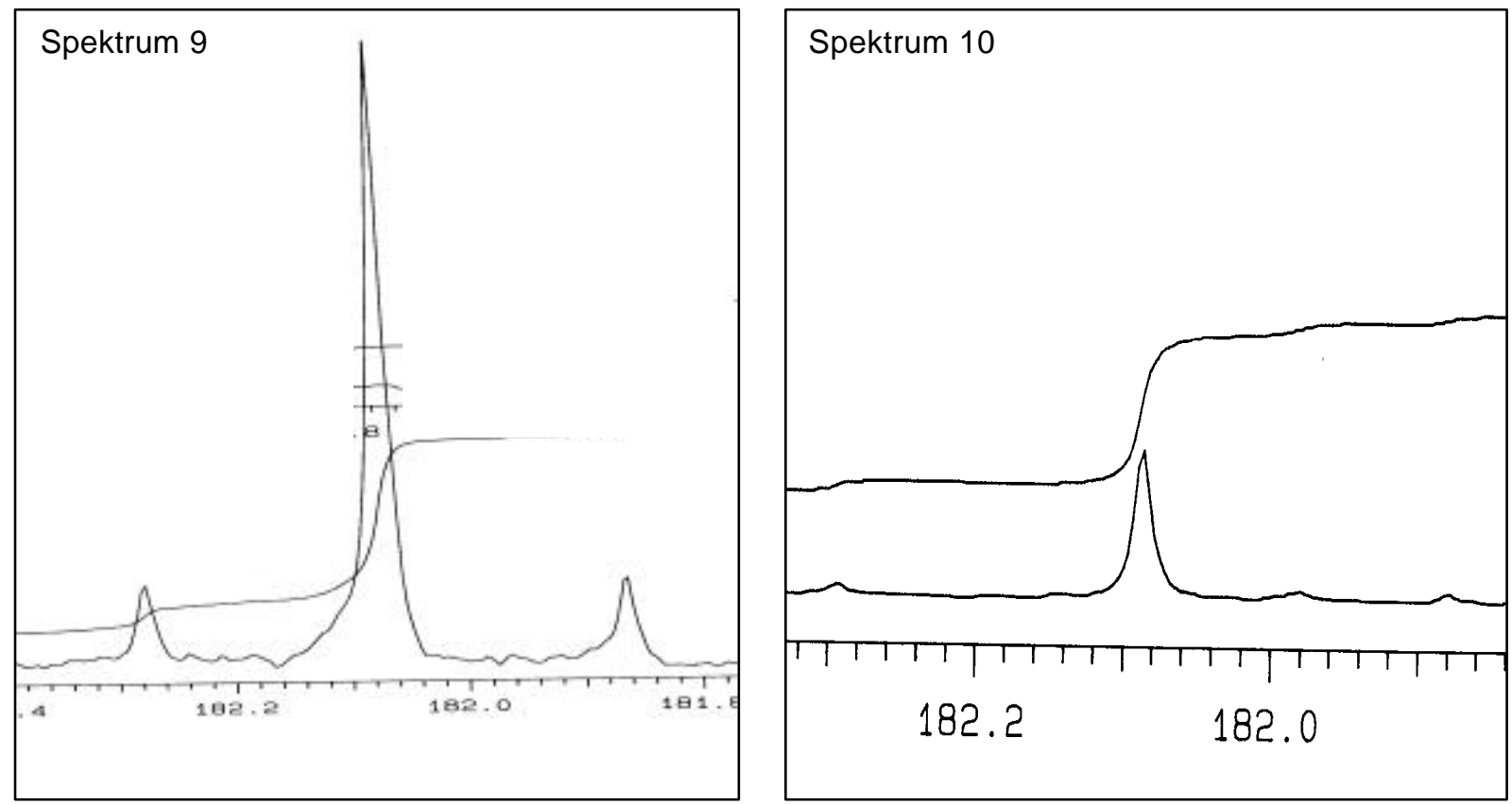

Spektrum 11: ${ }^{13} \mathrm{C}$-Banden der Carboxylgruppe des Acetats aus einer Inkubation mit Pansensaft aus einer batch-culture Inkubation mit im RUSITEC-System bei $0,4 \%$ Gallensalzkonzentration vorinkubiertem Pansensaft (3. Wdh.), $64 * 10^{4}$ fache Vergrößerung.

Spektrum 12: ${ }^{13} \mathrm{C}$-Banden der Carboxylgruppe des Acetats aus einer Inkubation mit Pansensaft aus einer batch-culture Inkubation mit im RUSITEC-System bei $0,6 \%$ Gallensalzkonzentration vorinkubiertem Pansensaft, 64*104 fache Vergrößerung.
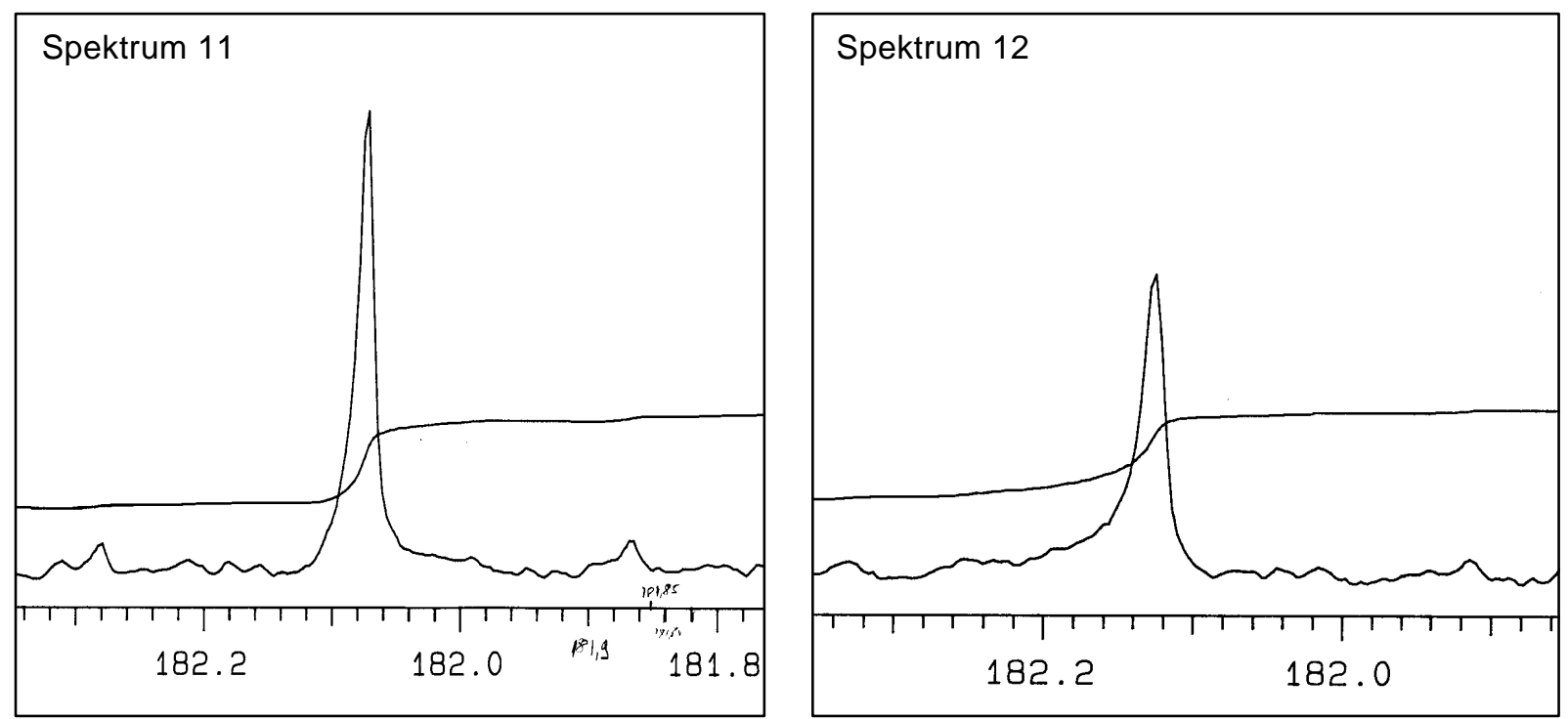
Anhang 15: Originaldaten der batch-culture-Untersuchungen mit nicht defauniertem Pansensaft. (Kodierung siehe Anhang 17)

\begin{tabular}{|c|c|c|c|c|c|c|c|c|c|c|c|c|}
\hline Nr. & RAT & NUE & PRO & SUB & TAG & Wdh & $\begin{array}{l}\text { SCFA } \\
\mu \mathrm{mol} \\
\end{array}$ & \begin{tabular}{|c|} 
Acetat \\
$\mu \mathrm{mol}$
\end{tabular} & \begin{tabular}{|c|}
$\begin{array}{c}\text { Propionat } \\
\mu \mathrm{mol}\end{array}$ \\
\end{tabular} & $\begin{array}{c}\text { Butyrat } \\
\mu \mathrm{mol} \\
\end{array}$ & $\begin{array}{c}\mathrm{CH}_{4} \\
\mu \mathrm{mol} \\
\end{array}$ & $\begin{array}{c}\mathrm{H}_{\mathrm{U}} / \mathrm{H}_{\mathrm{P}} \\
\% \\
\end{array}$ \\
\hline 1 & 1 & 1 & 1 & 1 & 1 & 1 & 2812 & 1385 & 1157 & 270 & 475 & 95 \\
\hline 2 & 1 & 1 & 1 & 1 & 1 & 2 & 2624 & 1306 & 1086 & 232 & 499 & 100 \\
\hline 3 & 1 & 1 & 1 & 1 & 1 & 3 & 2792 & 1355 & 1169 & 269 & 476 & 97 \\
\hline 19 & 1 & 1 & 1 & 1 & 2 & 1 & 2462 & 1357 & 875 & 231 & 484 & 92 \\
\hline 20 & 1 & 1 & 1 & 1 & 2 & 2 & 2540 & 1360 & 920 & 260 & 479 & 91 \\
\hline 21 & 1 & 1 & 1 & 1 & 2 & 3 & 2507 & 1313 & 928 & 266 & 421 & 88 \\
\hline 37 & 1 & 1 & 1 & 1 & 3 & 1 & 2783 & 1417 & 1066 & 300 & 427 & 87 \\
\hline 38 & 1 & 1 & 1 & 1 & 3 & 2 & 2868 & 1440 & 1114 & 315 & 413 & 86 \\
\hline 39 & 1 & 1 & 1 & 1 & 3 & 3 & 2947 & 1305 & 1267 & 375 & 414 & 92 \\
\hline 7 & 1 & 1 & 1 & 3 & 1 & 1 & 799 & 423 & 245 & 131 & 72 & 65 \\
\hline 8 & 1 & 1 & 1 & 3 & 1 & 2 & 721 & 408 & 198 & 115 & 68 & 61 \\
\hline 9 & 1 & 1 & 1 & 3 & 1 & 3 & 806 & 422 & 251 & 132 & 70 & 65 \\
\hline 25 & 1 & 1 & 1 & 3 & 2 & 1 & 629 & 407 & 131 & 91 & 61 & 53 \\
\hline 26 & 1 & 1 & 1 & 3 & 2 & 2 & 508 & 356 & 83 & 68 & 72 & 57 \\
\hline 27 & 1 & 1 & 1 & 3 & 2 & 3 & 404 & 305 & 50 & 49 & 51 & 49 \\
\hline 43 & 1 & 1 & 1 & 3 & 3 & 1 & 991 & 403 & 368 & 220 & 41 & 65 \\
\hline 44 & 1 & 1 & 1 & 3 & 3 & 2 & 1029 & 443 & 372 & 214 & 59 & 67 \\
\hline 45 & 1 & 1 & 1 & 3 & 3 & 3 & 1000 & 429 & 355 & 216 & 56 & 66 \\
\hline 4 & 1 & 1 & 1 & 2 & 1 & 1 & 1414 & 933 & 296 & 185 & 298 & 74 \\
\hline 5 & 1 & 1 & 1 & 2 & 1 & 2 & 1646 & 846 & 644 & 156 & 322 & 98 \\
\hline 6 & 1 & 1 & 1 & 2 & 1 & 3 & 1679 & 850 & 665 & 164 & 328 & 98 \\
\hline 22 & 1 & 1 & 1 & 2 & 2 & 1 & 1509 & 858 & 502 & 149 & 301 & 89 \\
\hline 23 & 1 & 1 & 1 & 2 & 2 & 2 & 1514 & 821 & 523 & 169 & 313 & 93 \\
\hline 24 & 1 & 1 & 1 & 2 & 2 & 3 & 1297 & 769 & 425 & 103 & 258 & 88 \\
\hline 40 & 1 & 1 & 1 & 2 & 3 & 1 & 2058 & 941 & 847 & 269 & 281 & 88 \\
\hline 41 & 1 & 1 & 1 & 2 & 3 & 2 & 2000 & 910 & 828 & 263 & 289 & 90 \\
\hline 42 & 1 & 1 & 1 & 2 & 3 & 3 & 2113 & 983 & 863 & 267 & 288 & 88 \\
\hline 55 & 1 & 2 & 1 & 1 & 1 & 1 & 2077 & 961 & 890 & 226 & 223 & 86 \\
\hline 56 & 1 & 2 & 1 & 1 & 1 & 2 & 1805 & 903 & 798 & 104 & 162 & 80 \\
\hline 57 & 1 & 2 & 1 & 1 & 1 & 3 & 2228 & 1100 & 911 & 217 & 179 & 77 \\
\hline 73 & 1 & 2 & 1 & 1 & 2 & 1 & 2123 & 1023 & 854 & 246 & 228 & 81 \\
\hline 74 & 1 & 2 & 1 & 1 & 2 & 2 & 2087 & 998 & 841 & 248 & 221 & 81 \\
\hline 75 & 1 & 2 & 1 & 1 & 2 & 3 & 2219 & 1051 & 904 & 264 & 234 & 81 \\
\hline 91 & 1 & 2 & 1 & 1 & 3 & 1 & 2169 & 1085 & 849 & 235 & 308 & 86 \\
\hline 92 & 1 & 2 & 1 & 1 & 3 & 2 & 2288 & 1096 & 923 & 269 & 315 & 87 \\
\hline 93 & 1 & 2 & 1 & 1 & 3 & 3 & 2322 & 1055 & 972 & 295 & 255 & 84 \\
\hline 61 & 1 & 2 & 1 & 3 & 1 & 1 & 489 & 227 & 133 & 129 & 29 & 58 \\
\hline
\end{tabular}


Anhang 15: Originaldaten der batch-culture-Untersuchungen mit nicht defauniertem Pansensaft (Fortsetzung 1).

\begin{tabular}{|c|c|c|c|c|c|c|c|c|c|c|c|c|}
\hline Nr. & RAT & NUE & PRO & SUB & TAG & Wdh & $\begin{array}{l}\text { SCFA } \\
\mu \mathrm{mol} \\
\end{array}$ & $\begin{array}{c}\text { Acetat } \\
\mu \mathrm{mol}\end{array}$ & $\begin{array}{c}\text { Propionat } \\
\mu \mathrm{mol} \\
\end{array}$ & $\begin{array}{c}\text { Butyrat } \\
\mu \mathrm{mol} \\
\end{array}$ & $\begin{array}{c}\mathrm{CH}_{4} \\
\mu \mathrm{mol} \\
\end{array}$ & $\begin{array}{c}\mathrm{Hu}_{\mathrm{u}} / \mathrm{H}_{\mathrm{P}} \\
\% \\
\end{array}$ \\
\hline 62 & 1 & 2 & 1 & 3 & 1 & 2 & 674 & 339 & 179 & 156 & 19 & 51 \\
\hline 63 & 1 & 2 & 1 & 3 & 1 & 3 & 513 & 285 & 121 & 107 & 20 & 48 \\
\hline 79 & 1 & 2 & 1 & 3 & 2 & 1 & 432 & 290 & 75 & 67 & 23 & 41 \\
\hline 80 & 1 & 2 & 1 & 3 & 2 & 2 & 512 & 305 & 111 & 96 & 20 & 46 \\
\hline 81 & 1 & 2 & 1 & 3 & 2 & 3 & 585 & 345 & 134 & 106 & 14 & 44 \\
\hline 97 & 1 & 2 & 1 & 3 & 3 & 1 & 541 & 273 & 140 & 128 & 23 & 53 \\
\hline 98 & 1 & 2 & 1 & 3 & 3 & 2 & 504 & 271 & 122 & 111 & 27 & 52 \\
\hline 99 & 1 & 2 & 1 & 3 & 3 & 3 & 478 & 216 & 131 & 131 & 23 & 57 \\
\hline 58 & 1 & 2 & 1 & 2 & 1 & 1 & 1338 & 680 & 546 & 112 & 148 & 81 \\
\hline 59 & 1 & 2 & 1 & 2 & 1 & 2 & 1195 & 605 & 483 & 107 & 152 & 85 \\
\hline 60 & 1 & 2 & 1 & 2 & 1 & 3 & 1380 & 637 & 596 & 147 & 181 & 90 \\
\hline 76 & 1 & 2 & 1 & 2 & 2 & 1 & 1067 & 594 & 404 & 69 & 148 & 82 \\
\hline 77 & 1 & 2 & 1 & 2 & 2 & 2 & 1061 & 596 & 402 & 63 & 152 & 84 \\
\hline 78 & 1 & 2 & 1 & 2 & 2 & 3 & 981 & 568 & 360 & 53 & 148 & 83 \\
\hline 94 & 1 & 2 & 1 & 2 & 3 & 1 & 1158 & 631 & 432 & 95 & 161 & 82 \\
\hline 95 & 1 & 2 & 1 & 2 & 3 & 2 & 1319 & 661 & 522 & 136 & 174 & 85 \\
\hline 96 & 1 & 2 & 1 & 2 & 3 & 3 & 1123 & 628 & 412 & 83 & 156 & 81 \\
\hline 109 & 2 & 1 & 1 & 1 & 1 & 1 & 2714 & 1532 & 866 & 316 & 513 & 85 \\
\hline 110 & 2 & 1 & 1 & 1 & 1 & 2 & 2709 & 1565 & 853 & 291 & 491 & 83 \\
\hline 111 & 2 & 1 & 1 & 1 & 1 & 3 & 2662 & 1499 & 852 & 311 & 496 & 85 \\
\hline 127 & 2 & 1 & 1 & 1 & 2 & 1 & 3117 & 1663 & 1016 & 438 & 540 & 83 \\
\hline 128 & 2 & 1 & 1 & 1 & 2 & 2 & 2832 & 1594 & 894 & 344 & 536 & 85 \\
\hline 129 & 2 & 1 & 1 & 1 & 2 & 3 & 2450 & 1514 & 714 & 222 & 542 & 87 \\
\hline 145 & 2 & 1 & 1 & 1 & 3 & 1 & 3339 & 1591 & 1187 & 561 & 659 & 94 \\
\hline 146 & 2 & 1 & 1 & 1 & 3 & 2 & 3547 & 1674 & 1266 & 607 & 646 & 90 \\
\hline 147 & 2 & 1 & 1 & 1 & 3 & 3 & 3290 & 1607 & 1152 & 531 & 642 & 92 \\
\hline 115 & 2 & 1 & 1 & 3 & 1 & 1 & 1304 & 671 & 377 & 256 & 128 & 65 \\
\hline 116 & 2 & 1 & 1 & 3 & 1 & 2 & 1197 & 650 & 336 & 211 & 131 & 65 \\
\hline 117 & 2 & 1 & 1 & 3 & 1 & 3 & 1233 & 672 & 344 & 217 & 125 & 64 \\
\hline 133 & 2 & 1 & 1 & 3 & 2 & 1 & 1292 & 585 & 424 & 283 & 118 & 69 \\
\hline 134 & 2 & 1 & 1 & 3 & 2 & 2 & 1117 & 595 & 339 & 183 & 120 & 67 \\
\hline 135 & 2 & 1 & 1 & 3 & 2 & 3 & 1132 & 607 & 339 & 186 & 122 & 67 \\
\hline 151 & 2 & 1 & 1 & 3 & 3 & 1 & 1180 & 565 & 390 & 225 & 126 & 74 \\
\hline 152 & 2 & 1 & 1 & 3 & 3 & 2 & 1177 & 539 & 389 & 249 & 124 & 75 \\
\hline 153 & 2 & 1 & 1 & 3 & 3 & 3 & 1199 & 565 & 391 & 243 & 132 & 72 \\
\hline 112 & 2 & 1 & 1 & 2 & 1 & 1 & 1840 & 1002 & 660 & 178 & 298 & 82 \\
\hline 113 & 2 & 1 & 1 & 2 & 1 & 2 & 2047 & 1132 & 720 & 195 & 309 & 85 \\
\hline
\end{tabular}


Anhang 15: Originaldaten der batch-culture-Untersuchungen mit nicht defauniertem Pansensaft (Fortsetzung 2).

\begin{tabular}{|c|c|c|c|c|c|c|c|c|c|c|c|c|}
\hline Nr. & RAT & NUE & PRO & SUB & TAG & Wdh & $\begin{array}{l}\text { SCFA } \\
\mu \mathrm{mol} \\
\end{array}$ & \begin{tabular}{|c|} 
Acetat \\
$\mu \mathrm{mol}$
\end{tabular} & \begin{tabular}{|c|}
$\begin{array}{c}\text { Propionat } \\
\mu \mathrm{mol}\end{array}$ \\
\end{tabular} & $\begin{array}{c}\text { Butyrat } \\
\mu \mathrm{mol} \\
\end{array}$ & $\begin{array}{c}\mathrm{CH}_{4} \\
\mu \mathrm{mol} \\
\end{array}$ & $\begin{array}{c}\mathrm{H}_{\mathrm{U}} / \mathrm{H}_{\mathrm{P}} \\
\% \\
\end{array}$ \\
\hline 114 & 2 & 1 & 1 & 2 & 1 & 3 & 1825 & 1034 & 637 & 154 & 310 & 93 \\
\hline 160 & 2 & 1 & 1 & 2 & 2 & 1 & 2035 & 1016 & 779 & 240 & 278 & 84 \\
\hline 161 & 2 & 1 & 1 & 2 & 2 & 2 & 1729 & 979 & 605 & 145 & 288 & 84 \\
\hline 162 & 2 & 1 & 1 & 2 & 2 & 3 & 1922 & 887 & 754 & 281 & 297 & 89 \\
\hline 148 & 2 & 1 & 1 & 2 & 3 & 1 & 1981 & 902 & 786 & 293 & 385 & 100 \\
\hline 149 & 2 & 1 & 1 & 2 & 3 & 2 & 2142 & 1007 & 821 & 314 & 369 & 92 \\
\hline 150 & 2 & 1 & 1 & 2 & 3 & 3 & 2087 & 1011 & 791 & 285 & 274 & 83 \\
\hline 163 & 2 & 2 & 1 & 1 & 1 & 1 & 2416 & 1348 & 721 & 347 & 632 & 97 \\
\hline 164 & 2 & 2 & 1 & 1 & 1 & 2 & 2624 & 1457 & 785 & 382 & 668 & 96 \\
\hline 165 & 2 & 2 & 1 & 1 & 1 & 3 & 2730 & 1499 & 821 & 410 & 649 & 93 \\
\hline 181 & 2 & 2 & 1 & 1 & 2 & 1 & 3414 & 1638 & 1195 & 581 & 600 & 88 \\
\hline 182 & 2 & 2 & 1 & 1 & 2 & 2 & 3514 & 1660 & 1220 & 634 & 588 & 86 \\
\hline 183 & 2 & 2 & 1 & 1 & 2 & 3 & 4120 & 1840 & 1478 & 802 & 632 & 85 \\
\hline 199 & 2 & 2 & 1 & 1 & 3 & 1 & 3520 & 1819 & 1212 & 489 & 599 & 85 \\
\hline 200 & 2 & 2 & 1 & 1 & 3 & 2 & 3400 & 1746 & 1181 & 473 & 627 & 89 \\
\hline 201 & 2 & 2 & 1 & 1 & 3 & 3 & 3157 & 1618 & 1095 & 444 & 616 & 91 \\
\hline 169 & 2 & 2 & 1 & 3 & 1 & 1 & 1099 & 603 & 306 & 190 & 150 & 70 \\
\hline 170 & 2 & 2 & 1 & 3 & 1 & 2 & 1051 & 566 & 297 & 188 & 155 & 73 \\
\hline 171 & 2 & 2 & 1 & 3 & 1 & 3 & 981 & 537 & 269 & 175 & 140 & 71 \\
\hline 187 & 2 & 2 & 1 & 3 & 2 & 1 & 1686 & 708 & 574 & 404 & 131 & 69 \\
\hline 188 & 2 & 2 & 1 & 3 & 2 & 2 & 1463 & 666 & 486 & 311 & 119 & 68 \\
\hline 189 & 2 & 2 & 1 & 3 & 2 & 3 & 1357 & 589 & 457 & 311 & 125 & 71 \\
\hline 205 & 2 & 2 & 1 & 3 & 3 & 1 & 1207 & 599 & 381 & 227 & 142 & 72 \\
\hline 206 & 2 & 2 & 1 & 3 & 3 & 2 & 1100 & 552 & 342 & 206 & 144 & 74 \\
\hline 207 & 2 & 2 & 1 & 3 & 3 & 3 & 1098 & 534 & 351 & 213 & 148 & 76 \\
\hline 166 & 2 & 2 & 1 & 2 & 1 & 1 & 1657 & 947 & 515 & 195 & 411 & 96 \\
\hline 167 & 2 & 2 & 1 & 2 & 1 & 2 & 1753 & 975 & 558 & 220 & 416 & 95 \\
\hline 168 & 2 & 2 & 1 & 2 & 1 & 3 & 1823 & 1001 & 581 & 241 & 295 & 80 \\
\hline 184 & 2 & 2 & 1 & 2 & 2 & 1 & 2033 & 1001 & 732 & 300 & 310 & 84 \\
\hline 185 & 2 & 2 & 1 & 2 & 2 & 2 & 2223 & 1058 & 805 & 360 & 282 & 79 \\
\hline 186 & 2 & 2 & 1 & 2 & 2 & 3 & 2362 & 1224 & 810 & 328 & 296 & 76 \\
\hline 202 & 2 & 2 & 1 & 2 & 3 & 1 & 2186 & 1151 & 781 & 254 & 366 & 84 \\
\hline 203 & 2 & 2 & 1 & 2 & 3 & 2 & 2089 & 1119 & 736 & 234 & 369 & 86 \\
\hline 204 & 2 & 2 & 1 & 2 & 3 & 3 & 2099 & 1108 & 747 & 244 & 368 & 88 \\
\hline
\end{tabular}


Anhang 16: Originaldaten der batch-culture-Untersuchungen mit defauniertem Pansensaft. (Kodierung siehe Anhang 17)

\begin{tabular}{|c|c|c|c|c|c|c|c|c|c|c|c|c|}
\hline Nr. & RAT & NUE & PRO & SUB & TAG & Wdh & $\begin{array}{l}\text { SCFA } \\
\mu \mathrm{mol}\end{array}$ & \begin{tabular}{|c} 
Acetat \\
$\mu \mathrm{mol}$
\end{tabular} & $\begin{array}{c}\text { Propionat } \\
\mu \mathrm{mol}\end{array}$ & $\begin{array}{c}\text { Butyrat } \\
\mu \mathrm{mol}\end{array}$ & $\begin{array}{r}\mathrm{CH}_{4} \\
\mu \mathrm{mol}\end{array}$ & $\begin{array}{c}\mathrm{Hu}_{\mathrm{u}} / \mathrm{H}_{\mathrm{P}} \\
\%\end{array}$ \\
\hline 10 & 1 & 1 & 2 & 1 & 1 & 1 & 1166 & 433 & 673 & 60 & 0 & 84 \\
\hline 11 & 1 & 1 & 2 & 1 & 1 & 2 & 1199 & 438 & 703 & 59 & 0 & 85 \\
\hline 12 & 1 & 1 & 2 & 1 & 1 & 3 & 1052 & 404 & 612 & 35 & 0 & 84 \\
\hline 28 & 1 & 1 & 2 & 1 & 2 & 1 & 985 & 409 & 543 & 33 & 0 & 79 \\
\hline 29 & 1 & 1 & 2 & 1 & 2 & 2 & 943 & 338 & 557 & 49 & 0 & 86 \\
\hline 30 & 1 & 1 & 2 & 1 & 2 & 3 & 826 & 371 & 452 & 2 & 0 & 78 \\
\hline 46 & 1 & 1 & 2 & 1 & 3 & 1 & 802 & 340 & 670 & 62 & 0 & 70 \\
\hline 47 & 1 & 1 & 2 & 1 & 3 & 2 & 1112 & 349 & 816 & 93 & 0 & 88 \\
\hline 48 & 1 & 1 & 2 & 1 & 3 & 3 & 1381 & 469 & 847 & 96 & 0 & 85 \\
\hline 16 & 1 & 1 & 2 & 3 & 1 & 1 & 595 & 267 & 228 & 100 & 0 & 57 \\
\hline 17 & 1 & 1 & 2 & 3 & 1 & 2 & 633 & 298 & 235 & 99 & 0 & 55 \\
\hline 18 & 1 & 1 & 2 & 3 & 1 & 3 & 703 & 340 & 255 & 108 & 0 & 53 \\
\hline 34 & 1 & 1 & 2 & 3 & 2 & 1 & 431 & 275 & 100 & 56 & 0 & 37 \\
\hline 35 & 1 & 1 & 2 & 3 & 2 & 2 & 449 & 245 & 67 & 137 & 0 & 37 \\
\hline 36 & 1 & 1 & 2 & 3 & 2 & 3 & 586 & 264 & 180 & 142 & 0 & 50 \\
\hline 52 & 1 & 1 & 2 & 3 & 3 & 1 & 824 & 294 & 358 & 172 & 0 & 65 \\
\hline 53 & 1 & 1 & 2 & 3 & 3 & 2 & 688 & 266 & 246 & 175 & 0 & 57 \\
\hline 54 & 1 & 1 & 2 & 3 & 3 & 3 & 827 & 301 & 351 & 174 & 0 & 64 \\
\hline 13 & 1 & 1 & 2 & 2 & 1 & 1 & 386 & 165 & 223 & 2 & 0 & 83 \\
\hline 14 & 1 & 1 & 2 & 2 & 1 & 2 & 356 & 196 & 177 & 10 & 0 & 64 \\
\hline 15 & 1 & 1 & 2 & 2 & 1 & 3 & 486 & 171 & 291 & 23 & 0 & 87 \\
\hline 31 & 1 & 1 & 2 & 2 & 2 & 1 & 338 & 113 & 202 & 23 & 0 & 87 \\
\hline 32 & 1 & 1 & 2 & 2 & 2 & 2 & 327 & 130 & 185 & 12 & 0 & 81 \\
\hline 33 & 1 & 1 & 2 & 2 & 2 & 3 & 490 & 215 & 238 & 36 & 0 & 68 \\
\hline 49 & 1 & 1 & 2 & 2 & 3 & 1 & 734 & 221 & 428 & 86 & 0 & 85 \\
\hline 50 & 1 & 1 & 2 & 2 & 3 & 2 & 574 & 121 & 380 & 73 & 0 & 99 \\
\hline 51 & 1 & 1 & 2 & 2 & 3 & 3 & 561 & 171 & 304 & 86 & 0 & 79 \\
\hline 64 & 1 & 2 & 2 & 1 & 1 & 1 & 809 & 299 & 392 & 118 & 0 & 72 \\
\hline 65 & 1 & 2 & 2 & 1 & 1 & 2 & 786 & 323 & 368 & 95 & 0 & 68 \\
\hline 66 & 1 & 2 & 2 & 1 & 1 & 3 & 842 & 336 & 388 & 118 & 0 & 67 \\
\hline 82 & 1 & 2 & 2 & 1 & 2 & 1 & 1008 & 336 & 460 & 212 & 0 & 70 \\
\hline 83 & 1 & 2 & 2 & 1 & 2 & 2 & 958 & 309 & 431 & 218 & 0 & 70 \\
\hline 84 & 1 & 2 & 2 & 1 & 2 & 3 & 935 & 316 & 449 & 170 & 0 & 72 \\
\hline 100 & 1 & 2 & 2 & 1 & 3 & 1 & 757 & 277 & 340 & 140 & 0 & 68 \\
\hline 101 & 1 & 2 & 2 & 1 & 3 & 2 & 814 & 286 & 376 & 152 & 0 & 69 \\
\hline 102 & 1 & 2 & 2 & 1 & 3 & 3 & 814 & 295 & 355 & 164 & 0 & 66 \\
\hline
\end{tabular}


Anhang 16: Originaldaten der batch-culture-Untersuchungen mit defauniertem Pansensaft (Fortsetzung 1)

\begin{tabular}{|c|c|c|c|c|c|c|c|c|c|c|c|c|}
\hline Nr. & RAT & NUE & PRO & SUB & TAG & Wdh & $\begin{array}{l}\text { SCFA } \\
\mu \mathrm{mol}\end{array}$ & \begin{tabular}{|c|} 
Acetat \\
$\mu \mathrm{mol}$
\end{tabular} & $\begin{array}{c}\text { Propionat } \\
\mu \mathrm{mol}\end{array}$ & $\begin{array}{c}\text { Butyrat } \\
\mu \mathrm{mol}\end{array}$ & $\begin{array}{c}\mathrm{CH}_{4} \\
\mu \mathrm{mol} \\
\end{array}$ & $\begin{array}{c}\mathrm{Hu}_{\mathrm{u}} / \mathrm{H}_{\mathrm{P}} \\
\% \\
\end{array}$ \\
\hline 70 & 1 & 2 & 2 & 3 & 1 & 1 & 393 & 243 & 85 & 65 & 0 & 36 \\
\hline 71 & 1 & 2 & 2 & 3 & 1 & 2 & 433 & 262 & 99 & 72 & 0 & 38 \\
\hline 72 & 1 & 2 & 2 & 3 & 1 & 3 & 503 & 279 & 126 & 98 & 0 & 42 \\
\hline 88 & 1 & 2 & 2 & 3 & 2 & 1 & 473 & 318 & 87 & 68 & 0 & 31 \\
\hline 89 & 1 & 2 & 2 & 3 & 2 & 2 & 424 & 298 & 64 & 62 & 0 & 28 \\
\hline 90 & 1 & 2 & 2 & 3 & 2 & 3 & 388 & 242 & 73 & 73 & 0 & 34 \\
\hline 106 & 1 & 2 & 2 & 3 & 3 & 1 & 507 & 288 & 124 & 95 & 0 & 41 \\
\hline 107 & 1 & 2 & 2 & 3 & 3 & 2 & 251 & 166 & 42 & 43 & 0 & 31 \\
\hline 108 & 1 & 2 & 2 & 3 & 3 & 3 & 307 & 218 & 44 & 45 & 0 & 27 \\
\hline 67 & 1 & 2 & 2 & 2 & 1 & 1 & 305 & 105 & 174 & 26 & 0 & 84 \\
\hline 68 & 1 & 2 & 2 & 2 & 1 & 2 & 380 & 122 & 219 & 39 & 0 & 85 \\
\hline 69 & 1 & 2 & 2 & 2 & 1 & 3 & 374 & 113 & 225 & 36 & 0 & 88 \\
\hline 85 & 1 & 2 & 2 & 2 & 2 & 1 & 236 & 96 & 126 & 13 & 0 & 77 \\
\hline 86 & 1 & 2 & 2 & 2 & 2 & 2 & 227 & 98 & 105 & 24 & 0 & 67 \\
\hline 87 & 1 & 2 & 2 & 2 & 2 & 3 & 215 & 99 & 102 & 14 & 0 & 66 \\
\hline 103 & 1 & 2 & 2 & 2 & 3 & 1 & 346 & 149 & 171 & 26 & 0 & 71 \\
\hline 104 & 1 & 2 & 2 & 2 & 3 & 2 & 302 & 113 & 168 & 21 & 0 & 81 \\
\hline 105 & 1 & 2 & 2 & 2 & 3 & 3 & 327 & 115 & 178 & 34 & 0 & 79 \\
\hline 118 & 2 & 1 & 2 & 1 & 1 & 1 & 1626 & 517 & 948 & 161 & 0 & 85 \\
\hline 119 & 2 & 1 & 2 & 1 & 1 & 2 & 1401 & 445 & 850 & 106 & 0 & 89 \\
\hline 120 & 2 & 1 & 2 & 1 & 1 & 3 & 1303 & 428 & 795 & 80 & 0 & 89 \\
\hline 136 & 2 & 1 & 2 & 1 & 2 & 1 & 1319 & 483 & 759 & 77 & 0 & 84 \\
\hline 137 & 2 & 1 & 2 & 1 & 2 & 2 & 1447 & 455 & 891 & 101 & 0 & 91 \\
\hline 138 & 2 & 1 & 2 & 1 & 2 & 3 & 1206 & 474 & 689 & 43 & 0 & 82 \\
\hline 154 & 2 & 1 & 2 & 1 & 3 & 1 & 1457 & 460 & 899 & 98 & 0 & 104 \\
\hline 155 & 2 & 1 & 2 & 1 & 3 & 2 & 1593 & 440 & 1000 & 153 & 0 & 103 \\
\hline 156 & 2 & 1 & 2 & 1 & 3 & 3 & 1474 & 433 & 913 & 128 & 0 & 95 \\
\hline 124 & 2 & 1 & 2 & 3 & 1 & 1 & 781 & 325 & 281 & 175 & 0 & 56 \\
\hline 125 & 2 & 1 & 2 & 3 & 1 & 2 & 736 & 343 & 256 & 137 & 0 & 53 \\
\hline 126 & 2 & 1 & 2 & 3 & 1 & 3 & 698 & 348 & 235 & 115 & 0 & 52 \\
\hline 142 & 2 & 1 & 2 & 3 & 2 & 1 & 540 & 216 & 196 & 128 & 0 & 57 \\
\hline 143 & 2 & 1 & 2 & 3 & 2 & 2 & 545 & 201 & 204 & 140 & 0 & 59 \\
\hline 144 & 2 & 1 & 2 & 3 & 2 & 3 & 318 & 169 & 113 & 36 & 0 & 51 \\
\hline 160 & 2 & 1 & 2 & 3 & 3 & 1 & 760 & 232 & 317 & 211 & 0 & 70 \\
\hline 161 & 2 & 1 & 2 & 3 & 3 & 2 & 611 & 206 & 269 & 136 & 0 & 71 \\
\hline 162 & 2 & 1 & 2 & 3 & 3 & 3 & 671 & 269 & 267 & 135 & 0 & 61 \\
\hline 121 & 2 & 1 & 2 & 2 & 1 & 1 & 442 & 139 & 279 & 24 & 0 & 93 \\
\hline
\end{tabular}


Anhang 16: Originaldaten der batch-culture-Untersuchungen mit defauniertem Pansensaft (Fortsetzung 2)

\begin{tabular}{|c|c|c|c|c|c|c|c|c|c|c|c|c|}
\hline Nr. & RAT & NUE & PRO & SUB & TAG & Wdh & $\begin{array}{l}\text { SCFA } \\
\mu \mathrm{mol} \\
\end{array}$ & \begin{tabular}{|c|} 
Acetat \\
$\mu \mathrm{mol}$ \\
\end{tabular} & $\begin{array}{c}\text { Propionat } \\
\mu \mathrm{mol} \\
\end{array}$ & $\begin{array}{c}\text { Butyrat } \\
\mu \mathrm{mol}\end{array}$ & $\begin{array}{c}\mathrm{CH}_{4} \\
\mu \mathrm{mol} \\
\end{array}$ & $\begin{array}{c}\mathrm{Hu}_{\mathrm{u}} / \mathrm{H}_{\mathrm{P}} \\
\% \\
\end{array}$ \\
\hline 122 & 2 & 1 & 2 & 2 & 1 & 2 & 486 & 128 & 304 & 54 & 0 & 92 \\
\hline 123 & 2 & 1 & 2 & 2 & 1 & 3 & 586 & 188 & 334 & 64 & 0 & 84 \\
\hline 139 & 2 & 1 & 2 & 2 & 2 & 1 & 463 & 138 & 283 & 42 & 0 & 89 \\
\hline 140 & 2 & 1 & 2 & 2 & 2 & 2 & 397 & 121 & 254 & 22 & 0 & 95 \\
\hline 141 & 2 & 1 & 2 & 2 & 2 & 3 & 390 & 64 & 268 & 58 & 0 & 106 \\
\hline 157 & 2 & 1 & 2 & 2 & 3 & 1 & 381 & 82 & 259 & 40 & 0 & 105 \\
\hline 158 & 2 & 1 & 2 & 2 & 3 & 2 & 354 & 38 & 265 & 51 & 0 & 120 \\
\hline 159 & 2 & 1 & 2 & 2 & 3 & 3 & 470 & 93 & 300 & 77 & 0 & 97 \\
\hline 172 & 2 & 2 & 2 & 1 & 1 & 1 & 1071 & 406 & 583 & 82 & 5 & 79 \\
\hline 173 & 2 & 2 & 2 & 1 & 1 & 2 & 1108 & 432 & 596 & 80 & 3 & 77 \\
\hline 174 & 2 & 2 & 2 & 1 & 1 & 3 & 1012 & 386 & 556 & 70 & 0 & 78 \\
\hline 190 & 2 & 2 & 2 & 1 & 2 & 1 & 1397 & 472 & 838 & 87 & 0 & 88 \\
\hline 191 & 2 & 2 & 2 & 1 & 2 & 2 & 1339 & 454 & 814 & 71 & 0 & 89 \\
\hline 192 & 2 & 2 & 2 & 1 & 2 & 3 & 1394 & 474 & 836 & 84 & 3 & 88 \\
\hline 208 & 2 & 2 & 2 & 1 & 3 & 1 & 1178 & 444 & 688 & 46 & 41 & 85 \\
\hline 209 & 2 & 2 & 2 & 1 & 3 & 2 & 1496 & 544 & 856 & 96 & 58 & 83 \\
\hline 210 & 2 & 2 & 2 & 1 & 3 & 3 & 1130 & 429 & 663 & 38 & 0 & 84 \\
\hline 178 & 2 & 2 & 2 & 3 & 1 & 1 & 594 & 282 & 188 & 124 & 2 & 51 \\
\hline 179 & 2 & 2 & 2 & 3 & 1 & 2 & 612 & 278 & 200 & 134 & 2 & 53 \\
\hline 180 & 2 & 2 & 2 & 3 & 1 & 3 & 530 & 258 & 169 & 103 & 8 & 53 \\
\hline 196 & 2 & 2 & 2 & 3 & 2 & 1 & 613 & 225 & 242 & 146 & 0 & 61 \\
\hline 197 & 2 & 2 & 2 & 3 & 2 & 2 & 784 & 299 & 294 & 191 & 0 & 59 \\
\hline 198 & 2 & 2 & 2 & 3 & 2 & 3 & 937 & 246 & 394 & 297 & 5 & 62 \\
\hline 214 & 2 & 2 & 2 & 3 & 3 & 1 & 475 & 210 & 167 & 98 & 0 & 55 \\
\hline 215 & 2 & 2 & 2 & 3 & 3 & 2 & 700 & 309 & 241 & 150 & 0 & 54 \\
\hline 216 & 2 & 2 & 2 & 3 & 3 & 3 & 590 & 261 & 206 & 123 & 4 & 55 \\
\hline 175 & 2 & 2 & 2 & 2 & 1 & 1 & 328 & 110 & 162 & 56 & 0 & 72 \\
\hline 176 & 2 & 2 & 2 & 2 & 1 & 2 & 316 & 113 & 155 & 48 & 1 & 72 \\
\hline 177 & 2 & 2 & 2 & 2 & 1 & 3 & 250 & 81 & 130 & 39 & 4 & 78 \\
\hline 193 & 2 & 2 & 2 & 2 & 2 & 1 & 477 & 116 & 280 & 81 & 0 & 87 \\
\hline 194 & 2 & 2 & 2 & 2 & 2 & 2 & 372 & 93 & 232 & 47 & 0 & 92 \\
\hline 195 & 2 & 2 & 2 & 2 & 2 & 3 & 423 & 104 & 251 & 68 & 0 & 89 \\
\hline 211 & 2 & 2 & 2 & 2 & 3 & 1 & 377 & 127 & 205 & 45 & 0 & 78 \\
\hline 212 & 2 & 2 & 2 & 2 & 3 & 2 & 245 & 68 & 160 & 17 & 0 & 98 \\
\hline 213 & 2 & 2 & 2 & 2 & 3 & 3 & 328 & 104 & 189 & 35 & 0 & 83 \\
\hline
\end{tabular}


Anhang 17: Codierung zu Anhang 15 und 16.

\begin{tabular}{|c|c|c|c|}
\hline Ration & RAT & $\begin{array}{l}\text { Heu-Kraftfutter } \\
\text { Stroh-Harnstoff }\end{array}$ & $\begin{array}{l}1 \\
2\end{array}$ \\
\hline \multirow{2}{*}{ Nüchterungsdauer } & \multirow{2}{*}{ NUE } & 16 Stunden & 1 \\
\hline & & 24 Stunden & 2 \\
\hline \multirow{2}{*}{ Protozoen } & \multirow{2}{*}{ PRO } & nicht defauniert & 1 \\
\hline & & defauniert & 2 \\
\hline \multirow{3}{*}{$\begin{array}{c}\text { in-vitro- } \\
\text { Substratqualität }\end{array}$} & \multirow{3}{*}{ SUB } & $\mathrm{Heu}$ & 1 \\
\hline & & Stroh & 2 \\
\hline & & Dickdarminhalt & 3 \\
\hline \multirow{3}{*}{ Tag } & \multirow{3}{*}{ TAG } & 1 & 1 \\
\hline & & 2 & 2 \\
\hline & & 3 & 3 \\
\hline \multirow{3}{*}{ Wiederholung } & \multirow{3}{*}{ Wdh } & 1 & 1 \\
\hline & & 2 & 2 \\
\hline & & 3 & 3 \\
\hline
\end{tabular}

